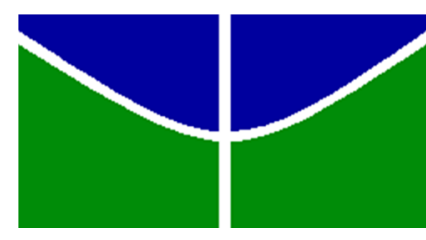

UNIVERSIDADE DE BRASÍLIA - UnB

Programa de Pós-Graduação em

Nanociência e Nanobiotecnologia

MARIANA PEREIRA DA SILVA

ESTUDO DA SÍNTESE E AVALIAÇÃO DAS PROPRIEDADES MAGNETOTÉRMICAS DE NANOPARTÍCULAS NÃO ESFÉRICAS DE MAGNETITA

BRASÍLIA - DF

2015 


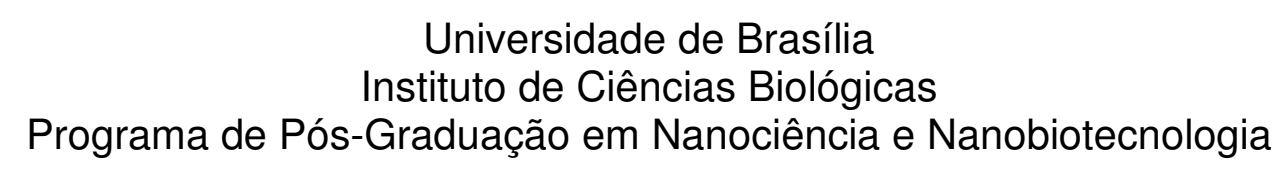

MARIANA PEREIRA DA SILVA

\title{
ESTUDO DA SÍNTESE E AVALIAÇÃO DAS PROPRIEDADES MAGNETO- TÉRMICAS DE NANOPARTíCULAS NÃO ESFÉRICAS DE MAGNETITA
}

\begin{abstract}
Dissertação apresentada ao programa de Pós-Graduação em Nanociências e Nanobiotecnologia, do Instituto de Ciências Biológicas da Universidade de Brasília, como parte integrante dos requisitos para obtenção do Título de Mestre em Nanociências e Nanobiotecnologia.
\end{abstract}

Orientador: Prof. Dr. Marcelo Henrique Sousa

BRASÍLIA - DF 
Dissertação de Mestrado

Mariana Pereira da Silva

Título:

\section{"Estudo da síntese e avaliação das propriedades magneto- térmicas de nanopartículas não esféricas de magnetita."}

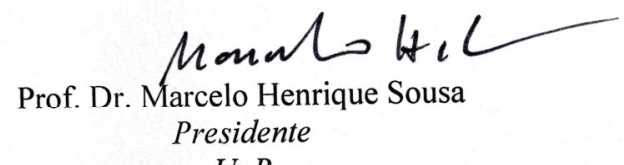

$U n B$

Profa. Dra. Claure Naín Lunardi Gomes Membro Titular Interno Vinculado ao Programa $U n B$

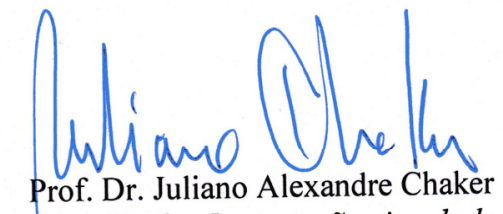
Membro Titular Interno não vinculado ao programa UnB

Prof. Dr. Ricardo Bentes de Azevedo Membro Suplente Interno vinculado ao programa UnB 
Dedico este trabalho, a todas as pessoas que tornaram possível sua realização. 


\section{AGRADECIMENTOS}

Agradeço a todos que, com seus conhecimentos, incentivos, compreensão e críticas colaboraram para que eu ultrapassasse mais essa etapa. Em especial agradeço:

A Deus, essa misteriosa fonte de vida e energia.

A minha família e amigos, por todo companheirismo, apoio e infindáveis momentos de alegria.

Ao prof. Dr. Marcelo Henrique Sousa, base da minha formação científica.

Obrigada pela orientação, confiança, profissionalismo e tempo dedicado.

Aos professores e funcionários responsáveis pela minha formação, obrigada pelos conhecimentos transmitidos. 


\section{RESUMO}

O uso de nanopartículas magnéticas (NPM) na biotecnologia e na medicina é um tema em destaque e que já conta com aplicações efetivas e outras em pleno avanço tecnológico. Pelas suas dimensões reduzidas, as NPMs têm facilidade para transitar em diversos compartimentos do organismo e, também pela possibilidade de serem funcionalizadas com ligantes específicos, podem se acumular nos tecidos tumorais. Dessa forma, em diversas aplicações biomédicas, as NPMs são utilizadas, tanto para fins terapêuticos, como para fins diagnósticos - ou simultaneamente com a função "teranóstica". Dentre as diversas potenciais aplicações terapêuticas, esse trabalho é focado na elaboração de materiais para aplicações no tratamento contra o câncer por hipertemia. O objetivo desse estudo é o de estabelecer, estudar e otimizar uma rota de síntese em meio aquoso, por precipitação homogênea, para síntese de nanopartículas magnéticas alongadas, assim como estudar suas propriedades magnetotérmicas, visando aplicações em magnetohipertermia. A síntese da nanopartículas foi realizada por meio da coprecipitação de $\mathrm{Fe}^{2+}$ e $\mathrm{Fe}^{3+}$ em meio alcalino a $95^{\circ} \mathrm{C}$. Com a finalidade de se obter nanopartículas magnéticas alongadas, vários parâmetros de síntese foram verificados, principalmente a natureza química e a concentração da fonte de íons $\mathrm{OH}^{-}$. Além disso, a presença ou ausência e a natureza e a concentração de ânions complexantes $\left(\mathrm{SO}_{4}{ }^{2-}\right)$ também foi verificada como fator para geração de estruturas magnéticas alongadas. Dois tipos de base foram testadas para a síntese das nanoestruturas magnéticas, uma base convencional $\left(\mathrm{NH}_{4} \mathrm{OH}\right)$ e $\mathrm{CO}\left(\mathrm{NH}_{2}\right)_{2}$, uma base que gera $\mathrm{OH}^{-}$homogeneamente, por decomposição. Os resultados mostraram que, apesar da presença de $\mathrm{SO}_{4}{ }^{2-}$ (agente catalisador de forma), nanopartículas magnéticas alongadas foram obtidas somente na presença de $\mathrm{CO}\left(\mathrm{NH}_{2}\right)_{2}$. Apesar de se utilizar a $\mathrm{CO}\left(\mathrm{NH}_{2}\right)_{2}$ como agente precipitante, nanopartículas magnéticas alongadas somente foram obtidas na presença de $\mathrm{SO}_{4}{ }^{2-}$. Nas concentrações estudadas, nanopartículas maiores foram obtidas em maior quantidade de $\mathrm{SO}_{4}{ }^{2-}$. $\mathrm{A}$ variação do $\mathrm{pH}$ em função do tempo de síntese também foi avaliada, quando 0 $\mathrm{NH}_{4} \mathrm{OH}$ foi utilizado, $\mathrm{O} \mathrm{pH}$, bastante alto imediatamente a adição desse reagente, vai diminuindo a medida que o sistema entra em refluxo e a amônia é volatilizada. No caso da $\mathrm{CO}\left(\mathrm{NH}_{2}\right)_{2}$, à medida que esse reagente se decompõe, o $\mathrm{pH}$ aumenta homogeneamente. Para as duas concentrações de $\mathrm{CO}\left(\mathrm{NH}_{2}\right)_{2}$ estudadas, dois grupos de NPs foram obtidos em diferentes tempos de síntese. Em ambos os casos, as fases goethita e magnetita foram observadas, sendo que, com a evolução do tempo a fase deu lugar à magnetita. Os testes de magnetohipertermia mostraram que, para as nanopartículas alongadas, a variação de temperatura é proporcional ao campo alternado aplicado e sensível às diferentes frequências.

Palavras-chave: nanopartículas magnéticas; magnetohipertermia; uréia; sulfato. 


\begin{abstract}
The use of magnetic nanoparticles (NPM) in biotechnology and medicine is a major theme and which already has effective applications and other technological advance in full. By its smaller size, the NPMs have facility to carry over into the various compartments of the body and also by the possibility of being functionalized with specific ligands, can accumulate in tumor tissues. Thus, in various biomedical applications, NPMs are used both for therapeutic purposes, such as for diagnostic purposes - or simultaneously with "teranóstica" function. Among the many potential therapeutic applications, this work is focused on the development of materials for applications in cancer treatment by hyperthermia. The aim of this study is to establish, study and optimize a route of synthesis in aqueous medium, by homogeneous precipitation, for synthesis of elongated magnetic nanoparticles, and to study their properties magnetotérmicas, aiming at applications in magnetohyperthermia. Synthesis of nanoparticles was performed by co-precipitation of $\mathrm{Fe}^{3+}$ and $\mathrm{Fe}^{2+}$ in an alkaline medium at $95{ }^{\circ} \mathrm{C}$. In order to obtain elongated magnetic nanoparticles, several synthesis parameters were observed, particularly the chemical nature and concentration of the source of $\mathrm{OH}^{-}$ions. Moreover, the presence or absence and the nature and concentration of complexing anions $\left(\mathrm{SO}_{4}{ }^{2-}\right)$ was also found as a factor for generation of elongate magnetic structures. Two basic types were tested for the synthesis of magnetic nanostructures, a conventional basic $\left(\mathrm{NH}_{4} \mathrm{OH}\right)$ and $\mathrm{CO}\left(\mathrm{NH}_{2}\right)_{2}$, that generates a base $\mathrm{OH}^{-}$homogeneously by decomposition. The results showed that, despite the presence of $\mathrm{SO}_{4}{ }^{2-}$ (catalyst form), elongated magnetic nanoparticles were obtained only in the presence of $\mathrm{CO}\left(\mathrm{NH}_{2}\right)_{2}$. Although using $\mathrm{CO}\left(\mathrm{NH}_{2}\right)_{2}$ as the precipitating agent, elongated magnetic nanoparticles were obtained only in the presence of $\mathrm{SO}_{4}{ }^{2-}$. The concentrations studied larger nanoparticles were obtained in greater quantity of $\mathrm{SO}_{4}{ }^{2-}$. The variation of $\mathrm{pH}$ due to the synthesis time was also evaluated, when the $\mathrm{NH}_{4} \mathrm{OH}$ was used, $\mathrm{pH}$, very high immediately by the addition of this reagent will diminish as the system enters reflux and ammonia is volatilized. In the case of $\mathrm{CO}\left(\mathrm{NH}_{2}\right)_{2}$, as this reagent is decomposed, increasing the $\mathrm{pH}$ homogeneously. For the two concentrations of $\mathrm{CO}\left(\mathrm{NH}_{2}\right)_{2}$ study, two groups of NPs were collected in different times of synthesis. In both cases, goethite and magnetite phases were observed, whereas, with the time evolution phase was replaced with magnetite. Magnetohyperthermia tests showed that for the elongated nanoparticles, the temperature variation is proportional to the applied alternating field and sensitive to different frequencies.
\end{abstract}

Keywords: magnetic nanoparticles; magnetohyperthermia; urea; sulfate. 


\section{SUMÁRIO}

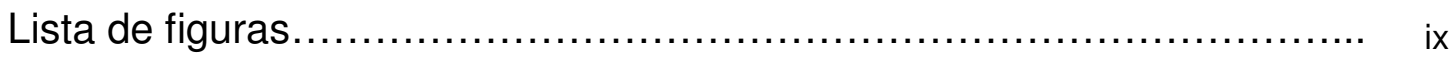

Lista de tabelas..................................................................... $x$

Lista de abreviaturas e siglas..................................................... xii

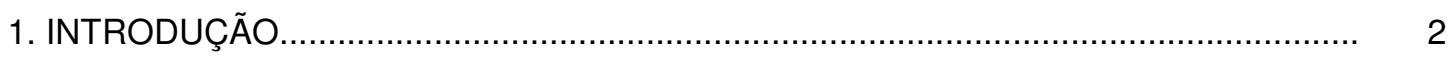

1.1. Aplicações biomédicas de NPM: magnetohipertermia (MHT) ........................... 5

1.2. Propriedades magnéticas dos óxidos de ferro e o princípio da MHT..................... 9

1.2.1. Propriedades magnéticas........................................................................ 13

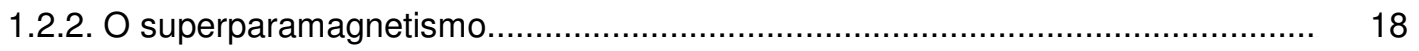

1.2.3. O princípio da magnetohipertermia.............................................................. 22

1.3. Síntese de NPM alongadas em meio aquoso................................................... 24

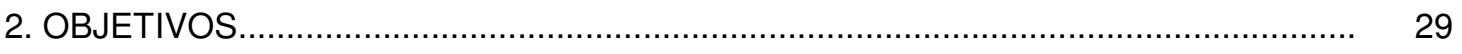

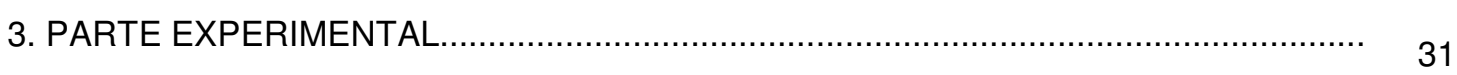

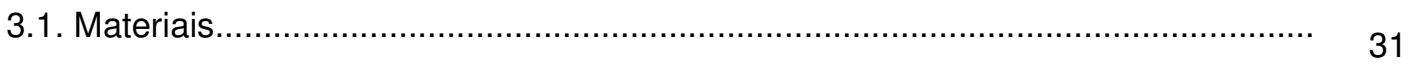

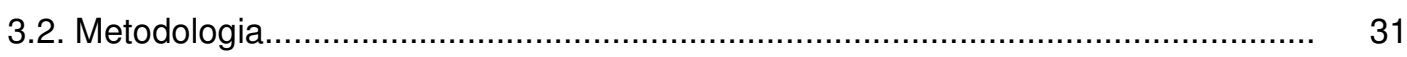

3.2.1. Síntese das nanopartículas.................................................................... 32

3.2.2. Caracterização dos materiais.................................................................... 34

3.2.2.1. Microscopia eletrônica de transmissão (MET)............................................ 34

3.2.2.2. Difração de Raios-X (DRX) ................................................................... 35

3.2.2.3. Medidas de magnetização...................................................................... $\quad 35$

3.2.2.4. Determinação de ferro por dicromatometria.............................................. 36

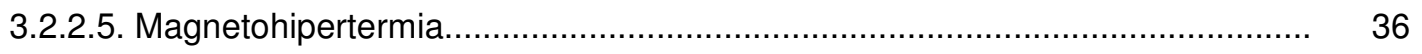

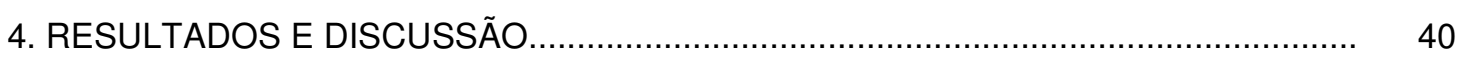

4.1. O efeito da ureia e do sulfato........................................................................... 40

4.2. O efeito do tempo de reação e da concentração da ureia..................................... 44

4.3. O efeito da variação do pH na formação das NPMs........................................... 55

4.4. Mecanismo de formação das NPs.................................................................... 58

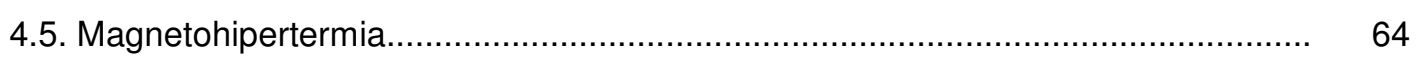

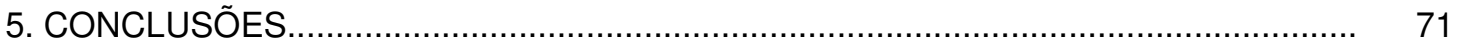

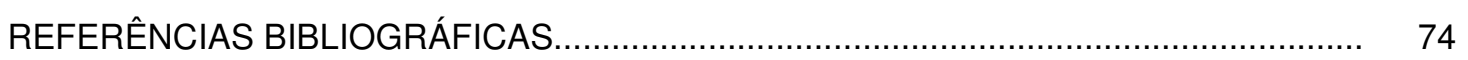




\section{LISTA DE FIGURAS}

Figura 1 - Representação da técnica de hipertermia magnética: a) as nanopartículas magnéticas são administradas e, transportadas pelos vasos sanguíneos, são localizadas especificamente na região das células de um tumor; b) em seguida um campo magnético alternado é aplicado, provocando um aquecimento nas nanopartículas e, em c), localmente o tumor.

Figura 2 - Representação da cela unitária da estrutura espinélio: as esferas verdes simbolizam os átomos de oxigênio, as vermelhas simbolizam os cátions nos sítios tetraédricos e as amarelas representam os cátions posicionados nos sítios octaédricos.....

Figura 3 - Representação da estrutura cristalina da goethita.

Figura 4 - Esquema com a classificação dos diferentes tipos de magnetismo cooperativo e individual.

Figura 5 - Representação dos domínios magnéticos e do momento magnético resultante, dentro de uma amostra, separados pelas paredes de Bloch.

Figura 6 - Comportamento magnético sob a influência de um campo magnético. As curvas de magnetização (magnetização $\times$ campo magnético) para os diferentes tipos de materiais são plotadas no gráfico. Os valores de magnetização de saturação $\left(M_{s}\right)$ magnetização remanente $\left(M_{\mathrm{r}}\right)$ e de campo coercitivo $\left(H_{\mathrm{c}}\right)$ são destacados na figura.

Figura 7 - Modelos de relaxação do momento magnético em um FM: na relaxação browniana a NPM gira em conjunto com o momento magnético do monodomínio. $\mathrm{Na}$ relaxação de Néel, o momento magnético gira dentro da estrutura do monodomínio...

Figura 8 - Imagens de MET para nanopartículas obtidas: a) em $\mathrm{NH}_{4} \mathrm{OH}$, com $\mathrm{FeCl}_{3} / \mathrm{FeSO}_{4}$; b) em $\mathrm{CO}\left(\mathrm{NH}_{2}\right)_{2}$, com $\mathrm{FeCl}_{3} / \mathrm{FeSO}_{4}$; c) em ureia, com $\mathrm{NH}_{4} \mathrm{Fe}\left(\mathrm{SO}_{4}\right)_{2} / \mathrm{FeSO}_{4}$; d) em ureia, com $\mathrm{FeCl}_{3} / \mathrm{FeCl}_{2}$

Figura 9 - Difratogramas de raios $X$ para nanopartículas obtidas: a) em $\mathrm{NH}_{4} \mathrm{OH}$, com $\mathrm{FeCl}_{3} / \mathrm{FeSO}_{4}$; b) em $\mathrm{CO}\left(\mathrm{NH}_{2}\right)_{2}$, com $\mathrm{FeCl}_{3} / \mathrm{FeSO}_{4}$; c) em $\mathrm{CO}\left(\mathrm{NH}_{2}\right)_{2}$, com $\mathrm{NH}_{4} \mathrm{Fe}\left(\mathrm{SO}_{4}\right)_{2} / \mathrm{FeSO}_{4}$; d) em $\mathrm{CO}\left(\mathrm{NH}_{2}\right)_{2}$, com $\mathrm{FeCl}_{3} / \mathrm{FeCl}_{2}$.

Figura 10 - Imagens de MET para nanopartículas obtidas em $\mathrm{CO}\left(\mathrm{NH}_{2}\right)_{2}$, com $\mathrm{NH}_{4} \mathrm{Fe}\left(\mathrm{SO}_{4}\right)_{2} / \mathrm{FeSO}_{4}, \frac{\mathrm{Fe}_{\text {tot }}}{\text { ureia }}=1 / 5$, em diferentes tempos de síntese.

Figura 11 - Larguras e comprimentos médios calculados para as nanopartículas mostradas na figura 10 .

Figura 12 - Difratogramas de raios $X$ para nanopartículas obtidas em $\mathrm{CO}\left(\mathrm{NH}_{2}\right)_{2}$, com $\mathrm{NH}_{4} \mathrm{Fe}\left(\mathrm{SO}_{4}\right)_{2} / \mathrm{FeSO}_{4}, \frac{\mathrm{Fe}_{\text {tot }}}{\text { ureia }}=1 / 5$, em diferentes tempos de síntese. Os índices são para a estrutura cristalina da magnetita e os asteriscos indicam os principais picos da estrutura cristalina da gothieta.

Figura 13 - Curvas de magnetização a $300 \mathrm{~K}$ para nanopartículas obtidas em $\mathrm{CO}\left(\mathrm{NH}_{2}\right)_{2}$, 
com $\mathrm{NH}_{4} \mathrm{Fe}\left(\mathrm{SO}_{4}\right)_{2} / \mathrm{FeSO}_{4}, \frac{\mathrm{Fe}_{t o t}}{\text { ureia }}=1 / 5$ (a) e 1/25 (c), em diferentes tempos de síntese. A região da histerese é ampliada nas figuras (b) e (d).

Figura 14 - Valores de magnetização de saturação plotados em função do tempo de refluxo para nanopartículas obtidas em $\mathrm{CO}\left(\mathrm{NH}_{2}\right)_{2}$, com $\mathrm{NH}_{4} \mathrm{Fe}\left(\mathrm{SO}_{4}\right)_{2} / \mathrm{FeSO}_{4}, \frac{\mathrm{Fe}_{\text {tot }}}{\text { ureia }}=1 / 5$. No gráfico inserido, a magnetização à saturação é plotada em função do \% de magnetita calculado por Rietveld (círculos pretos) e por dosagens químicas (círculos brancos).

Figura 15 - Imagens de MET para nanopartículas obtidas em $\mathrm{CO}\left(\mathrm{NH}_{2}\right)_{2}$, com $\mathrm{NH}_{4} \mathrm{Fe}\left(\mathrm{SO}_{4}\right)_{2} / \mathrm{FeSO}_{4}, \quad \frac{\mathrm{Fe}_{\text {tot }}}{\text { ureia }}=1 / 25$, em diferentes tempos de síntese.

Figura 16 - Difratogramas de raios X para nanopartículas obtidas em $\mathrm{CO}\left(\mathrm{NH}_{2}\right)_{2}$, com $\mathrm{NH}_{4} \mathrm{Fe}\left(\mathrm{SO}_{4}\right)_{2} / \mathrm{FeSO}_{4}, \frac{\mathrm{Fe}_{\text {tot }}}{\text { ureia }}=1 / 25$, em diferentes tempos de síntese. Os índices são para a estrutura cristalina da magnetita e os asteriscos indicam os principais picos da estrutura cristalina da goethita.

Figura 17 - Variação do pH em função do tempo para sistemas contendo: (círculos preto) $\frac{\mathrm{Fe}_{\text {tot }}}{\mathrm{NH}_{4} \mathrm{OH}}=1 / 10$; (quadrado azul) $\frac{\mathrm{Fe}_{\text {tot }}}{\text { ureia }}=1 / 5$; (círculos vermelho) $\frac{\mathrm{Fe}_{\text {tot }}}{\text { ureia }}=1 / 25$, a 95 $\stackrel{\circ}{ } \mathrm{C}$.

Figura 18 - Mecanismo e rotas de síntese propostos para a formação da magnetita, em meio aquoso e em função do $\mathrm{pH}$, a partir dos íons de $\mathrm{Fe}^{2+}$ e $\mathrm{Fe}^{3+}$ em solução

Figura 19 - Representação da adsorção preferencial do $\mathrm{SO}_{4}{ }^{2-}$ a faces paralelas a um determinado eixo de cristais de óxido de ferro, impedindo a adsorção de mais espécies metálicas nessas faces e, assim, o crescimento isotrópico da partícula.

Figura 20 - Variação da temperatura em função do tempo de medição para a amostra obtidas em $\mathrm{CO}\left(\mathrm{NH}_{2}\right)_{2}$, com $\mathrm{NH}_{4} \mathrm{Fe}\left(\mathrm{SO}_{4}\right)_{2} / \mathrm{FeSO}_{4}, \frac{\mathrm{Fe}_{\text {tot }}}{\text { ureia }}=1 / 5,6 \mathrm{~h}$ de refluxo, variando-se 0 campo magnético aplicado.

Figura 21 - Variação da potência dissipada específica (SLP) em função do campo quadrado para a amostra obtidas em $\mathrm{CO}\left(\mathrm{NH}_{2}\right)_{2}$, com $\mathrm{NH}_{4} \mathrm{Fe}\left(\mathrm{SO}_{4}\right)_{2} / \mathrm{FeSO}_{4}, \frac{\mathrm{Fe}_{\text {tot }}}{\text { ureia }}=1 / 5,6$ $\mathrm{h}$ de refluxo

Figura 22 - . Comparação da variação da temperatura em função do tempo de medição entre as amostras: (vermelhos) alongadas e (preto) esféricas, em diferentes campos. 


\section{LISTA DE TABELAS}

Tabela 1 - Condições de síntese das nanopartículas do primeiro grupo.

${ }^{*}$ Razão molar $\mathrm{Fe}_{\text {tot.. }} / \mathrm{NH}_{4} \mathrm{OH}$.

Tabela 2 - Condições de síntese das nanopartículas do segundo grupo

Tabela 3 - Condições de síntese das nanopartículas do terceiro grupo.

Tabela 4 - Dados de composição e características magnéticas a $300 \mathrm{~K}$ para as nanopartículas obtidas em ureia, com $\mathrm{NH}_{4} \mathrm{Fe}\left(\mathrm{SO}_{4}\right)_{2} / \mathrm{FeSO}_{4}, \frac{\mathrm{Fe}_{\text {tot }}}{\text { ureia }}=1 / 5$, em diferentes tempos de síntese.

Tabela 5 - Dados de composição e características magnéticas a $300 \mathrm{~K}$ para as nanopartículas obtidas em ureia, com $\mathrm{NH}_{4} \mathrm{Fe}\left(\mathrm{SO}_{4}\right)_{2} / \mathrm{FeSO}_{4}, \frac{\mathrm{Fe}_{\text {tot }}}{\text { ureia }}=1 / 5$, em diferentes tempos de síntese. 


\section{LISTA DE ABREVIATURAS E SIGLAS}

\begin{tabular}{|c|c|c|}
\hline CMA & ...................... & Campo magnético alternado \\
\hline DRX & $\ldots .$. & Difração de raios $X$ \\
\hline $\mathrm{H}$ & $\ldots$. & Campo magnético \\
\hline $\mathrm{HC}$ & .. & Campo coercitivo \\
\hline M & ....... & Metal \\
\hline MET & 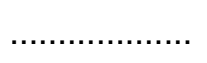 & Microscopia eletrônica de transmissão \\
\hline MHT & $\ldots .$. & Magnetohipertermia \\
\hline $\mathrm{Mr}$ & 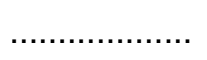 & Magnetização Remanente \\
\hline Ms & 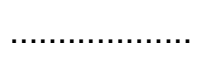 & Magnetização de Saturação \\
\hline NPs & ........ & Nanopartículas \\
\hline NPM & $\ldots \ldots$. & Nanopartícula Magnética \\
\hline SAR & 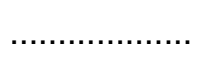 & Potência dissipada específica (Specific absortion rote) \\
\hline SLP & $\ldots \ldots \ldots \ldots \ldots \ldots$ & Taxa de absorção específica (Specific loss power) \\
\hline SPM & $\ldots \ldots$ & Superparamagnético \\
\hline VSM & ....... & $\begin{array}{l}\text { Magnetômetro de amostra vibrante (Vibrating sample } \\
\text { magnetometer) }\end{array}$ \\
\hline $\mathrm{NaH}_{2} \mathrm{PO}_{4}$ & $\ldots .$. & Fosfato de sódio \\
\hline $\mathrm{NaH}_{2} \mathrm{PO}_{2}$ & ....... & Hipofosfito de sódio \\
\hline $\left.\mathrm{Fe}\left(\mathrm{NO}_{3}\right)_{3}\right)$ & $\ldots .$. & Nitrato de ferro (III) \\
\hline $\mathrm{Fe}\left(\mathrm{ClO}_{4}\right)_{3}$ & $\ldots \ldots \ldots \ldots \ldots \ldots$ & Perclorato de ferro (III) \\
\hline $\mathrm{FeCl}_{3} \cdot 6 \mathrm{H}_{2} \mathrm{O}$ & $\ldots \ldots \ldots \ldots \ldots \ldots$ & Cloreto férrico hexahidratado \\
\hline $\mathrm{FeSO}_{4} \cdot 7 \mathrm{H}_{2} \mathrm{O}$ & ....... & Sulfato ferroso heptahidratado \\
\hline $\mathrm{NH}_{4} \mathrm{Fe}\left(\mathrm{SO}_{4}\right)_{2} \cdot 6 \mathrm{H}_{2} \mathrm{O}$ & $\ldots \ldots$ & Sulfato férrico amoniacal hexahidratado \\
\hline $\mathrm{FeCl}_{2} \cdot 4 \mathrm{H}_{2} \mathrm{O}$ & $\ldots$. & Cloreto ferroso tetrahidratado \\
\hline $\mathrm{HCl}$ & ......... & Ácido clorídrico \\
\hline $\mathrm{SnCl}_{2}$ & ....... & Cloreto estanoso dihidratado \\
\hline $\mathrm{HgCl}_{2}$ & $\ldots \ldots \ldots \ldots \ldots \ldots$ & Cloreto de mercúrio \\
\hline $\mathrm{K}_{2} \mathrm{Cr}_{2} \mathrm{O}_{7}$ & $\ldots \ldots \ldots \ldots \ldots \ldots$ & Dicromato de potássio \\
\hline $\mathrm{CO}\left(\mathrm{NH}_{2}\right)_{2}$ & $\ldots$ & Uréia \\
\hline $\mathrm{NH}_{4} \mathrm{OH}$ & $\ldots \ldots .$. & Hidróxido de amônio \\
\hline $\mathrm{H}_{2} \mathrm{SO}_{4}$ & ........ & Ácido sulfúrico \\
\hline $\mathrm{H}_{3} \mathrm{PO}_{4}$ & $\ldots \ldots$. & Ácido fosfórico \\
\hline$\left(\mathrm{C}_{6} \mathrm{H}_{5}\right)_{2} \mathrm{NH}$ & 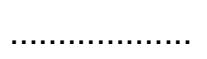 & Difenilamina \\
\hline
\end{tabular}




\section{INTRODUÇÃO}




\section{1- INTRODUÇÃO}

A nanotecnologia, que abrange a escala de tamanho da ordem da bilionésima parte do metro, busca novas propriedades de materiais que possam ser aplicadas em áreas diversificadas, destacando-se a biotecnologia e a medicina [1]. Em especial, nesses setores, o uso de nanopartículas magnéticas (NPM) é um tema em destaque e que já conta com aplicações efetivas e outras em pleno avanço tecnológico [2]. De fato, quando a dimensão da partícula é reduzida à escala nanométrica, os materiais apresentam propriedades físicas, químicas e biológicas únicas e extraordinariamente dependentes do tamanho [3]. É nesse contexto que, como resultado de suas propriedades magnéticas exclusivas e da sua capacidade de interações biológicas tanto a nível celular quanto a nível molecular, as NPM têm atraído grande atenção para potenciais aplicações biomédicas [2]. Em virtude dessas propriedades físicas e químicas sintonizáveis com o tamanho, além da manipulabilidade por um campo magnético externo, as NPM podem ser efetivamente utilizadas como agentes de contraste para ressonância magnética nuclear, como mediadores de calor no tratamento por hipertermia e, adicionalmente, como vetores magnéticos em aplicações de distribuição de drogas [4].

Particularmente promissor, o processo de magnetohipertermia (MHT) envolve a introdução de NPMs em um tecido doente e a aplicação de um campo magnético alternado, de intensidade e frequência adequadas, suficiente para causar um aquecimento das nanoestruturas. Esse aquecimento é imediatamente transmitido ao tecido em questão, de tal forma que, se a temperatura puder ser mantida acima dos $42^{\circ} \mathrm{C}$ por tempo adequado, o tecido é normalmente destruído [5]. Além disso, a MHT pode otimizar os processos de liberação controlada de fármacos conjugados a sistemas 
NPMs-polímero, já que o aquecimento desse compósito pode induzir "degradação" ou abrandamento do polímero e permitir o controle da liberação do fármaco ali aprisionado.

De fato, nanomateriais magnéticos que apresentem taxas de aquecimento bem características são requeridos para ativação das aplicações terapêuticas de hipertermia com campos magnéticos. Além disso, as nanopartículas têm de ser projetadas de tal maneira que apresentem acumulação suficiente e distribuição adequada na área-alvo e, assim, permitam a aplicação de campos magnéticos alternados brandos, evitando efeitos colaterais ao paciente. Em alguns trabalhos que trazem revisões acerca dos subsídios necessários para o "aquecimento magnético", assim como características dos nanomateriais para um bom resultado da técnica de termoterapia, o que se nota é que a hipertermia terapêutica tem se tornado cada vez mais diversificada, necessitando de novos requerimentos para o design de nanossistemas adequados a essas novas demandas [6]. Enquanto as técnicas já bem estabelecidas de MHT têm como base a injeção direta de NPMs em um tumor alvo [7], as novas tendências para aplicação dessa técnica preveem nanomateriais magnéticos para acúmulo, não só no tumor, mas também nas regiões de metástase [8]. Além disso, a aplicação de hipertermia para tratamento de lesões malignas usando NPMs, além de ter potencial importante para aniquilar diretamente as células doentes, também pode aumentar a susceptibilidade dessas regiões para tratamentos convencionais como rádio e quimioterapias [9].

Assim, ainda continua um desafio o desenvolvimento de NPMs com propriedades otimizadas para atender as aplicações multifacetadas da MHT. Nesse sentido, é necessário considerar as várias etapas de elaboração, principalmente a síntese de NPMs com valores altos de taxa de aquecimento (SAR) e com superfícies que possam ser quimicamente modificadas para se obter uma boa estabilidade coloidal, 
assegurar um status "não-tóxico" em condições fisiológicas e introduzir biomoléculas que aumentem a especificidade com o meio biológico.

Mais comumente, nanopartículas esféricas da ordem de $10 \mathrm{~nm}$, de óxidos de ferro (magnetita e maguemita), têm sido usadas na MHT. Entretanto, grandes esforços vêm sendo feitos a fim de otimizar a eficiência do aquecimento dessas nanopartículas, para aplicações em hipertermia, por meio do ajuste de parâmetros-chave, tais como composição, tamanho e morfologia. É nesse sentido que compósitos e outras ferritas (óxidos mistos de ferro, como $\mathrm{MFe}_{2} \mathrm{O}_{4}$, em que $\mathrm{M}$ é um metal de transição ), além de diferentes geometrias ("core-shell” e não esféricas ) e faixas de tamanhos variadas têm sido propostas para os nanomateriais utilizados em MHT [10].

No entanto trabalhos acerca da elaboração de materiais magnéticos, para aplicações biomédicas, com formas diferentes das esféricas ainda são raros. E assim, surgiu a motivação para o desenvolvimento da pesquisa. Espera-se que, em função de sua morfologia anisotrópica, essas nanopartículas se comportem de modo diferenciado das esféricas, no que tange às suas propriedades magnéticas, ópticas e magnetotérmicas; às interações com entidades biológicas e o seu transporte in vivo, o que poderá vir a potencializar a aplicação desses sistemas na magnetohipertermia e possivelmente em outras terapias. 


\subsection{Aplicações biomédicas de NPM: magnetohipertermia (MHT)}

O desenvolvimento de novos nanomateriais e sua aplicação em biomedicina tem recebido bastante atenção nos últimos anos. Os avanços significativos que foram feitos na síntese de nanomateriais com geometria controlada e propriedades físico-químicas e superfícies modificadas resultaram na melhoria da biocompatibilidade e direcionamento ativo, levando ao desenvolvimento de uma gama diversificada de nanomateriais que podem reconhecer diversos tipos de cânceres, entregar fármacos, além de destruir tumores por uma variedade de técnicas terapêuticas [11].

De fato, as nanopartículas magnéticas têm despertado grande interesse na área biotecnológica porque seu tamanho médio é menor ou comparável com o de vírus (20 a $450 \mathrm{~nm})$, proteínas $(5$ a $50 \mathrm{~nm})$ e genes $(2 \mathrm{~nm}$ de largura e de 10 a $100 \mathrm{~nm}$ de comprimento). Além disso, a capacidade de serem manipuladas por um gradiente de campo magnético externo para transporte e imobilização in vivo de modo não-invasivo as tornam candidatas promissoras para muitos estudos [2].

Em aplicações biomédicas, existe a preferência por partículas que apresentem comportamento superparamagnético em temperatura ambiente, o que significa que a magnetização tende a zero, na ausência de campo magnético. Esse fato implica que não existem forças coercitivas ou remanência, evitando interações magnéticas dipolares entre as partículas e, eventualmente, a sua agregação, o que poderia causar problemas adversos derivados da formação de coágulos nos capilares [12].

Os óxidos de ferro, como a magnetita $\left(\mathrm{Fe}_{3} \mathrm{O}_{4}\right)$ e a maguemita $\left(\gamma-\mathrm{Fe}_{2} \mathrm{O}_{3}\right)$, são os materiais mais investigados/utilizados na maioria das técnicas/aplicações biomédicas, devido à sua elevada biocompatibilidade, estabilidade química em condições fisiológicas, baixa toxicidade, e por apresentarem características de composição e 
morfológicas, além de propriedades químicas, físicas e biológicas, manipuláveis durante diversos processos de síntese, que são, em geral simples e econômicos. Além desses óxidos, as ferritas tipo $\mathrm{MFe}_{2} \mathrm{O}_{4}$, em que $\mathrm{M}$ é um metal divalente, geralmente de transição, como o $\mathrm{Co}, \mathrm{Mn}, \mathrm{Ni}, \mathrm{Cu}$ e $\mathrm{Zn}$, ou ainda mistas, têm sido empregadas para esses mesmos fins [13].

Pelas suas dimensões reduzidas, as NPMs têm facilidade para transitar em diversos compartimentos do organismo e, também pela possibilidade de serem funcionalizadas com ligantes específicos, têm preferência para se acumular nos tecidos tumorais. Dessa forma, em diversas aplicações biomédicas, as NPMs são utilizadas, tanto para fins terapêuticos, como para fins diagnósticos - ou simultaneamente com a função "teranóstica" - no tratamento contra o câncer, em sistemas de distribuição e carreamento de drogas [14], em ressonância magnética nuclear [15], e na hipertermia magnética [16]. Dentre as diversas potenciais aplicações terapêuticas, esse trabalho é focado na elaboração de materiais para aplicações no tratamento contra o câncer por hipertemia.

Em seu sentido clínico mais geral, a hipertermia consiste em um procedimento terapêutico onde os tecidos são aquecidos acima dos limites de temperatura fisiológicos normais [17] e baseia-se no aumento da temperatura $\left(41-46{ }^{\circ} \mathrm{C}\right)$ de uma determinada região do corpo que esteja afetada por uma neoplasia. Tumores geralmente são estruturas primitivas e caóticas, o que pode resultar em áreas destituídas de nutrientes, com baixas concentrações de oxigênio (hipóxia), altamente ácidas e as células que existem nestas condições são, em geral, mais sensíveis ao efeito citotóxico do calor. Portanto, o aumento de temperatura altera a síntese de DNA e RNA, enfraquece os sistemas enzimáticos celulares necessários para o metabolismo e para a divisão celular, desestabiliza algumas proteínas celulares e assim causam a morte celular. Essa 
modalidade de tratamento complementa tratamentos atualmente disponíveis, incluindo quimioterapia, radioterapia, cirurgia, terapia genética e imunoterapia para o câncer [18].

A hipertermia pode ser alcançada pela aplicação de laser, radiofrequência, microondas, ultrassom, infravermelho ou implantes ferromagnéticos [19]. Entretanto, o grande desafio da indução de calor (aumento de temperatura) em pacientes com câncer baseia-se na dificuldade de aplicar ou gerar calor localmente sem, contudo, danificar as células normais vizinhas. Nesse sentido, as nanopartículas magnéticas surgem como agentes alternativos para aquecer especificamente o alvo, preservando os tecidos saudáveis.

A hipertermia magnética ou magnetohipertermia (MHT) permite induzir remotamente o calor local por meio das perdas de energia das nanopartículas magnéticas sob um campo magnético oscilante. $\mathrm{O}$ aumento de temperatura requerido pela hipertermia pode ser atingido pela dispersão das nanopartículas magnéticas no tecido doente e posterior aplicação de um campo magnético alternado (CMA). As partículas magnéticas, quando submetidas a um CMA, por meio de processos de perdas energéticas transformam a energia eletromagnética em calor, permitindo, assim, o aumento da temperatura em regiões bem definidas espacialmente, em que as células tumorais e as nanopartículas estão localizadas [12]. Simplificadamente, para induzir a hipertermia especificamente no alvo, as nanopartículas magnéticas são guiadas e retidas na região tumoral por um gradiente de campo magnético externo (ver figura 1), após a administração. Aplica-se, então um CMA, de intensidade e frequência tal, que a direção de magnetização das partículas seja continuamente revertida, gerando calor necessário para causar a lise das células tumorais, que é liberado para as células vizinhas. Se essa temperatura puder ser mantida na faixa preferencial de $42-44^{\circ} \mathrm{C}$ por $30 \mathrm{~min}$ ou mais, o tumor pode ser total ou parcialmente destruído. A minimização dos danos aos tecidos 
normais circunvizinhos faz da MHT uma técnica promissora para o tratamento de cânceres diversos.
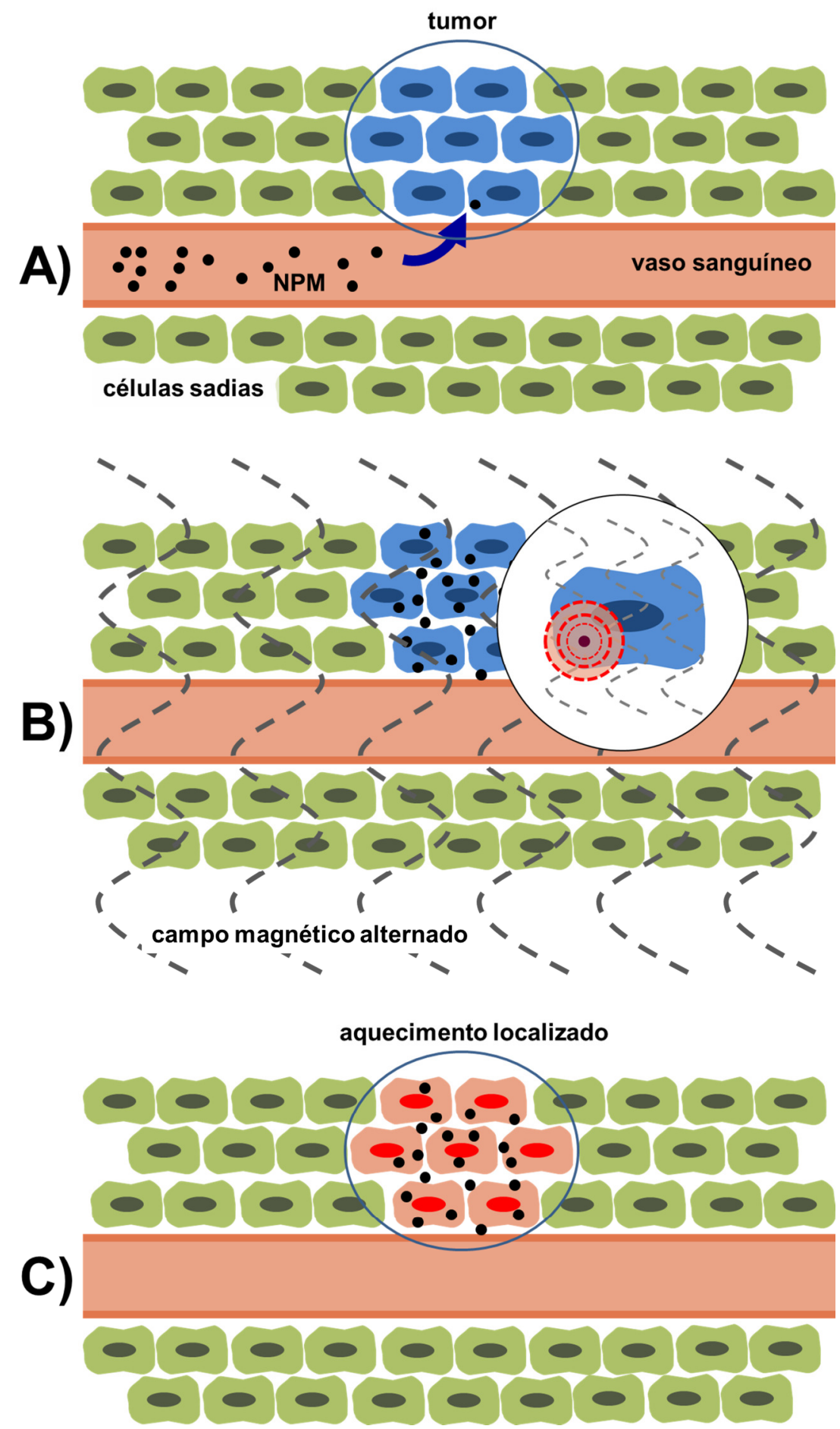

Figura 1 - Representação da técnica de hipertermia magnética: a) as nanopartículas magnéticas são administradas e, transportadas pelos vasos sanguíneos, são localizadas especificamente na região das células de um tumor; b) em seguida um campo magnético alternado é aplicado, provocando um aquecimento nas nanopartículas e, em c), localmente o tumor. 


\subsection{Propriedades magnéticas dos óxidos de ferro e o princípio da MHT}

Os óxidos de ferro são compostos formados pelo ferro (Fe) combinados com o oxigênio $(\mathrm{O})$ e grupos hidroxilas $(\mathrm{OH})$, largamente distribuídos ao redor do planeta. Sua larga produção em laboratório, associada com suas excelentes propriedades físicas e químicas, bem como a possibilidade de manipulação dessas propriedades, tornam esses materiais bastante interessantes para aplicações biológicas [20].

$\mathrm{Na}$ natureza, os óxidos de ferro podem ser encontrados sob muitas formas distintas, sendo as mais comuns e conhecidas, a magnetita, a maguemita e a hematita. Existem, porém, outras formas menos conhecidas, de fases puras dos óxidos de ferro e de oxi-hidróxidos, como a goethita, akaganetita, lepidocrocita, etc. [21]. Em nanobiotecnologia, as nanopartículas mais utilizadas são, sem dúvida, as ferritas magnéticas, especialmente magnetita $\left(\mathrm{Fe}_{3} \mathrm{O}_{4}\right)$ e maguemita $\left(\gamma-\mathrm{Fe}_{2} \mathrm{O}_{3}\right)$, por sua elevada magnetização, facilidade de síntese e grande aplicabilidade na área biomédica, devido a sua biocompatibilidade e biodegradabilidade. São variados os métodos de síntese desses nanomateriais - os processos físicos, como deposição em fase gasosa e litografia por feixe de elétrons, são bastante limitados pela sua inabilidade para controlar o tamanho das partículas magnéticas em nanoescala [22] e, por isso, pouco utilizados. Já os processos químicos permitem maior controle da morfologia, do tamanho e das propriedades físicas e físico-químicas dos nanomateriais. Por isso, são mais empregados e exemplos sínteses, por coprecipitação [23], decomposição térmica [24], reação hidrotérmica, [25] processos sol-gel [26], nanoreatores [27], oxidação [28], injeção de fluxo [29], processos eletroquímicos [30], aerossol [31], decomposição sonoquímica [32] e fluidos supercríticos [33]. Dentre esses métodos, especial atenção tem sido dada às sínteses por coprecipitação em meio aquoso, já que são procedimentos simples, 
menos dispendiosos e têm alto rendimento. Além disso, não envolvem reagentes orgânicos ou solventes mais tóxicos, o que aumenta o potencial das nanopartículas para aplicações na área biomédica. Apesar das inúmeras vantagens desses métodos de obtenção em meio aquoso, outros óxidos de menor simetria e cristalinidade podem se formar durante as sínteses, como é o caso da goethita ( $\alpha$-FeOOH) [34], cuja estrutura e características são discutidas, juntamente com as da magnetita e maghemita [35], a seguir.

\section{- Magnetita - $\mathrm{Fe}_{3} \mathrm{O}_{4}$}

A magnetita é o óxido magnético mais abundante em rochas ígneas, metamórficas e sedimentares, sendo rara a sua ocorrência na forma pura. Suas propriedades magnéticas e elétricas são funções não apenas de seus raios iônicos e de valência, mas também, das propriedades químicas, morfológicas, estequiométricas e tamanho da partícula. Difere dos outros óxidos por possuir em sua estrutura ferro divalente e trivalente. A magnetita ideal é ferrimagnética à temperatura ambiente. A estrutura cristalina da magnetita pode ser descrita em termos da estrutura do espinélio $\left(\mathrm{MgAl}_{2} \mathrm{O}_{4}\right)$, uma ferrita.

As ferritas $\mathrm{MFe}_{2} \mathrm{O}_{4}$, em que $\mathrm{M}=\mathrm{Mn}^{2+}, \mathrm{Fe}^{2+}, \mathrm{Co}^{2+}, \mathrm{Ni}^{2+}, \mathrm{Cu}^{2+}, \mathrm{Zn}^{2+}$, apresentam arranjo cristalino do tipo espinélio [36], cuja cela unitária é formada por um empacotamento cúbico compacto de face centrada de 32 ânions $\mathrm{O}^{2-}$ que geram 64 interstícios tetraédricos e 32 octaédricos parcialmente ocupados pelos cátions metálicos $\mathrm{M}^{2+}$ e $\mathrm{Fe}^{3+}$ (1/8 dos sítios tetraédricos e 1/2 dos octaédricos). A figura 2 mostra, esquematicamente, a cela unitária da estrutura espinélio, na qual as esferas verdes representam os átomos de oxigênio, as vermelhas simbolizam os átomos nos interstícios 
tetraédricos e as amarelas, os átomos que ocupam os sítios octaédricos, destacados à direita, na figura.

Quando existem somente átomos do metal divalente (M) nos sítios tetraédricos e $\mathrm{Fe}^{3+}$ nos sítios octaédricos, a estrutura é classificada como espinélio normal. No caso do $\mathrm{Fe}^{3+}$ ocupar os sítios tetraédricos e metade dos octaédricos, e o metal divalente a outra metade dos octaédricos, o espinélio é classificado como inverso. Isso pode ser mais bem visualizado, ao se utilizar a fórmula cristalográfica $\left[\left(\mathrm{M}_{1-\theta} \mathrm{Fe}_{\theta}\right)_{\mathrm{A}}\left(\mathrm{M}_{\theta} \mathrm{Fe}_{2-\theta}\right)_{\mathrm{B}}\right] \mathrm{O}_{4}$, em que A representa os sítios tetraédricos e $\mathrm{B}$ os octaédricos. Nessa equação, quando $\theta$, que é o parâmetro de ocupação dos íons metálicos, é igual a zero, o espinélio é normal e quando esse valor é unitário, o espinélio é inverso. Entretanto, principalmente na escala nano, quase sempre $0<\theta<1$, e o espinélio é classificado como misto.
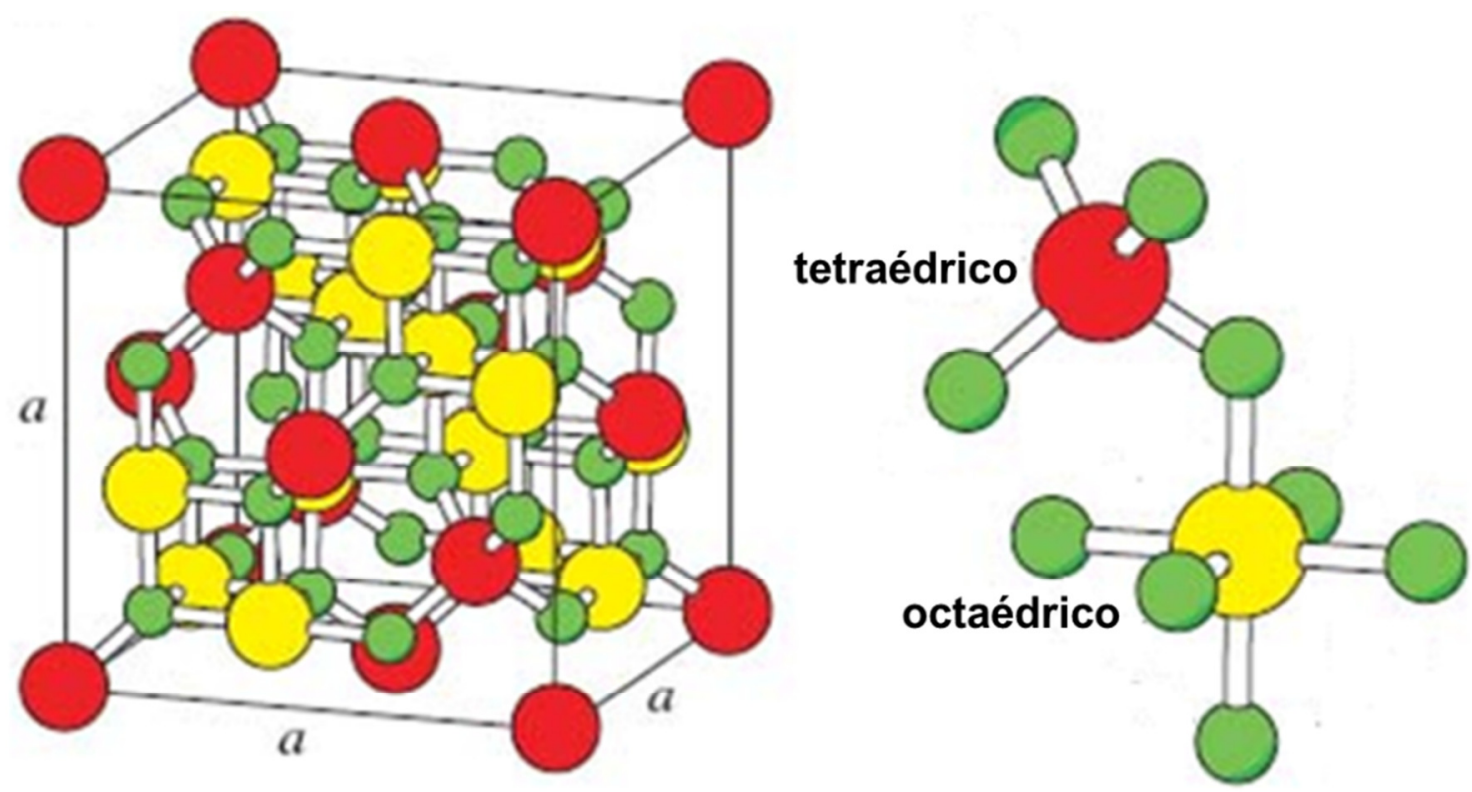

Figura 2 - Representação da cela unitária da estrutura espinélio: as esferas verdes simbolizam os átomos de oxigênio, as vermelhas simbolizam os cátions nos sítios tetraédricos e as amarelas representam os cátions posicionados nos sítios octaédricos. 


\section{- Maghemita $-\gamma-\mathrm{Fe}_{2} \mathrm{O}_{3}$}

A estrutura da maghemita possui estrutura cristalina similar à da magnetita (estrutura cúbica espinélio), porém a principal diferença é a presença de $\mathrm{Fe}^{3+}$ como o único cátion na $\gamma-\mathrm{Fe}_{2} \mathrm{O}_{3}$. Cada célula unitária (cúbica) contém, em média, 32 íons $\mathrm{O}^{2-}$, 21,33 íons $\mathrm{Fe}^{3+}$ e 2,66 vacâncias, sendo que os cátions estão distribuídos em 8 sítios tetraédricos e 16 octaédricos. As vacâncias estão localizadas nos sítios octaédricos. A maghemita é um óxido ferrimagnético a temperatura ambiente e suas propriedades magnéticas dependem do tamanho de partículas e dos efeitos de superfície.

\section{- Goethita - $\alpha-\mathrm{FeO}(\mathrm{OH})$}

A goethita, forma comum de oxi-hidróxido de ferro, $\alpha$-FeOOH apresenta estrutura cristalina ortorrômbica. Consiste em um arranjo hexagonal de ânions $\mathrm{O}^{2-} \mathrm{e}$ $\mathrm{OH}^{-}$empilhados na direção [010], com $\mathrm{Fe}^{3+}$ ocupando metade dos sítios octaédricos em cada camada. Cada átomo de ferro é circundado por três $\mathrm{O}^{2-}$ e três $\mathrm{OH}^{-}$, formando octaedros $\mathrm{FeO}_{3}(\mathrm{OH})_{3}$. Cadeias duplas desses octaedros ligados por arestas são ligadas a outras cadeias duplas pelos vértices, formando uma estrutura ortorrômbica conforme mostrado na figura 3 .

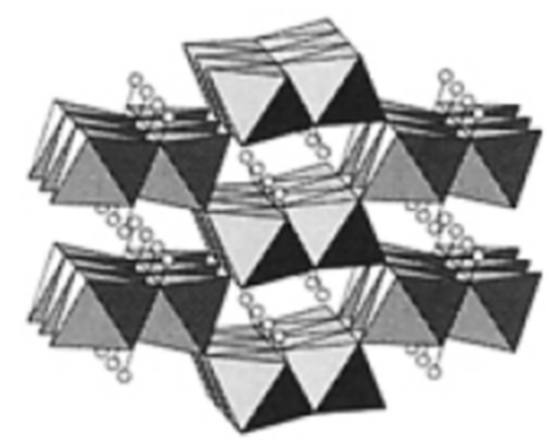

Figura 3 - Representação da estrutura cristalina da goethita. 


\subsubsection{Propriedades magnéticas}

As propriedades magnéticas de um material estão relacionadas ao movimento dos elétrons nos átomos e a compreensão da sua dinâmica é fundamental para o entendimento dos mecanismos que regem os sistemas magnéticos nas aplicações biomédicas. O momento magnético, $m$, é um parâmetro utilizado para quantificar as propriedades magnéticas de um material [20]. Em um átomo ou íon livre, ele é originado do spin dos elétrons, do seu momento angular orbital em relação ao núcleo e da mudança no momento orbital, induzida por um campo magnético aplicado [37,38]. Ele não pode ser medido diretamente, mas é dado em função da susceptibilidade magnética molar, $\chi$, segundo $m=2,83 \sqrt{\chi T}$, em que $T$ é a temperatura absoluta e $\chi$ denota a relação entre a magnetização, $M$ (soma dos momentos magnéticos dos átomos da amostra por unidade de volume) sofrida por um material disposto em um campo magnético aplicado, $H$ [39]: $M=\chi H$. A unidade utilizada para $m$ é Joule/Tesla, mas utiliza-se também magneton de Bohr (MB). O magneton de Bohr, $\mu_{B}$, é o momento magnético associado ao movimento orbital de um elétron, girando na primeira órbita de Bohr.

Dessa forma, o momento magnético de um átomo é a soma vetorial dos momentos magnéticos associados ao movimento dos elétrons em suas órbitas e ao spin de cada um deles. Uma vez que, tanto o momento angular orbital quanto o momento de spin são quantizados, o momento magnético também será quantizado.

Considerando a dinâmica de interação entre os momentos magnéticos, podemos distinguir duas situações: magnetismo individual e magnetismo cooperativo.

O magnetismo individual se caracteriza pela ausência de interações magnéticas de longo alcance, de modo que os momentos magnéticos estão orientados aleatoriamente a campo zero. Dentro desse quadro, duas situações são possíveis: 
- Diamagnetismo: os momentos magnéticos individuais dos elétrons se cancelam e o átomo não possui momento resultante. A susceptibilidade magnética dessas substâncias é pequena (da ordem de $10^{-6}$ ), negativa e independente da temperatura [20]. O átomo de zinco ( $\mathrm{Zn}$ ) é um exemplo de diamagnetismo, pois possui 30 elétrons, todos emparelhados, de modo que o orbital $3 d$ está completo, como mostra a figura 4.

- Paramagnetismo: o cancelamento dos momentos magnéticos individuais é parcial, uma vez que existem elétrons desemparelhados e o átomo possui um momento magnético resultante. Assim, a aplicação de um campo magnético promove o alinhamento parcial dos momentos magnéticos paralelamente ao campo. A susceptibilidade magnética está na faixa de 0 a 0,01 , é positiva e varia com a temperatura. O átomo de ferro (Fe) é um exemplo de paramagnetismo, uma vez que apresenta quatro de seus 26 elétrons desemparelhados $\left(d^{6}\right)$, como mostra a figura 4.

No magnetismo cooperativo, os materiais possuem ordenamento magnético proveniente de interações magnéticas de longo alcance entre os momentos magnéticos atômicos, conduzindo a uma magnetização espontânea. Essa situação só ocorre abaixo de uma temperatura crítica, denominada temperatura de Curie $\left(T_{\mathrm{C}}\right)$, para materiais ferromagnéticos e ferrimagnéticos, e temperatura de Néel $\left(T_{\mathrm{N}}\right)$, para materiais antiferromagnéticos. Acima dessa temperatura, os efeitos de flutuações térmicas são suficientes para quebrar a ordem e o material se torna paramagnético. Dentro desse quadro, três tipos de ordenamento são possíveis (figura 4): 
- Ferromagnetismo: os momentos magnéticos dos diferentes átomos estão alinhados paralelamente. Esses materiais apresentam um momento magnético resultante e uma alta e positiva susceptibilidade magnética $\left(0,01-10^{6}\right)$;

- Antiferromagnetismo: os momentos magnéticos de igual magnitude dos diferentes átomos estão alinhados antiparalelamente entre si, de modo que se anulam e o momento magnético resultante do material é zero. Eles apresentam uma susceptibilidade magnética pequena e positiva $(0-0,1)$;

- Ferrimagnetismo: tal qual no antiferromagnetismo, os momentos magnéticos dos diferentes átomos estão alinhados antiparalelamente entre si. Entretanto, a magnitude desses diferentes momentos magnéticos é desigual, levando a um momento magnético resultante diferente de zero.

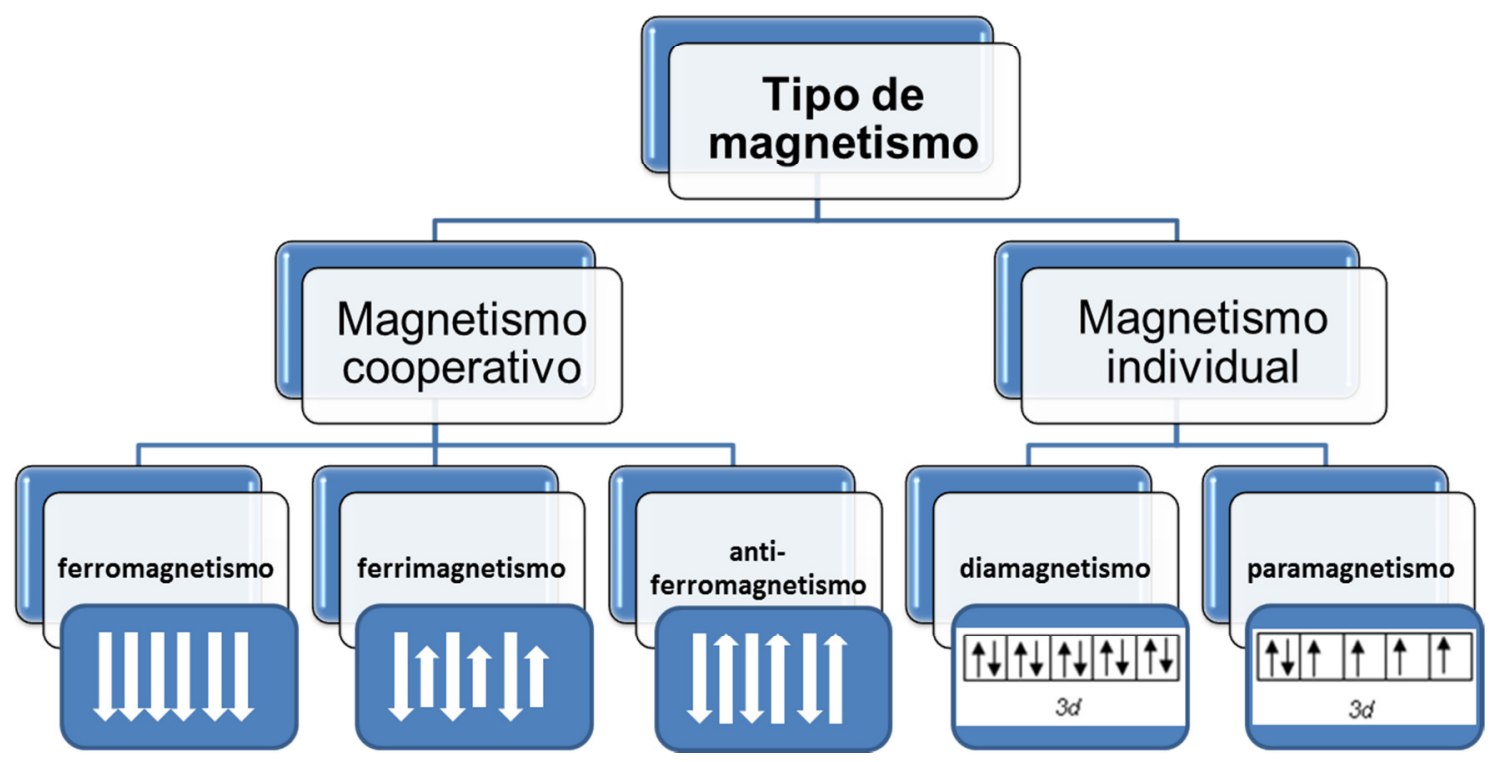

Figura 4 - Esquema com a classificação dos diferentes tipos de magnetismo cooperativo e individual. 
Em um cristal, portanto, a magnetização é resultado da interação dos momentos magnéticos de muitos átomos. Para que a energia magnetostática desse sistema seja minimizada, ele se subdivide em regiões com diferentes tamanhos e formas, em cujos interiores os momentos magnéticos tendem a se alinhar espontaneamente, em uma mesma direção, gerando momentos magnéticos resultantes opostos. Essas regiões são chamadas de domínios magnéticos e seus limites são as "paredes de Bloch" (figura 5).

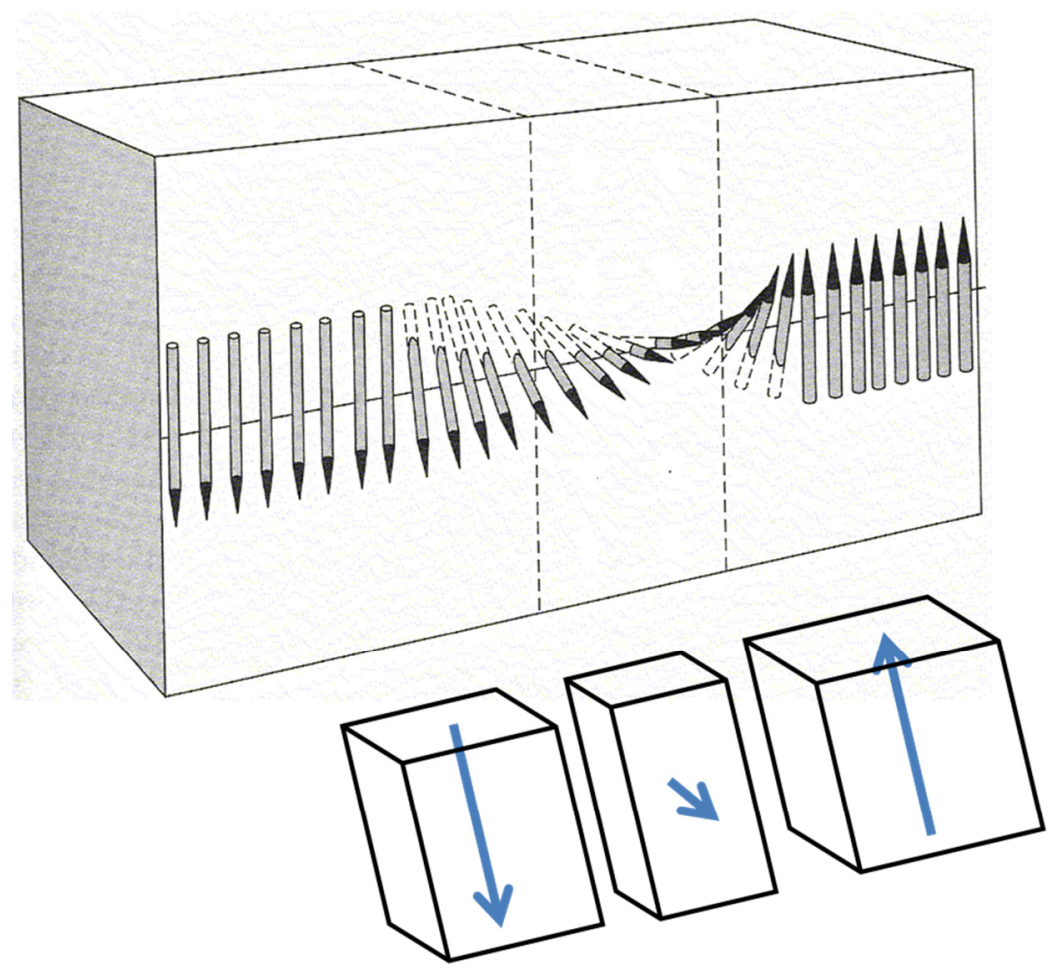

Figura 5. Representação dos domínios magnéticos e do momento magnético resultante, dentro de uma amostra, separados pelas paredes de Bloch.

O alinhamento espontâneo dos momentos magnéticos se dá segundo direções preferenciais, chamadas de eixos de fácil magnetização ou eixos de magnetização espontânea. Essa preferência na orientação dos momentos magnéticos está associada a uma energia (anisotropia magnética), que é mínima quando os momentos magnéticos estão orientados ao longo destes eixos. 
Assim, cada um desses domínios possui um vetor magnetização próprio, oriundo do alinhamento dos momentos magnéticos individuais segundo os eixos de fácil magnetização dentro do domínio. Os vetores magnetização de todos os domínios da amostra podem não estar alinhados, originando uma magnetização menor do que a esperada se todos esses vetores estivessem perfeitamente alinhados. Diminuindo-se o tamanho das partículas, diminui-se o número de domínios até uma dimensão crítica, abaixo da qual se tem um monodomínio magnético.

Aplicando-se um campo magnético $H$ a uma amostra, é possível notar que a sua magnetização $M$ aumenta com o aumento da força do campo aplicado até um valor máximo, denominado magnetização de saturação, $M_{S}$ (figura 6). Nessa situação, os momentos magnéticos de todos os domínios estão alinhados. A curva de $M$ versus $H$ mostra um laço de histerese correspondente à magnetização e desmagnetização, porque nem todos os domínios magnéticos da amostra retornam às suas orientações originais, quando o campo magnético aplicado é reduzido, após ter atingido a $M_{S}$. Dessa forma, quando $H$ retorna a zero, há uma magnetização remanente, $M_{R}$, que pode ser removida pela aplicação de um campo magnético reverso, denominado campo coercitivo, $H_{C}$. Materiais com um monodomínio magnético não apresentam laço de histerese, pois eles são superparamagnéticos (SPM). 


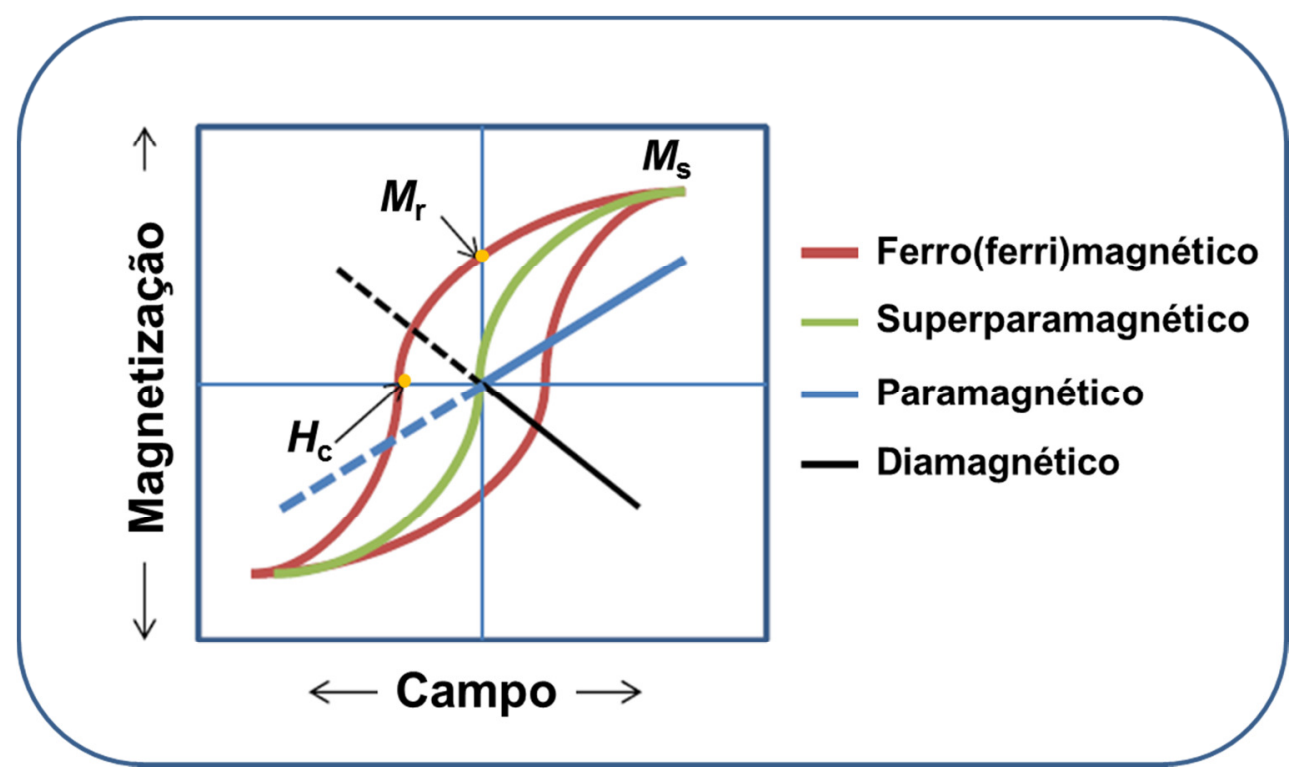

Figura 6 - Comportamento magnético sob a influência de um campo magnético. As curvas de magnetização (magnetização $\times$ campo magnético) para os diferentes tipos de materiais são plotadas no gráfico. Os valores de magnetização de saturação $\left(M_{\mathrm{s}}\right)$ magnetização remanente $\left(M_{\mathrm{r}}\right)$ e de campo coercitivo $\left(H_{\mathrm{c}}\right)$ são destacados na figura.

\subsubsection{O superparamagnetismo}

O fenômeno do superparamagnetismo pode ocorrer em monodomínios magnéticos ou em temperaturas muito elevadas [40]. Os fundamentos físicos do superparamagnetismo são baseados numa lei de ativação para o tempo de relaxação $\tau$ da partícula, tido como o tempo médio que a partícula leva para passar de um estado de equilíbrio a outro. Dois mecanismos de relaxação são fundamentais e possuem o seu tempo de relaxação característico: relaxação browniana e relaxação de Néel-Brown.

A relaxação browniana corresponde à rotação física das partículas propriamente ditas e o seu tempo de relaxação, $\tau_{\mathrm{B}}[41]$ depende das propriedades hidrodinâmicas do fluido no qual as nanopartículas estão dispersas: $\tau_{B}=3 \eta V_{B} / k_{B} T$, em que $\eta$ é a 
viscosidade do meio no qual às partículas estão suspensas; $V_{B}$ é o volume hidrodinâmico da partícula que inclui qualquer camada não-magnética; $k_{\beta}$ é a constante de Boltzmann; e $T$ a temperatura.

Já a relaxação de Néel-Brown diz respeito à rotação dos momentos magnéticos dentro de cada partícula e o seu tempo de relaxação, $\tau_{\mathrm{N}}$, sobre o qual se apoia o superparamagnetismo, é determinada pela energia de anisotropia magnética das nanopartículas superparamagnéticas relativa à energia térmica: $\tau_{N}=\tau_{0} \exp \left(K_{\alpha} V / k_{\beta} T\right)$, em que $\tau_{0}$ é tempo de relaxação do spin (da ordem de $10^{-9}$ ); $K_{\alpha}$ é a densidade de energia anisotrópica; $V$ é o volume da partícula. O produto de $K_{\alpha} \mathrm{e}$ $V$ fornece a barreira de energia, $E$, que separa os dois estados de equilíbrio.

Uma partícula é dita superparamagnética quando $\tau_{\mathrm{N}}$ é menor que o tempo necessário para a realização de uma medida, $t_{\mathrm{m}}$. Entretanto, se $\tau_{\mathrm{N}}$ for maior que $t_{\mathrm{m}}$, a partícula se encontra no chamado estado "bloqueado". Assim, se $k_{\beta} T \gg E$, ou seja, para altas temperaturas ou volumes muito pequenos, $\tau_{\mathrm{N}}$ tende a ser menor que $t_{\mathrm{m}}$, os momentos magnéticos das partículas flutuam livremente e o sistema está no estado superparamagnético. Por outro lado, se $k_{\beta} T \ll<$, ou seja, em temperaturas mais baixas e para partículas com volume maior, $\tau_{\mathrm{N}}$ tende a ser maior que $t_{\mathrm{m}}$, de modo que o momento da partícula se encontra em um vale durante a medida e o sistema está no estado "bloqueado" (figura 6). Então, para partículas muito pequenas, $\Delta E$ é comparável a $k_{\beta} T$ à temperatura ambiente, de maneira que elas podem apresentar superparamagnetismo nessa condição. Assim, na ausência de um campo magnético externo, os momentos magnéticos das partículas estão orientados aleatoriamente. Quando um campo magnético é aplicado, os momentos magnéticos tendem a se orientar 
na direção desse campo, que, a partir de certo valor, conduz todos os momentos magnéticos a se alinharem paralelamente à sua direção, atingindo a magnetização de saturação. Na medida em que o campo é reduzido, não há magnetização remanente e, portanto, não há laço de histerese. Isso evita, por exemplo, que as nanopartículas magnéticas superparamagnéticas se aglomerem no corpo na ausência de um campo magnético externo, podendo provocar a obstrução de vasos sanguíneos.

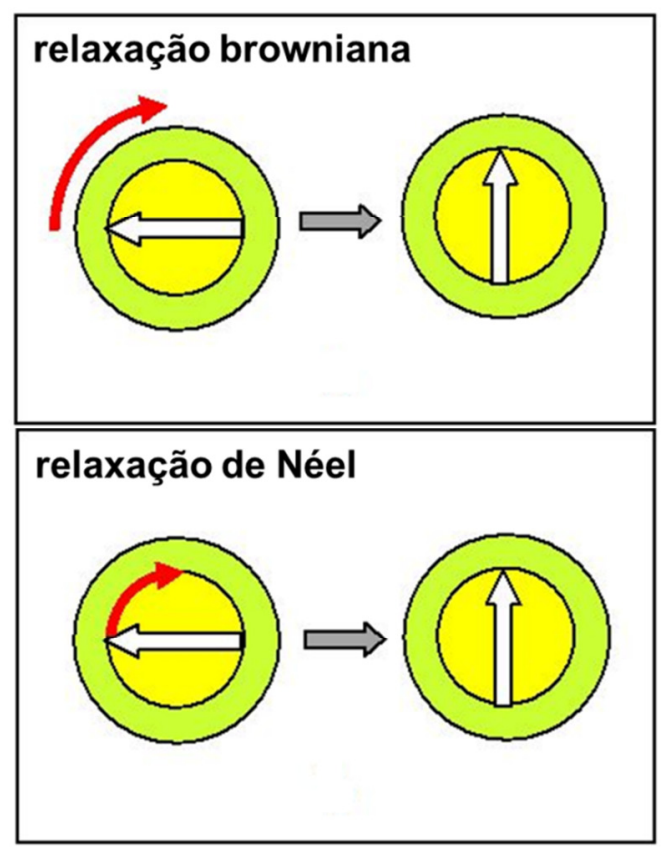

Figura 7 - Modelos de relaxação do momento magnético em um FM: na relaxação browniana a NPM gira em conjunto com o momento magnético do monodomínio. Na relaxação de Néel, o momento magnético gira dentro da estrutura do monodomínio.

Quando dispersos num líquido carreador, as NPM possuem graus suplementares de liberdade, associados à rotação mecânica, o que conduz ao mecanismo de rotação do momento magnético (rotação browniana). Assim, na ausência de um campo magnético externo, a magnetização global de um fluido magnético é nula, pois os momentos magnéticos associados a cada partícula ou "monodomínio", giram livremente, seja pelo mecanismo de Néel ou de rotação browniana (ver figura 7). Em presença de um campo 
magnético aplicado, os momentos magnéticos das partículas tendem a se orientar na direção do campo e o um fluido magnético adquire uma magnetização e podem atingir saturação da magnetização. Em regime diluído, no qual as interações partícula-partícula são desprezíveis, a distribuição de orientação dos momentos magnéticos, em presença de um campo aplicado, resulta do balanço entre a energia magnética das partículas e da sua agitação térmica. $\mathrm{O}$ valor de magnetização de saturação é $M_{\mathrm{s}}=m_{\mathrm{s}} \phi, m_{\mathrm{s}}$ sendo a magnetização de saturação da partícula magnética e $\phi$ a fração volumétrica em material magnético no fluido [42].

Diferentemente da goethita, que é antiferromagnética, nos espinélios, em que a ordem é do tipo ferrimagnética, há um alinhamento antiparalelo dos momentos magnéticos como no antiferromagnetismo. Entretanto, há uma diferença de magnitude entre os momentos alinhados em sentidos contrários e o material apresenta uma magnetização espontânea, porém em menor proporção, como os ferromagnéticos.

Nos óxidos espinélio, os metais se encontram separados por átomos de oxigênio, de forma que as interações de troca somente são possíveis via orbitais $p$ do oxigênio e são chamadas de "interações de supertroca" [20]. Nesse caso, as constantes de troca dependem, principalmente, dos tipos de íons e das distâncias e dos ângulos de ligação entre esses átomos. Nas ferritas, as interações de troca são sempre negativas entre os sítios A e B, ou seja, há um alinhamento antiparalelo global entre os spins nos sítios octaédricos e tetraédricos. Nos sítios tetraédricos, os momentos magnéticos são todos paralelos. Por outro lado, os sítios B são subdivididos em duas sub-redes, cujos ambientes cristalográficos são diferenciados. Assim, nas ferritas normais, as interações BB são negativas (os spins dos íons ferro são alinhados antiparalelamente nesses sítios), ao passo que, nas ferritas inversas, essas interações são positivas (os spins dos íons ferro são alinhados paralelamente aos spins dos íons do metal divalente). De uma maneira 
geral, a magnetização de uma ferrita (normal ou inversa) é função dos momentos magnéticos dos íons divalentes, uma vez que os momentos dos íons ferro se anulam, nos dois casos. A redução à escala nanométrica, entretanto, faz surgir numerosos fenômenos, diferentes daqueles observados nos materiais maciços, que devem ser levados em conta, ao se analisar as propriedades magnéticas desses nanomateriais. Um efeito evidente é o aumento da proporção de átomos situados na superfície da NP, em relação aos mais internos. A debilitada coordenação desses átomos reduz, consideravelmente, as suas interações de troca. Assim, se por um lado o reduzido volume induz uma configuração de monodomínio ideal, por outro, induz à existência de uma camada de spins com orientação pouco correlata aos do núcleo da NP [43]. Além disso, a redistribuição catiônica, comum nessa faixa de tamanho, também modifica as propriedades magnéticas das NP.

\subsubsection{O princípio da magnetohipertermia}

Magnetohipertermia é o aumento da temperatura de sistemas magnéticos proveniente da interação de seus momentos magnéticos com um campo oscilante de alta frequência gerado por uma corrente alternada [44]. Ao aplicar um campo magnético externo em um material magnético, seus momentos magnéticos tendem a se alinhar a este campo. Invertendo o sentido do campo, esses momentos também invertem sua orientação e com isso podem dissipar certa quantidade de energia na forma de calor, dependendo de algumas propriedades do campo aplicado e do material que compõe o sistema. 
Existem basicamente três processos de dissipação sob ação de campo alternado [45]: a perda por histerese, a perda por correntes parasitas (ou eddy currents) e a perda anômala. A perda anômala está relacionada às mudanças de configurações nos domínios magnéticos dos materiais. No caso de sistemas monodomínio, como as nanopartículas estudadas neste trabalho, pode ser negligenciada. Já as perdas por correntes parasitas estão relacionadas à condutividade dos materiais expostos ao campo magnético alternado. A partir da Lei da Indução de Faraday é possível mostrar que a variação do campo magnético produz correntes na superfície dos materiais condutores e essas correntes dissipam energia pelo efeito Joule. Dessa forma, embora as perdas por correntes parasitas não sejam o foco da aplicação de hipertermia magnética, entender e controlar esse processo é essencial para a correta interpretação dos resultados. Por fim, a perda por histerese está relacionada à interação entre a magnetização do material e o campo alternado.

Na perda por histerese a magnetização tende a alinhar-se em direção ao campo aplicado, mas quando o tempo necessário para que esse alinhamento ocorra é maior que o tempo de oscilação do campo, surge uma diferença de fase. Essa diferença de fase provoca o surgimento de uma curva de histerese com uma determinada área. Esse processo é denominado histerese dinâmica [44].

Vários parâmetros podem afetar a capacidade de dissipação térmica de sistemas magnéticos como, tamanho, forma e modificação em sua superfície [46]. Existem grupos de pesquisa ao redor do mundo que trabalham com diferentes descrições do fenômeno de hipertermia magnética. Alguns afirmam que as partículas ferromagnéticas geralmente aquecem devido à perda por histerese [47] e partículas superparamagnéticas aquecem devido à perda por relaxação [48]. Mas outros resultados indicam que a 
hipertermia magnética deve ser sempre descrita pelo processo de histerese dinâmica [49].

No contexto específico da MHT, é mais comum o estudo em termos da potência dissipada específica (specific loss power - SLP) ou taxa de absorção específica (specific absorption rate - SAR), dada por $S A R=\frac{\bar{P}}{\rho} c \frac{M}{m} \frac{\Delta T}{\Delta t}$. em que $\rho$ é a densidade do material magnético, $c$ é o calor específico da amostra, $m$ é a massa de material magnético presente na amostra e $M$ é a massa total da amostra (neste caso, material magnético somado ao líquido carreador). Na maioria dos casos, apesar da presença das nanopartículas magnéticas, compostas por diferentes materiais, o calor específico desses colóides pode ser aproximado para o valor do líquido carreador, no caso desse trabalho, a água $(c=4,19 \mathrm{~J} / \mathrm{gK})$.

\subsection{Síntese de NPM alongadas em meio aquoso}

Vários procedimentos de síntese têm sido desenvolvidos para a preparação de nanopartículas de óxido de ferro. Dentre esses procedimentos, o processo mais simples, barato e ambientalmente viável baseia-se no método por coprecipitação, conforme já discutido. O método de síntese por coprecipitação em meio aquoso consiste na preparação de uma solução, contendo os cátions desejados seguida da precipitação estequiométrica desses cátions, simultaneamente e na forma de óxidos. Particularmente, os óxidos de ferro são precipitados a partir de uma solução aquosa de $\mathrm{Fe}^{2+} \mathrm{e} / \mathrm{ou} \mathrm{Fe}^{3+}$, em meio alcalino. A formação da magnetita $\left(\mathrm{Fe}_{3} \mathrm{O}_{4}\right)$ pode ser representada pela equação química.

$$
\mathrm{Fe}^{2+}+2 \mathrm{Fe}^{3+}+8 \mathrm{OH}^{-} \rightarrow \mathrm{Fe}_{3} \mathrm{O}_{4}+4 \mathrm{H}_{2} \mathrm{O}
$$

(Eq. Quím. 1) 
Essa reação ocorre, por meio do ajuste do pH da solução - a magnetita pode ser obtida quando o pH da solução está entre $8-14$, juntamente com o $\mathrm{Fe}^{3+}: \mathrm{Fe}^{2+}$ na proporção de 2:1. No caso da formação da magnetita, ocorre a coprecipitação de Fe(II) e Fe(III), com formação de cristal misto. Esses mesmos íons, que podem estar coordenados octaedricamente ou tetraedricamente por moléculas de água, formam entre si pontes hidroxo e oxo à medida que o $\mathrm{pH}$ é alterado, de forma que, em condições limítrofes, uma estrutura do tipo espinélio pode surgir [50]. No entanto, a magnetita é bastante instável na presença de oxigênio e tende a se oxidar, formando maghemita.

$$
\left(\gamma-\mathrm{Fe}_{2} \mathrm{O}_{3}\right): 2 \mathrm{Fe}_{3} \mathrm{O}_{4}+1 / 2 \mathrm{O}_{2} \rightarrow 3 \mathrm{Fe}_{2} \mathrm{O}_{3} \text {. }
$$

(Eq. Quím. 2)

Para a síntese das nanopartículas de óxidos de ferro, vários parâmetros podem ser variados, a fim de se controlar características como: tamanho, propriedades magnéticas e de superfície. O tamanho e a forma das nanopartículas de óxido de ferro podem ser controlados por ajuste de $\mathrm{pH}$, força iônica, temperatura, tipo de sais, como por exemplo, (sulfatos, nitratos, cloretos e acetatos), ou ainda na proporção de $\mathrm{Fe}^{2+} / \mathrm{Fe}^{+}$[20].

Uma das metodologias utilizadas para a síntese das nanopartículas alongadas é a hidrólise forçada de sais de ferro na presença de certos ânions que influenciam a forma das partículas. Nesse procedimento, aproveita-se a vantagem de que cátions hidratados de ferro são desprotonados em soluções aquosas a temperaturas próximas de $100{ }^{\circ} \mathrm{C}$. Dois dos ânions que podem ser utilizados com essa finalidade são $\mathrm{PO}_{4}{ }^{3-}$ e o $\mathrm{SO}_{4}{ }^{2-}$. Uma vez que, por meio de sua adsorção a faces (direções) específicas dos óxidos, eles retardam o crescimento do cristal na direção normal a esse eixo, originando partículas alongadas [51]. Ozaki e colaboradores [52] foram os primeiros a realizar essa síntese, de maneira que muitos estudos posteriores foram desenvolvidos, utilizando a mesma metodologia para a obtenção de partículas de hematita nesse formato[53,54,55,56,57]. Eles desenvolveram dois procedimentos para a síntese de nanopartículas alongadas de 
hematita. No primeiro método, soluções aquosas ou etanol/água contendo $\mathrm{FeCl}_{3} \mathrm{e}$ $\mathrm{NaH}_{2} \mathrm{PO}_{4}$ ou $\mathrm{NaH}_{2} \mathrm{PO}_{2}$, respectivamente foram envelhecidas a $100{ }^{\circ} \mathrm{C}$ por diferentes períodos de tempo. O segundo método consistiu em, primeiramente, precipitar hidróxido de ferro pela adição de $\mathrm{NaOH}$ a uma solução de $\mathrm{Fe}\left(\mathrm{NO}_{3}\right)_{3}$, com subsequente adição de $\mathrm{HCl}$ e $\mathrm{NaH}_{2} \mathrm{PO}_{4}$, seguido por envelhecimento a $100{ }^{\circ} \mathrm{C}$. Os autores observaram que a adição de pequenas quantidades de íons $\mathrm{PO}_{4}{ }^{3-}$ ou $\mathrm{PO}_{3}{ }^{3-}$ levou a alteração na forma das partículas resultantes, tornando-as alongadas. Um ano depois, os autores publicaram um estudo no qual obtiveram maguemita a partir da hematita sintetizada, por tratamento térmico. As partículas obtidas mantiveram o formato das precursoras [58].

Além dessa metodologia, Sugimoto e colaboradores [59] prepararam partículas alongadas de hematita, utilizando o método sol-gel, com adição de $\mathrm{PO}_{4}{ }^{3-}$ e $\mathrm{SO}_{4}{ }^{2-}$. Ocaña e colaboradores [60] obtiveram nanopartículas de hematita pela precipitação de $\mathrm{Fe}\left(\mathrm{ClO}_{4}\right)_{3}$, na presença de $\mathrm{CO}\left(\mathrm{NH}_{2}\right)_{2}$ e $\mathrm{PO}_{4}{ }^{3-}$. É sabido que a $\mathrm{CO}\left(\mathrm{NH}_{2}\right)_{2}$ libera íons hidróxido, quando aquecida à sua temperatura de decomposição em solução aquosa, alcalinizando o meio [61]. Foi nessa direção que nanopartículas alongadas de magnetita a partir da hidrólise da $\mathrm{CO}\left(\mathrm{NH}_{2}\right)_{2}$, sob temperatura, na presença de sais de $\mathrm{Fe}^{2+}$ e $\mathrm{Fe}^{3+}$. Compostos orgânicos também foram utilizados para conferir a forma elipsoidal a essas partículas [51], tais como citratos, oxalatos [62], glicina [63] e asparagina [64].

É nessa direção que esse trabalho propõe o estudo da síntese de nanopartículas magnéticas alongadas em meio homogêneo (decomposição da $\left.\mathrm{CO}\left(\mathrm{NH}_{2}\right)_{2}\right)$ na presença de $\mathrm{SO}_{4}{ }^{2-}$. Em relação às propriedades magnéticas de nanopartículas alongadas, uma das vantagens mais evidentes de seu uso é que elas apresentam anisotropia magnética de forma, ao passo que nanopartículas esféricas são isotrópicas. A anisotropia magnética de forma é uma propriedade que reflete a existência de uma direção preferencial de 
magnetização dependente da forma da partícula. Dessa forma, os momentos magnéticos de nanopartículas esféricas estão dispostos aleatoriamente e tendem a se cancelar, diluindo a força do sinal magnético. Já nas nanopartículas elipsoidais, eles tendem a se orientar segundo o seu eixo longo, de modo que eles estarão sempre apontados para dois sentidos possíveis, dentro de uma mesma direção. Assim, a força do sinal magnético é potencializada. Ou seja, partículas alongadas experimentam uma maior força quando comparadas às partículas esféricas de mesmo volume. Alguns autores mostraram algumas situações em que se espera um comportamento diferenciado entre nanopartículas anisotrópicas e isotrópicas, em meio biológico [65]. São elas: em aplicações de imagens por ressonância magnética e tratamento de câncer por hipertermia, em que se esperam diferenças nos tempos de relaxação; em sistemas transportadores de drogas e de genes, nos quais a vetorização magnética tende a ser favorecida, visto que o gene também tem forma anisotrópica. 
OBJETIVOS 


\section{OBJETIVOS}

O objetivo geral desse trabalho foi o de estabelecer, estudar e otimizar uma rota de síntese em meio aquoso, por precipitação homogênea, para elaboração de nanopartículas magnéticas alongadas, assim como estudar suas propriedades magnetotérmicas, visando aplicações em magnetohipertermia magnética.

Os objetivos específicos do trabalho foram:

- Estudar a influência da $\mathrm{CO}\left(\mathrm{NH}_{2}\right)_{2}$, como agente precipitante homogêneo, na formação de nanopartículas alongadas magnéticas;

- Estudar a influência do íon $\mathrm{SO}_{4}{ }^{2-}$, como agente catalisador de estrutura, na formação de nanopartículas alongadas magnéticas;

- Estudar a influência de outros parâmetros, como tempo e natureza de base, na formação de nanopartículas alongadas magnéticas;

- Caracterizar as propriedades estruturais, de composição e magnéticas para otimização da síntese de nanopartículas com as características desejadas;

- Propor, com base nos resultados, uma rota de síntese para explicar a formação das nanopartículas;

- Investigar as propriedades magnetotérmicas de algumas amostras selecionadas para verificar a viabilidade da sua aplicação em magnetohipertermia, no tratamento de câncer. 
METODOLOGIA 


\section{3- PARTE EXPERIMENTAL}

\section{1 - Materiais}

- Ácido clorídrico, HCl, P.A., VETEC - Química Fina LTDA;

- Ácido fosfórico, $\mathrm{H}_{3} \mathrm{PO}_{4}, 85 \%$, P.A, VETEC - Química Fina LTDA;

- Ácido sulfúrico, $\mathrm{H}_{2} \mathrm{SO}_{4}, 95 / 97 \%$, P.A., F. Maia S/A Ind.;

- Água Milli-Q;

- Dicromato de potássio, $\mathrm{K}_{2} \mathrm{Cr}_{2} \mathrm{O}_{7}$, P.A., Quimiobrás - Indústrias Químicas Limitada;

- Difenilamina, $\left(\mathrm{C}_{6} \mathrm{H}_{5}\right)_{2} \mathrm{NH}$, pureza $\geq 99 \%$, Aldrich;

- Cloreto de mercúrio (II), $\mathrm{HgCl}_{2}$, Merck;

- Cloreto estanoso dihidratado, P.A., $\mathrm{SnCl}_{2} \cdot 2 \mathrm{H}_{2} \mathrm{O}$, VETEC - Química Fina LTDA;

- Cloreto férrico hexahidratado, $\mathrm{FeCl}_{3} \cdot 6 \mathrm{H}_{2} \mathrm{O}$, P.A., VETEC - Química Fina LTDA;

- Cloreto ferroso tetrahidratdo, $\mathrm{FeCl}_{2} \cdot 4 \mathrm{H}_{2} \mathrm{O}$, Merck;

- Hidróxido de amônio, $\mathrm{NH}_{4} \mathrm{OH}$, P.A., InLab.

- Sulfato férrico amoniacal hexahidratado, $\mathrm{NH}_{4} \mathrm{Fe}\left(\mathrm{SO}_{4}\right)_{2} \cdot 6 \mathrm{H}_{2} \mathrm{O}$.;

- Sulfato ferroso heptahidratado, $\mathrm{FeSO}_{4} \cdot 7 \mathrm{H}_{2} \mathrm{O}$, Carlo Erba do Brasil;

- Uréia, $\mathrm{CO}\left(\mathrm{NH}_{2}\right)_{2}$, VETEC - Química Fina LTDA.

\section{2 - Metodologia}

A metodologia desse trabalho envolveu:

- A síntese das nanopartículas utilizando diferentes parâmetros; 
- A caracterização das amostras obtidas: a estrutura e o tamanho cristalino das NPMs produzidas foram caracterizados por difratometria de raios $\mathrm{X}$ (DRX), a morfologia e a distribuição em tamanho dessas NPs foram determinadas por microscopia eletrônica de transmissão (MET) e a composição química dos materiais foi estudada por dicromatometria. As propriedades magnéticas dos nanomateriais também foram investigadas por magnetometria de amostra vibrante (VSM), a temperatura ambiente;

- A avaliação das propriedades magnetotérmicas, por meio de medidas da taxa de aquecimento em função do tempo, com a aplicação de campos magnéticos alternados de intensidade e frequência diferentes.

\subsection{1 - Síntese das nanopartículas}

As nanopartículas foram sintetizadas por coprecipitação em meio alcalino de íons de $\mathrm{Fe}^{2+}$ e $\mathrm{Fe}^{3+}$ em solução aquosa a $95{ }^{\circ} \mathrm{C}$, sob refluxo e agitação vigorosa. Parâmetros como: a natureza da base utilizada para alcalinização do meio, o tempo de síntese e a natureza dos contra-íons, foram variados com o objetivo de alcançar o sistema mais adequado para os fins desse estudo.

A identificação das amostras, a natureza dos reagentes, bem como as condições de síntese estão detalhadas a seguir.

Em primeiro lugar, foram feitas duas sínteses, nas quais $\mathrm{FeCl}_{3} \cdot 6 \mathrm{H}_{2} \mathrm{O}$ e $\mathrm{FeSO}_{4} \cdot 7 \mathrm{H}_{2} \mathrm{O}$ e, respectivamente, $45 \mathrm{mmol}$ de $\mathrm{NH}_{4} \mathrm{OH}$ ou $22,5 \mathrm{mmol}$ de $\mathrm{CO}\left(\mathrm{NH}_{2}\right)_{2}$, foram colocados para reagir, sob refluxo, a $95{ }^{\circ} \mathrm{C}$. Nesse caso, o parâmetro investigado foi a natureza da fonte de $\mathrm{OH}^{-}$, seja por $\mathrm{NH}_{4} \mathrm{OH}$ ou $\mathrm{CO}\left(\mathrm{NH}_{2}\right)_{2}$. 
Ainda no primeiro grupo, foram realizadas duas novas sínteses. Para tal, 22,5 mmol de $\mathrm{CO}\left(\mathrm{NH}_{2}\right)_{2}$, na ausência de $\mathrm{SO}_{4}{ }^{2-}, \mathrm{FeCl}_{3} \cdot 6 \mathrm{H}_{2} \mathrm{O} / \mathrm{FeCl}_{2} \cdot 4 \mathrm{H}_{2} \mathrm{O}$, ou na presença de $\mathrm{SO}_{4}{ }^{2-}, \mathrm{NH}_{4} \mathrm{Fe}\left(\mathrm{SO}_{4}\right)_{2} \cdot 6 \mathrm{H}_{2} \mathrm{O} / \mathrm{FeSO}_{4} \cdot 7 \mathrm{H}_{2} \mathrm{O}$, foram colocados para reagir, sob refluxo, a 95 ${ }^{\circ} \mathrm{C}$.

\section{Reagente Utilizado}

Razão Molar

\begin{tabular}{|c|c|c|c|c|c|c|c|}
\hline Amostra & $\begin{array}{l}\text { Tempo de } \\
\text { Síntese (h) }\end{array}$ & $\mathrm{Fe}^{3+}$ & $\mathrm{Fe}^{2+}$ & $\begin{array}{c}\text { Natureza da } \\
\text { base }\end{array}$ & $\frac{\mathrm{Fe}^{3+}}{\mathrm{Fe}^{2+}}$ & $\frac{\mathrm{Fe}_{\text {tot }}}{\text { ureia }}$ & $\frac{\mathrm{SO}_{4}^{2-}}{\mathrm{Fe}_{t o t}}$ \\
\hline MP1 & 6 & $\mathrm{FeCl}_{3} .6 \mathrm{H}_{2} \mathrm{O}$ & $\mathrm{FeSO}_{4} .7 \mathrm{H}_{2} \mathrm{O}$ & $\mathrm{NH}_{4} \mathrm{OH}$ & $2: 1$ & $1: 10^{*}$ & $1: 3$ \\
\hline MP2 & 6 & $\mathrm{FeCl}_{3} \cdot 6 \mathrm{H}_{2} \mathrm{O}$ & $\mathrm{FeSO}_{4} .7 \mathrm{H}_{2} \mathrm{O}$ & $\mathrm{CO}\left(\mathrm{NH}_{2}\right)_{2}$ & $2: 1$ & 1:5 & $1: 3$ \\
\hline MP3 & 6 & $\mathrm{NH}_{4} \mathrm{Fe}\left(\mathrm{SO}_{4}\right)_{2} \cdot 6 \mathrm{H}_{2} \mathrm{O}$ & $\mathrm{FeSO}_{4} .7 \mathrm{H}_{2} \mathrm{O}$ & $\mathrm{CO}\left(\mathrm{NH}_{2}\right)_{2}$ & $2: 1$ & $1: 5$ & $5: 3$ \\
\hline MP4 & 6 & $\mathrm{FeCl}_{3} \cdot 6 \mathrm{H}_{2} \mathrm{O}$ & $\mathrm{FeCl}_{2} \cdot 4 \mathrm{H}_{2} \mathrm{O}$ & $\mathrm{CO}\left(\mathrm{NH}_{2}\right)_{2}$ & $2: 1$ & $1: 5$ & 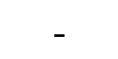 \\
\hline
\end{tabular}

Tabela 1 - Condições de síntese das nanopartículas do primeiro grupo.

*Razão molar $\mathrm{Fe}_{\text {tot. }} / \mathrm{NH}_{4} \mathrm{OH}$

As nanopartículas do segundo e do terceiro grupo (tabelas 2 e 3) foram sintetizadas na presença de íons $\mathrm{SO}_{4}{ }^{2-}$ e com razão molar $\mathrm{Fe}_{\text {total }} / \mathrm{CO}\left(\mathrm{NH}_{2}\right)_{2} 1: 5$ e 1:25, respectivamente. Alíquotas foram retiradas em diferentes tempo de reação.

\begin{tabular}{|c|c|c|c|c|c|c|c|}
\hline \multirow[b]{2}{*}{ Amostra } & \multirow[b]{2}{*}{$\begin{array}{l}\text { Tempo de } \\
\text { Síntese (h) }\end{array}$} & \multicolumn{3}{|c|}{ Reagente Utilizado } & \multicolumn{3}{|c|}{ Razão Molar } \\
\hline & & $\mathrm{Fe}^{3+}$ & $\mathrm{Fe}^{2+}$ & $\begin{array}{c}\text { Natureza da } \\
\text { base }\end{array}$ & $\frac{\mathrm{Fe}^{3-1}}{\mathrm{Fe}^{2-1}}$ & $\frac{\mathbf{F e}_{\text {tot }}}{\text { ureia }}$ & $\frac{\mathrm{SO}_{4}^{2-}}{\mathbf{F e}_{t o t}}$ \\
\hline MP5(1h) & 1 & $\mathrm{NH}_{4} \mathrm{Fe}\left(\mathrm{SO}_{4}\right)_{2} \cdot 6 \mathrm{H}_{2} \mathrm{O}$ & $\mathrm{FeSO}_{4} \cdot 7 \mathrm{H}_{2} \mathrm{O}$ & $\mathrm{CO}\left(\mathrm{NH}_{2}\right)_{2}$ & $2: 1$ & $1: 5$ & $5: 3$ \\
\hline $\operatorname{MP5}(2 \mathrm{~h})$ & 2 & $\mathrm{NH}_{4} \mathrm{Fe}\left(\mathrm{SO}_{4}\right)_{2} \cdot 6 \mathrm{H}_{2} \mathrm{O}$ & $\mathrm{FeSO}_{4} .7 \mathrm{H}_{2} \mathrm{O}$ & $\mathrm{CO}\left(\mathrm{NH}_{2}\right)_{2}$ & $2: 1$ & $1: 5$ & $5: 3$ \\
\hline MP5(4h) & 4 & $\mathrm{NH}_{4} \mathrm{Fe}\left(\mathrm{SO}_{4}\right)_{2} \cdot 6 \mathrm{H}_{2} \mathrm{O}$ & $\mathrm{FeSO}_{4} .7 \mathrm{H}_{2} \mathrm{O}$ & $\mathrm{CO}\left(\mathrm{NH}_{2}\right)_{2}$ & $2: 1$ & $1: 5$ & $5: 3$ \\
\hline MP5(6h) & 6 & $\mathrm{NH}_{4} \mathrm{Fe}\left(\mathrm{SO}_{4}\right)_{2} \cdot 6 \mathrm{H}_{2} \mathrm{O}$ & $\mathrm{FeSO}_{4} .7 \mathrm{H}_{2} \mathrm{O}$ & $\mathrm{CO}\left(\mathrm{NH}_{2}\right)_{2}$ & $2: 1$ & $1: 5$ & $5: 3$ \\
\hline MP5(8h) & 8 & $\mathrm{NH}_{4} \mathrm{Fe}\left(\mathrm{SO}_{4}\right)_{2} \cdot 6 \mathrm{H}_{2} \mathrm{O}$ & $\mathrm{FeSO}_{4} .7 \mathrm{H}_{2} \mathrm{O}$ & $\mathrm{CO}\left(\mathrm{NH}_{2}\right)_{2}$ & $2: 1$ & $1: 5$ & $5: 3$ \\
\hline MP5(12h) & 12 & $\mathrm{NH}_{4} \mathrm{Fe}\left(\mathrm{SO}_{4}\right)_{2} \cdot 6 \mathrm{H}_{2} \mathrm{O}$ & $\mathrm{FeSO}_{4} .7 \mathrm{H}_{2} \mathrm{O}$ & $\mathrm{CO}\left(\mathrm{NH}_{2}\right)_{2}$ & $2: 1$ & $1: 5$ & $5: 3$ \\
\hline
\end{tabular}

Tabela 2 - Condições de síntese das nanopartículas do segundo grupo. 


\begin{tabular}{|c|c|c|c|c|c|c|c|}
\hline \multirow[b]{2}{*}{ Amostra } & \multirow[b]{2}{*}{$\begin{array}{l}\text { Tempo de } \\
\text { Síntese (h) }\end{array}$} & \multicolumn{3}{|c|}{ Reagente Utilizado } & \multicolumn{3}{|c|}{ Razão Molar } \\
\hline & & $\mathrm{Fe}^{3+}$ & $\mathrm{Fe}^{2+}$ & $\begin{array}{c}\text { Natureza da } \\
\text { base }\end{array}$ & $\frac{\mathrm{Fe}^{3+}}{\mathrm{Fe}^{2+}}$ & $\frac{\mathrm{Fe}_{\text {tot }}}{\text { ureia }}$ & $\frac{\mathrm{SO}_{4}^{2-}}{\mathrm{Fe}_{t o t}}$ \\
\hline MP6(2h) & 2 & $\mathrm{NH}_{4} \mathrm{Fe}\left(\mathrm{SO}_{4}\right)_{2} \cdot 6 \mathrm{H}_{2} \mathrm{O}$ & $\mathrm{FeSO}_{4} \cdot 7 \mathrm{H}_{2} \mathrm{O}$ & $\mathrm{CO}\left(\mathrm{NH}_{2}\right)_{2}$ & $2: 1$ & $1: 25$ & $5: 3$ \\
\hline MP6(4h) & 4 & $\mathrm{NH}_{4} \mathrm{Fe}\left(\mathrm{SO}_{4}\right)_{2} \cdot 6 \mathrm{H}_{2} \mathrm{O}$ & $\mathrm{FeSO}_{4} \cdot 7 \mathrm{H}_{2} \mathrm{O}$ & $\mathrm{CO}\left(\mathrm{NH}_{2}\right)_{2}$ & $2: 1$ & $1: 25$ & $5: 3$ \\
\hline MP6(6h) & 6 & $\mathrm{NH}_{4} \mathrm{Fe}\left(\mathrm{SO}_{4}\right)_{2} \cdot 6 \mathrm{H}_{2} \mathrm{O}$ & $\mathrm{FeSO}_{4} \cdot 7 \mathrm{H}_{2} \mathrm{O}$ & $\mathrm{CO}\left(\mathrm{NH}_{2}\right)_{2}$ & $2: 1$ & $1: 25$ & $5: 3$ \\
\hline MP6(8h) & 8 & $\mathrm{NH}_{4} \mathrm{Fe}\left(\mathrm{SO}_{4}\right)_{2} \cdot 6 \mathrm{H}_{2} \mathrm{O}$ & $\mathrm{FeSO}_{4} .7 \mathrm{H}_{2} \mathrm{O}$ & $\mathrm{CO}\left(\mathrm{NH}_{2}\right)_{2}$ & $2: 1$ & $1: 25$ & $5: 3$ \\
\hline MP6(10h) & 10 & $\mathrm{NH}_{4} \mathrm{Fe}\left(\mathrm{SO}_{4}\right)_{2} \cdot 6 \mathrm{H}_{2} \mathrm{O}$ & $\mathrm{FeSO}_{4} \cdot 7 \mathrm{H}_{2} \mathrm{O}$ & $\mathrm{CO}\left(\mathrm{NH}_{2}\right)_{2}$ & $2: 1$ & $1: 25$ & $5: 3$ \\
\hline MP6(12h) & 12 & $\mathrm{NH}_{4} \mathrm{Fe}\left(\mathrm{SO}_{4}\right)_{2} \cdot 6 \mathrm{H}_{2} \mathrm{O}$ & $\mathrm{FeSO}_{4} .7 \mathrm{H}_{2} \mathrm{O}$ & $\mathrm{CO}\left(\mathrm{NH}_{2}\right)_{2}$ & $2: 1$ & $1: 25$ & $5: 3$ \\
\hline
\end{tabular}

Tabela 3 - Condições de síntese das nanopartículas do terceiro grupo.

Todas as amostras foram resfriadas e lavadas com água Milli-Q por decantação magnética e em seguida secas em estufa a $50{ }^{\circ} \mathrm{C}$ por 12 horas.

\subsection{2 - CARACTERIZAÇÃO DOS MATERIAIS}

As amostras sintetizadas foram caracterizadas pelas técnicas descritas a seguir.

\subsubsection{1 - Microscopia Eletrônica de Transmissão (MET)}

As imagens por MET foram obtidas, utilizando-se um microscópio de transmissão JEOL 1011, operando a $80 \mathrm{kV}$, no Instituto de Ciências Biológicas da Universidade de Brasília (UnB). Para preparação das amostras, as nanopartículas foram dispersas em $\mathrm{H}_{2} \mathrm{O}$ Milli-Q, com auxílio de um banho de ultrassom e em seguida depositou-se $5 \mu \mathrm{L}$ da amostra na tela de cobre de 300 malhas cobertas com Formvar $0,4 \%$ que foram secas a temperatura ambiente, por $24 \mathrm{~h}$ em papel filtro. As partículas foram medidas, utilizando o software ImageJ, versão 1.43 . 


\subsubsection{2 - Difração de Raios X (DRX)}

Para análise por DRX, as amostras de foram lavadas com acetona e secas em estufa a $45^{\circ} \mathrm{C}$. O pó obtido foi triturado e finamente pulverizado com auxílio de um graal de ágata e prensados em um porta-amostras de vidro. Em seguida foram analisadas em um difratômetro Miniflex 600, Rigaku, com detecção rápida DTex, operando a 40 $\mathrm{kV}, 30 \mathrm{~mA}$ e radiação $\mathrm{Cu}-K \alpha$, selecionada com um monocromador de grafite. As condições de varredura foram de 20 a $70^{\circ}$, com um passo de $0,02^{\circ}$ e velocidade de $5 \%$ min. Os dados obtidos foram tratados conforme descrito na referência [66], com auxílio do programa GSAS.

\subsubsection{3 - Medidas de Magnetização}

Os pós dessas amostras, obtidos por lavagem com acetona e secagem em estufa, foram analisados em magnetômetro VSM, em uma faixa de campo magnético, de -18 kOe a $+18 \mathrm{kOe}$, a $25^{\circ} \mathrm{C}$. As propriedades magnéticas das amostras foram obtidas a temperatura ambiente e em regime quase-estático, por meio de um magnetômetro de amostra vibrante (Vibrating Sample Magnetometer, VSM), modelo EV9, fabricado pela empresa ADE-MAGNETICS, na Universidade Federal de Goiás (UFG). A precisão de medidas desse VSM é de $10^{-6} \mathrm{emu}$. As bobinas são resfriadas com água e podem atingir um campo magnético de até $2 \mathrm{~T}$.

\subsubsection{4 - Determinação de ferro por dicromatometria}


A determinação de Fe (II) e $\mathrm{Fe}_{\text {total }}$ foi realizada pelo método de Dicromatometria. Nesse método, o Fe (II) é dosado, de acordo com a seguinte reação de óxido-redução:

$$
\mathrm{Cr}^{2} \mathrm{O}_{7}^{2-}+6 \mathrm{Fe}^{2+}+14 \mathrm{H}^{+} \rightarrow 6 \mathrm{Fe}^{3+}+2 \mathrm{Cr}^{3+}+7 \mathrm{H}_{2} \mathrm{O}
$$

(Eq. Quím. 3)

Para a determinação de $\mathrm{Fe}_{\text {total }}$, $\mathrm{Fe}$ (II) e Fe (III), as amostras foram digeridas em $\mathrm{HCl}$ e todo o ferro foi reduzido a $\mathrm{Fe}(\mathrm{II})$, com o auxílio de uma solução de $\mathrm{SnCl}_{2}$, adicionada gota a gota sob aquecimento até a obtenção de uma solução incolor. Após o resfriamento da solução, o excesso do $\mathrm{Sn}(\mathrm{II})$, um interferente do método, foi oxidado a Sn(IV), utilizando-se $10 \mathrm{ml}$ de uma solução de $\mathrm{HgCl}_{2}$, que não interfere no método. Para adequar a concentração hidrogeniônica e regular o potencial do sistema $\mathrm{Fe}(\mathrm{II}) / \mathrm{Fe}(\mathrm{III}), 15 \mathrm{~mL}$ de uma solução de $\mathrm{H}_{2} \mathrm{SO}_{4}$ e $\mathrm{H}_{3} \mathrm{PO}_{4}$ 1:1 foi adicionada ao sistema, a fim de se adequar a concentração hidrogeniônica e regular o potencial do sistema $\mathrm{Fe}(\mathrm{II}) / \mathrm{Fe}(\mathrm{III})$, para facilitar a visualização no ponto de viragem do indicador difenilamina. Feito isso, a amostra foi titulada com uma solução padrão de $\mathrm{K}_{2} \mathrm{Cr}_{2} \mathrm{O}_{7}$ até obtenção de uma solução "azul-perolada". A determinação de Fe(II) foi feita pelo mesmo processo, porém sem a adição de $\mathrm{SnCl}_{2}$ e $\mathrm{HgCl}_{2}$. A concentração de $\mathrm{Fe}(\mathrm{III})$ foi calculada pela diferença entre o $\mathrm{Fe}_{\text {total }}$ e o $\mathrm{Fe}(\mathrm{II})$.

\subsubsection{5 - Magnetohipertermia}

Os experimentos de hipertermia foram realizados na UFG, utilizando o sistema do equipamento comercial de hipertermia da Ambrell, modelo EasyHeat, que opera em campos de elevada amplitude e de baixa frequência de campo magnético alternado (CMA). Nesse estudo, a frequência utilizada foi de $300 \mathrm{kHz}$. Além disso, a amplitude do CMA foi obtida a partir de medições utilizando uma sonda de CMA adquirida da 
AMF Life Systems. Elas variaram de 169 a 312 Oe. As correntes utilizadas também variaram de 53 a $98 \mathrm{~A}$. As massas das amostras em pó utilizadas foram as mesmas $(0,0070 \pm 0,0002 \mathrm{~g})$. Um sistema de fibra óptica operando na região do infravermelho foi usado para medição da temperatura das amostras. 


\title{
RESULTADOS E
}

\author{
DISCUSSÃ̃
}




\section{RESULTADOS E DISCUSSÃO}

Com a finalidade de se obter nanopartículas magnéticas alongadas, alguns parâmetros de síntese foram verificados, principalmente a natureza da base e a concentração da fonte de íons $\mathrm{OH}^{-}$, os responsáveis pela hidrólise e condensação dos íons ferro a uma estrutura de óxido cristalino magnética. Além disso, a presença ou ausência e a natureza e a concentração de ânions complexantes $\left(\mathrm{SO}_{4}{ }^{-}\right)$também foi verificada como fator para geração de estruturas magnéticas alongadas.

\subsection{O efeito da ureia e do sulfato}

A figura 8 exibe as imagens obtidas por MET das nanopartículas obtidas no primeiro grupo de sínteses: conforme observado, as nanopartículas (NPs) obtidas com $\mathrm{NH}_{4} \mathrm{OH}$ - figura $8 \mathrm{a}$ - são aproximadamente esféricas e apresentam um diâmetro característico $<10 \mathrm{~nm}$. Por outro lado, quando a $\mathrm{CO}\left(\mathrm{NH}_{2}\right)_{2}$ foi utilizada, NPs alongadas $(\sim 50 \mathrm{~nm})$ foram obtidas (figura $8 \mathrm{~b})$. 

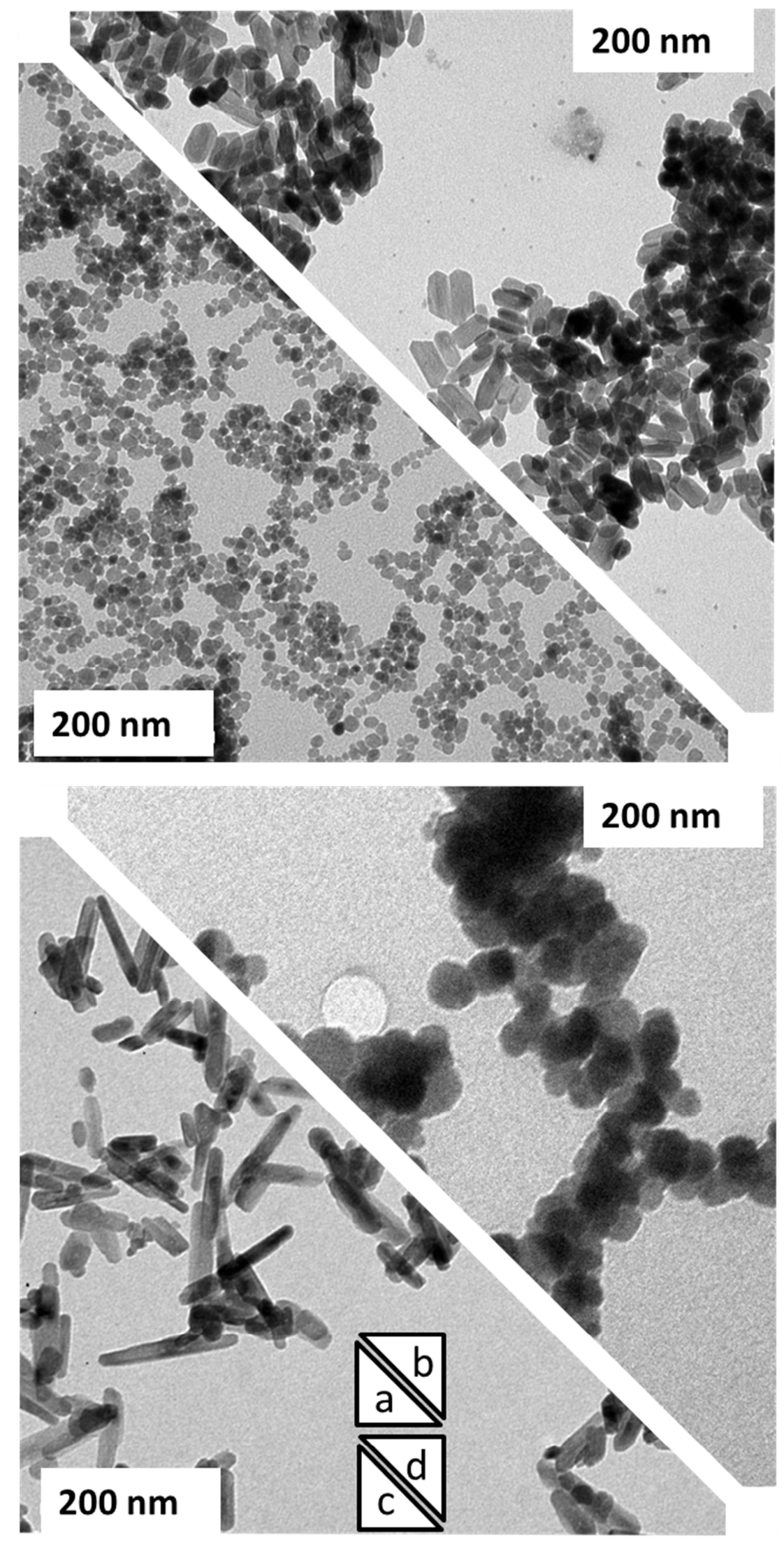

Figura 8 - Imagens de MET para nanopartículas obtidas: a) em $\mathrm{NH}_{4} \mathrm{OH}$, com $\mathrm{FeCl}_{3} / \mathrm{FeSO}_{4}$; b) em $\mathrm{CO}\left(\mathrm{NH}_{2}\right)_{2}$, com $\mathrm{FeCl}_{3} / \mathrm{FeSO}_{4}$; c) em ureia, com $\mathrm{NH}_{4} \mathrm{Fe}\left(\mathrm{SO}_{4}\right)_{2} / \mathrm{FeSO}_{4}$; d) em ureia, com $\mathrm{FeCl}_{3} / \mathrm{FeCl}_{2}$. 
Levando-se em conta que proporcionou a obtenção de NPs alongadas, a $\mathrm{CO}\left(\mathrm{NH}_{2}\right)_{2}$ passou a ser utilizada como fonte de $\mathrm{OH}^{-}$nos próximos experimentos. Assim, duas novas sínteses foram feitas na presença e ausência de $\mathrm{SO}_{4}{ }^{2-}$ para, então, verificar a influência desse íon complexante sobre as características das NPs produzidas.

A figura $8 \mathrm{c}$ mostra que as NPs obtidas na presença de $\mathrm{SO}_{4}{ }^{2-}$ foram alongadas, com dimensões próximas a $70 \mathrm{~nm}$. Diferentemente, na ausência de $\mathrm{SO}_{4}{ }^{2-}$, as nanopartículas obtidas foram aproximadamente esféricas com diâmetros característicos $>20 \mathrm{~nm}$ (figura 8d). Além disso, se as NPs das figuras $8 \mathrm{~b}$ e 8c, sintetizadas na presença de $\mathrm{SO}_{4}{ }^{2-}$, forem comparadas, é possível notar que as últimas apresentaram um comprimento médio maior. Dessa forma, é possível inferir que a concentração do íon $\mathrm{SO}_{4}{ }^{2-}$ também tem influência na elongação das NPs. De fato, no primeiro caso utilizando $\mathrm{FeCl}_{3} / \mathrm{FeSO}_{4}$ - a razão molar entre $\mathrm{SO}_{4}{ }^{2-}$ e ferro total é 1/3. Já no segundo caso, as NPs foram obtidas com a razão molar entre $\mathrm{SO}_{4}{ }^{2-}$ e ferro total igual a $5 / 3$. Ou seja, a presença de $\mathrm{SO}_{4}{ }^{2-}$ foi imprescindível para se obter NPs alongadas, e uma maior concentração utilizada levou a NPs com comprimentos maiores.

Em seguida, as características cristalinas das amostras exibidas na figura 8 foram investigadas por DRX, de forma que os respectivos difratogramas estão plotados no gráfico da figura 9. Após indexar os principais picos de difração utilizando a lei de Bragg, e comparando os resultados com os padrões ASTM, a estrutura espinélio foi identificada como a principal fase cristalina em todas as amostras. $\mathrm{O}$ parâmetro de cela calculado a partir do difratograma, para a amostra sintetizada na presença de $\mathrm{NH}_{4} \mathrm{OH}$, foi $8,352 \AA$. Quando a base foi $\mathrm{CO}\left(\mathrm{NH}_{2}\right)_{2}$, esses parâmetros foram, respectivamente, 8,387 $\mathrm{A}, 8,385 \AA$ e $8.391 \AA$, para as amostras sintetizadas usando os pares $\mathrm{Fe}^{3+} / \mathrm{Fe}^{2+}$, $\mathrm{FeCl}_{3} / \mathrm{FeSO}_{4}, \mathrm{FeCl}_{3} / \mathrm{FeCl}_{2}$, e $\mathrm{NH}_{4} \mathrm{Fe}\left(\mathrm{SO}_{4}\right)_{2} / \mathrm{FeSO}_{4}$. O primeiro está mais próximo do parâmetro de cela da maguemita padrão $(8,346 \AA$ A $)$ e os outros três concordam melhor 
com o valor do parâmetro de cela da magnetita padrão (8,391 ̊̊). É importante salientar que, apesar de apresentar mesma estrutura cristalina e algumas diferenças cristalográficas, os difratogramas da magnetita e da maguemita somente podem ser diferenciados a partir de uma análise minuciosa [67].

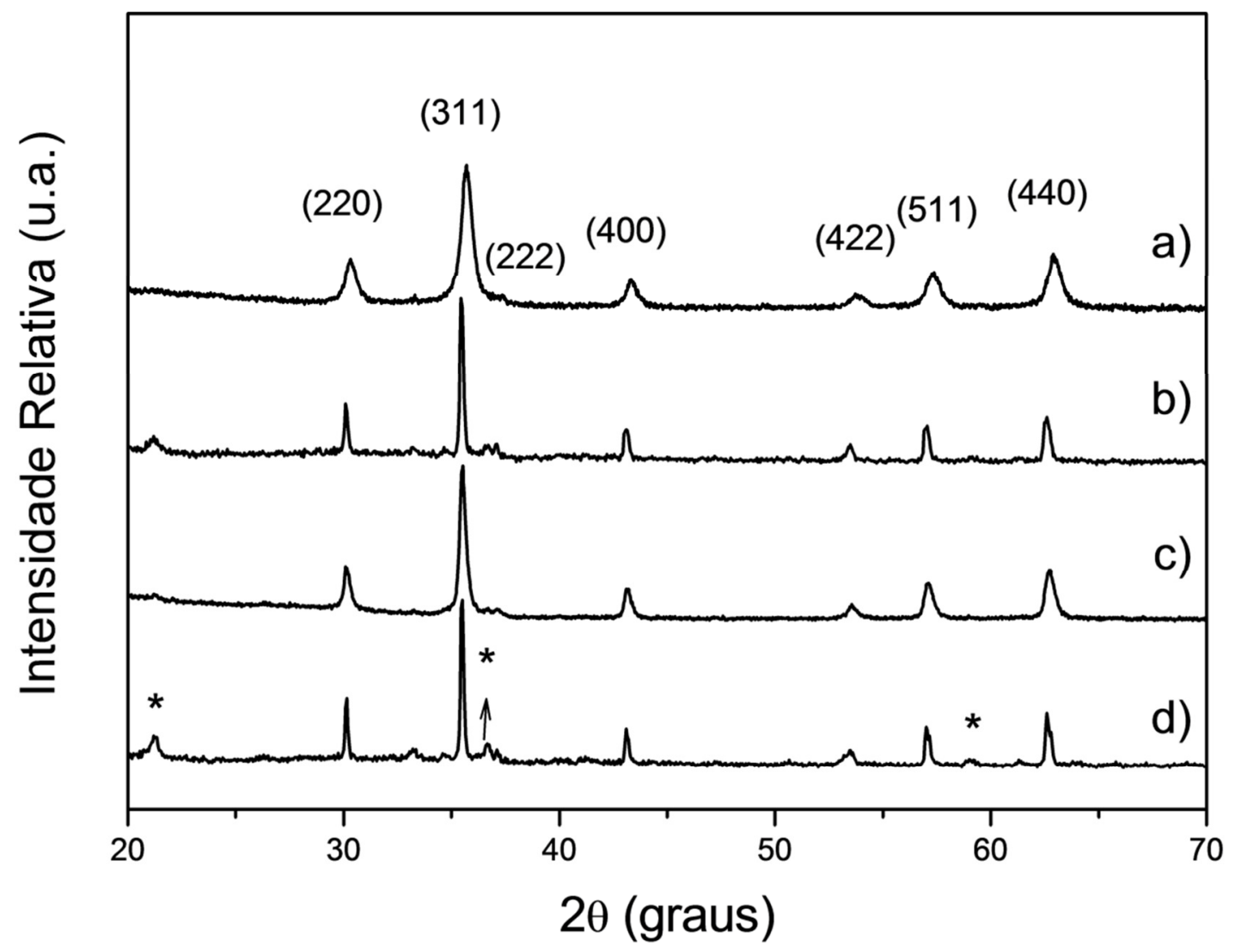

Figura 9 - Difratogramas de raios $\mathrm{X}$ para nanopartículas obtidas: a) em $\mathrm{NH}_{4} \mathrm{OH}$, com $\mathrm{FeCl}_{3} / \mathrm{FeSO}_{4}$; b) em $\mathrm{CO}\left(\mathrm{NH}_{2}\right)_{2}$, com $\mathrm{FeCl}_{3} / \mathrm{FeSO}_{4}$; c) em $\mathrm{CO}\left(\mathrm{NH}_{2}\right)_{2}$, com $\mathrm{NH}_{4} \mathrm{Fe}\left(\mathrm{SO}_{4}\right)_{2} / \mathrm{FeSO}_{4}$; d) em $\mathrm{CO}\left(\mathrm{NH}_{2}\right)_{2}$, com $\mathrm{FeCl}_{3} / \mathrm{FeCl}_{2}$.

Além disso, para as amostras obtidas utilizando-se $\mathrm{CO}\left(\mathrm{NH}_{2}\right)_{2}$, goethita $(\alpha$ FeOOH) também pôde ser identificada como uma segunda fase cristalina - os principais picos de difração desse composto estão marcados com asteriscos. Essa observação será mais bem investigada e discutida adiante. 


\subsection{O efeito do tempo de reação e da concentração da ureia}

Sínteses com razões molares $\mathrm{Fe}_{t o t} / \mathrm{CO}\left(\mathrm{NH}_{2}\right)_{2}-1 / 5$ e $1 / 25$ - e com o par $\mathrm{NH}_{4} \mathrm{Fe}\left(\mathrm{SO}_{4}\right)_{2} / \mathrm{FeSO}_{4}$, foram realizadas. Dessas sínteses, alíquotas de NPs foram retiradas em diferentes tempos de reação. Para o caso da menor concentração de $\mathrm{CO}\left(\mathrm{NH}_{2}\right)_{2}$, amostras com tempos de reação de $1,0 \mathrm{~h} ; 2,5 \mathrm{~h} ; 4,0 \mathrm{~h} ; 6,0 \mathrm{~h} ; 8,0 \mathrm{~h}$ e $12 \mathrm{~h}$ foram recolhidas e caracterizadas. Conforme imagens obtidas por microscopia (figura 10), em todos os tempos coletados, nanopartículas alongadas foram obtidas. Os histogramas das larguras e dos comprimentos - figura 11 mostram as larguras médias e comprimentos médios obtidos a partir desses histogramas e plotados em função do tempo de síntese. Como é possível notar, o comprimento médio varia de $40 \mathrm{~nm}$ para cerca de $70 \mathrm{~nm}$ à medida que a reação se processa, porém, a largura se mantem constante, em torno de $15 \mathrm{~nm}$. Entretanto, do ponto de vista qualitativo, todas as amostras analisadas parecem apresentar uma única fase, com um material homogêneo, sem diferenças significativas de contrastes, que indicariam fases mais ou menos cristalinas. 

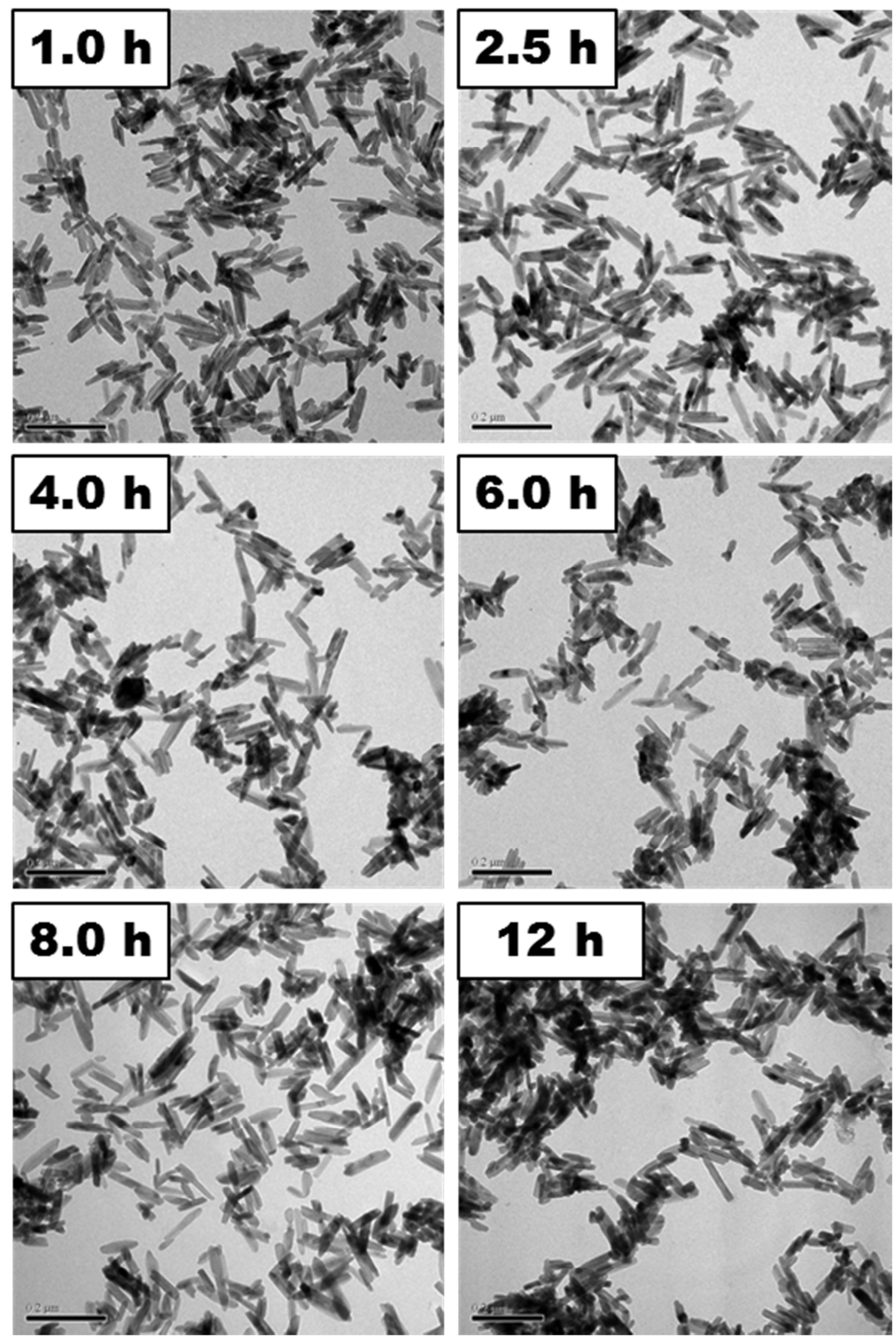

Figura 10 - Imagens de MET para nanopartículas obtidas em $\mathrm{CO}\left(\mathrm{NH}_{2}\right)_{2}$, com $\mathrm{NH}_{4} \mathrm{Fe}\left(\mathrm{SO}_{4}\right)_{2} / \mathrm{FeSO}_{4}$, $\frac{\mathrm{Fe}_{\text {tot }}}{\text { ureia }}=1 / 5$, em diferentes tempos de síntese. 


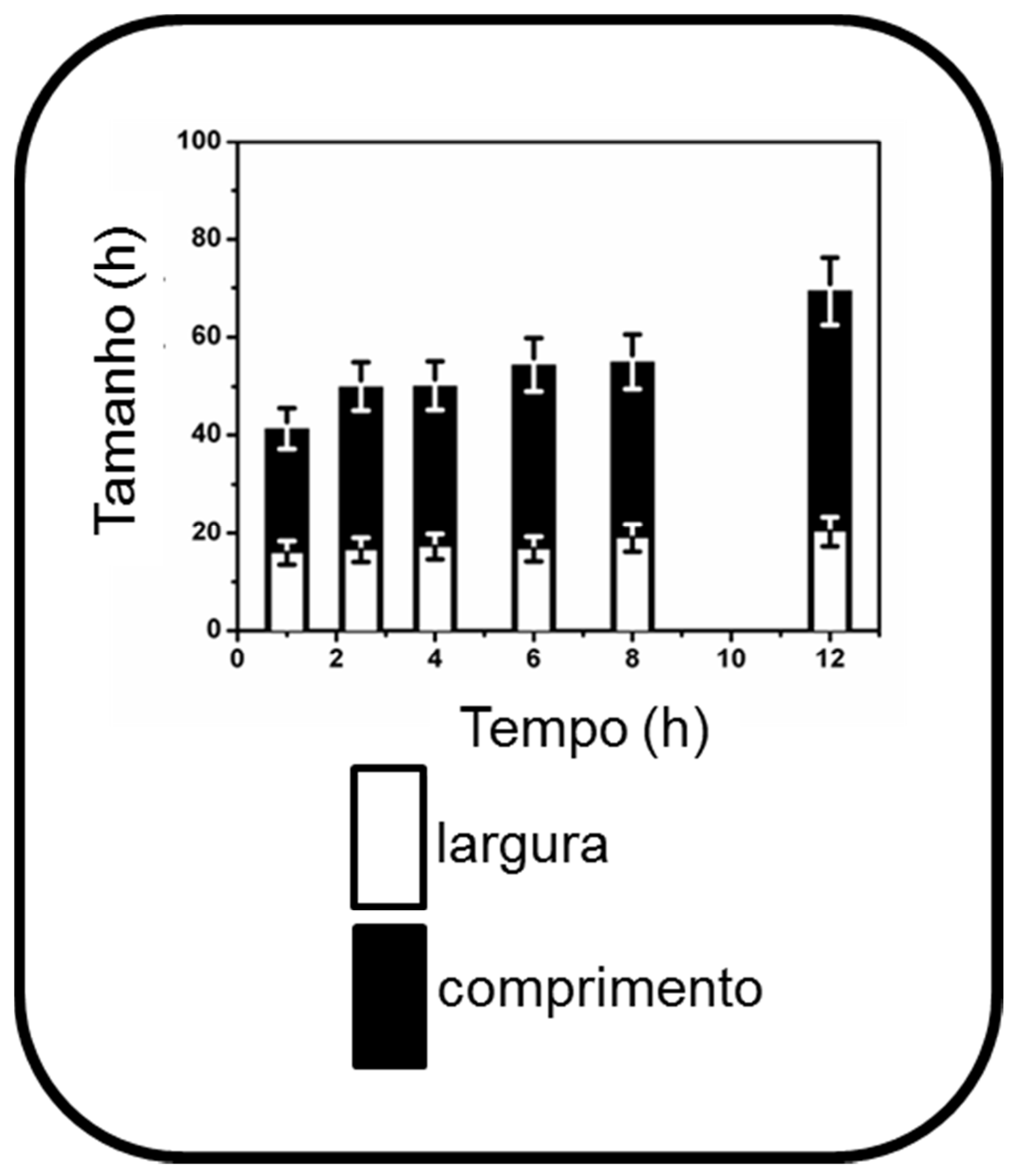

Figura 11 - Larguras e comprimentos médios calculados para as nanopartículas mostradas na figura 10.

Na figura 12, que mostra a evolução dos difratogramas, para as amostras sintetizadas em função do tempo, as fases magnetita e goethita estão presentes. Qualitativamente, é possível notar que os picos referentes à goethita vão desaparecendo, até ficarem quase imperceptíveis, à medida que o tempo de síntese aumenta. A fim de se quantificar o teor em massa de casa fase cristalina, foi feito o refinamento de Rietveld para os difratogramas obtidos, utilizando-se os parâmetros das fases magnetita e maguemita. 


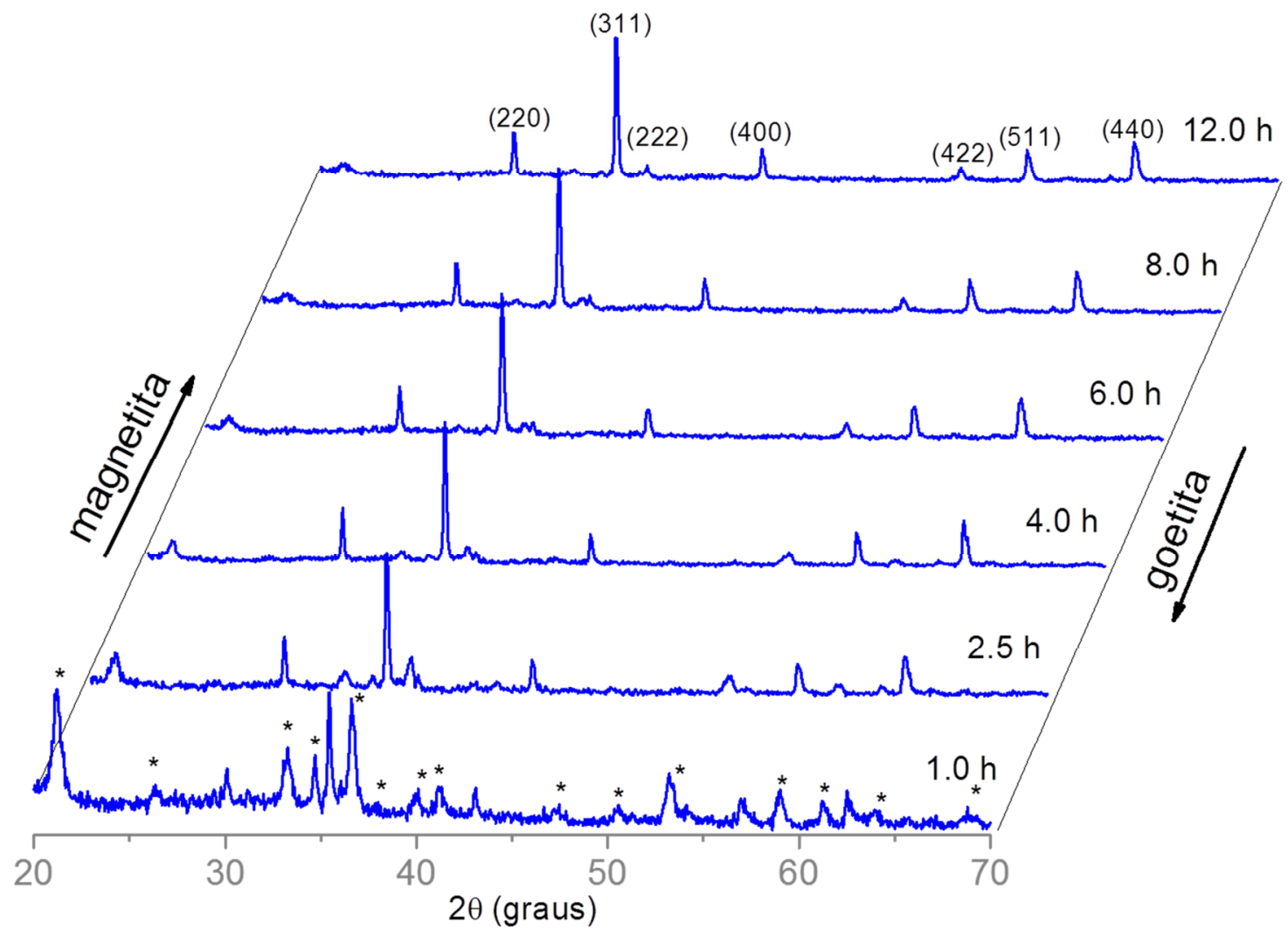

Figura 12 - Difratogramas de raios $\mathrm{X}$ para nanopartículas obtidas em $\mathrm{CO}\left(\mathrm{NH}_{2}\right)_{2}$, com $\mathrm{NH}_{4} \mathrm{Fe}\left(\mathrm{SO}_{4}\right)_{2} / \mathrm{FeSO}_{4}, \frac{\mathrm{Fe}_{\text {tot }}}{\text { ureia }}=1 / 5$, em diferentes tempos de síntese. Os índices são para a estrutura cristalina da magnetita e os asteriscos indicam os principais picos da estrutura cristalina da goethita.

A partir dos dados de composição listados na tabela 4, obtidos por Rietveld, é possível verificar que o percentual de magnetita, inicialmente igual a $30 \%$, aumenta para cerca de $80 \%$, após $12 \mathrm{~h}$ de refluxo, o que leva a crer que a goethita é transformada em magnetita nesse processo.

Além disso, considerando somente a presença de magnetita e de goethita nessas amostras, um modelo de composição química foi proposto, com base nas fórmulas químicas desses compostos e nos teores de $\mathrm{Fe}^{3+}$ e $\mathrm{Fe}^{2+}$ dosados em cada amostra. Nesse caso, se considera que todo $\mathrm{Fe}^{2+}$ encontrado corresponde, equivalentemente, à magnetita $\left(\mathrm{Fe}_{3} \mathrm{O}_{4}\right)$, de maneira que $\left[\mathrm{Fe}_{3} \mathrm{O}_{4}\right]$ seja proporcional a $\left[\mathrm{Fe}^{2+}\right]$. Por outro lado, o $\mathrm{Fe}^{3+}$ está envolvido na formação da magnetita e da goethita $(\alpha-\mathrm{FeOOH})$, tal que o teor de goethita 
é dado por $[\alpha-\mathrm{FeOOH}]$, proporcional a $\left[\mathrm{Fe}^{3+}\right]-2 \times\left[\mathrm{Fe}^{2+}\right]$. O percentual de magnetita estimado por esse modelo também está listado na tabela 4 e, inicialmente igual a cerca de $20 \%$, aumenta para cerca de 70\% após 12 h de síntese. Esses valores são menores que aqueles encontrados pelo refinamento Rietveld, provavelmente porque o modelo químico considera uma estequiometria perfeita para os compostos (magnetita e goethita), mas não considera a possibilidade de oxidação para maguemita. Esse último fator deve afetar menos no caso do refinamento de Rietveld, já que os difratogramas da magnetita são muito próximos aos da maguemita. De todas formas, essas duas metodologias são aproximativas já que outras fases cristalinas - ou não cristalinas - de óxidos, hidróxidos ou óxidos-hidróxidos podem estar presentes, coexistindo em menor proporção, com as fases aqui consideradas para o modelo.

\begin{tabular}{|c|c|c|c|c|c|c|}
\hline \multirow[b]{2}{*}{$\begin{array}{c}\text { Tempo } \\
\text { (h) }\end{array}$} & \multirow[b]{2}{*}[\mathrm{Fe}^{3+}]{$/\left[\mathrm{Fe}^{2+}\right]$} & \multicolumn{2}{|c|}{$\% \mathrm{Fe}_{3} \mathrm{O}_{4}(\mathrm{~m} / \mathrm{m})$} & \multicolumn{3}{|c|}{ Características Magnéticas } \\
\hline & & $\begin{array}{l}\text { Dosagem } \\
\text { Química }\end{array}$ & $\begin{array}{c}\text { DRX } \\
\text { Rietveld }\end{array}$ & $\begin{array}{c}M_{S} \\
(\mathrm{emu} / \mathrm{g})\end{array}$ & $\begin{array}{c}\mathbf{H}_{\mathrm{C}} \\
(\mathbf{O e})\end{array}$ & $\begin{array}{c}M_{R} \\
(e m u / g)\end{array}$ \\
\hline 1.0 & 22,5 & 12 & 21 & 12,3 & 79,6 & 0,7 \\
\hline 2.5 & 6,2 & 38 & 50 & 37,8 & 93,4 & 3,2 \\
\hline 4.0 & 4,7 & 51 & 60 & 50,8 & 67,0 & 3,0 \\
\hline 6.0 & 3,5 & 63 & 73 & 56,9 & 71,5 & 3,1 \\
\hline 8.0 & 3,3 & 67 & 74 & 55,5 & 82,1 & 4,1 \\
\hline 12.0 & 3,2 & 69 & 78 & 60,9 & 79,5 & 4,6 \\
\hline
\end{tabular}

Tabela 4 - Dados de composição e características magnéticas a $300 \mathrm{~K}$ para as nanopartículas obtidas em ureia, com $\mathrm{NH}_{4} \mathrm{Fe}\left(\mathrm{SO}_{4}\right)_{2} / \mathrm{FeSO}_{4}, \frac{\mathrm{Fe}_{\text {tot }}}{\text { ureia }}=1 / 5$, em diferentes tempos de síntese.

As magnetizações das amostras foram medidas à temperatura ambiente e as curvas obtidas em função do campo para as alíquotas retiradas com $2 \mathrm{~h}$ e $12 \mathrm{~h}$ de refluxo estão plotadas no gráfico da figura 13a. Para todas as amostras, a magnetização 
aumenta à medida que o campo magnético se intensifica, até atingir as magnetizações de saturação $\left(M_{\mathrm{s}}\right)$ listadas na tabela 4. Quando o ciclo de histerese é completado, é possível notar que há magnetização remanente $\left(M_{\mathrm{r}}\right)$ e campo coercitivo $\left(H_{\mathrm{c}}\right)$ consideráveis, conforme mostra o ciclo de magnetização para amostra sintetizada com $12 \mathrm{~h}$ de refluxo, na figura $13 \mathrm{~b}$.

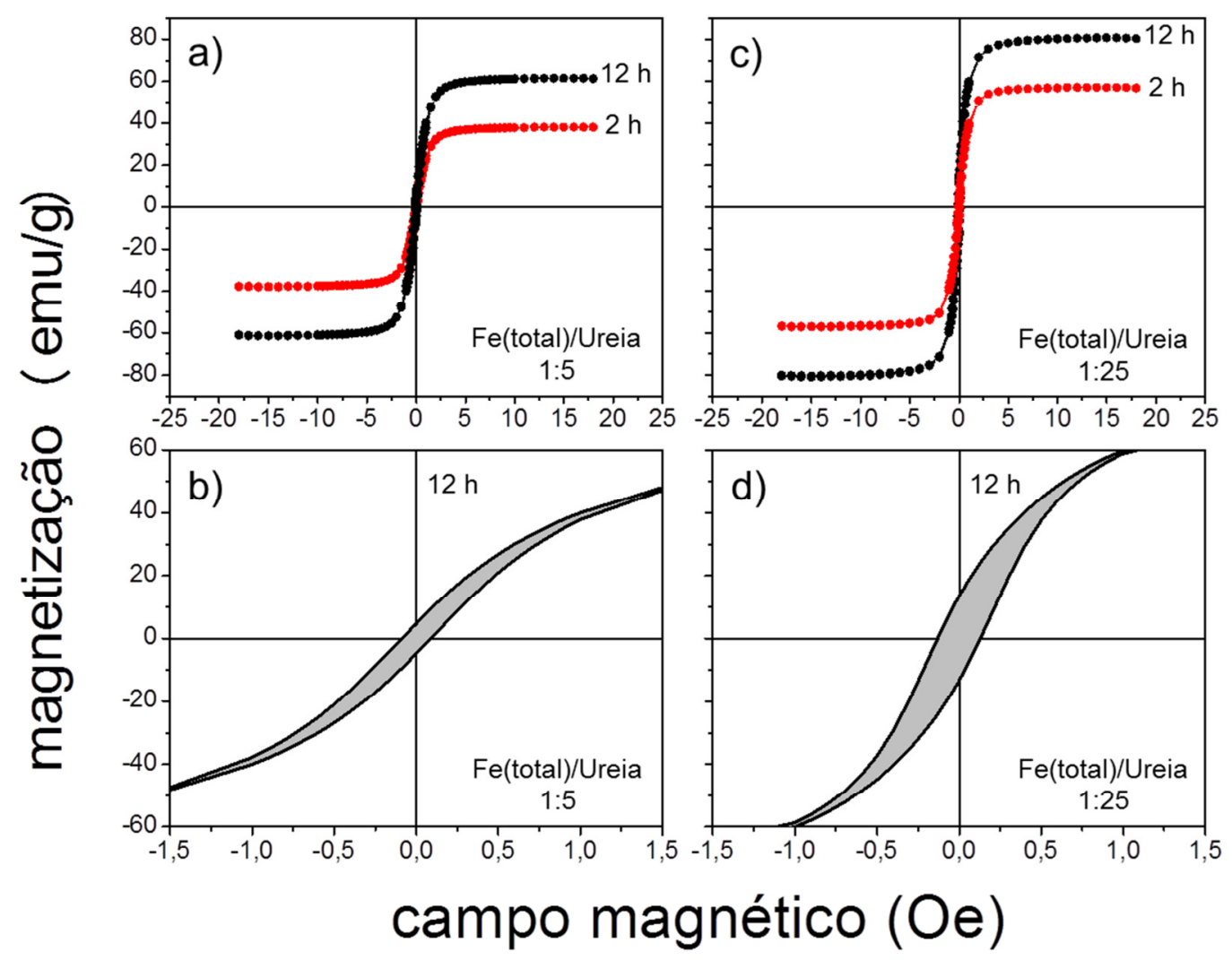

Figura 13 - Curvas de magnetização a $300 \mathrm{~K}$ para nanopartículas obtidas em $\mathrm{CO}\left(\mathrm{NH}_{2}\right)_{2}$, com $\mathrm{NH}_{4} \mathrm{Fe}\left(\mathrm{SO}_{4}\right)_{2} / \mathrm{FeSO}_{4}, \frac{\mathrm{Fe}_{\text {tot }}}{\text { ureia }}=1 / 5$ (a) e 1/25 (c), em diferentes tempos de síntese. A região da histerese é ampliada nas figuras (b) e (d).

Na figura 14, em que os valores de magnetização de saturação encontrados estão plotados em função do tempo de refluxo, observa-se que $M_{\mathrm{s}}$ aumenta à medida que esse tempo fica maior, tendendo a ficar constante em torno de $60 \mathrm{emu} / \mathrm{g}$, a partir de $5 \mathrm{~h}$ de 
reação. Essa variação corrobora com os resultados obtidos por DRX, uma vez que o teor de goethita - de magnetização irrisória $\left(M_{\mathrm{s}}^{\text {bulk }}<1 \mathrm{emu} / \mathrm{g}\right)-$ diminui com o tempo de síntese, dando lugar à magnetita, com magnetização de saturação muito mais importante $\left(M_{\mathrm{s}}^{\text {bulk }}>90 \mathrm{emu} / \mathrm{g}\right)$ e, pelo fato de que, no cálculo de $M_{\mathrm{s}}$ para as amostras estudadas, a magnetização é normalizada pela massa de toda a amostra.

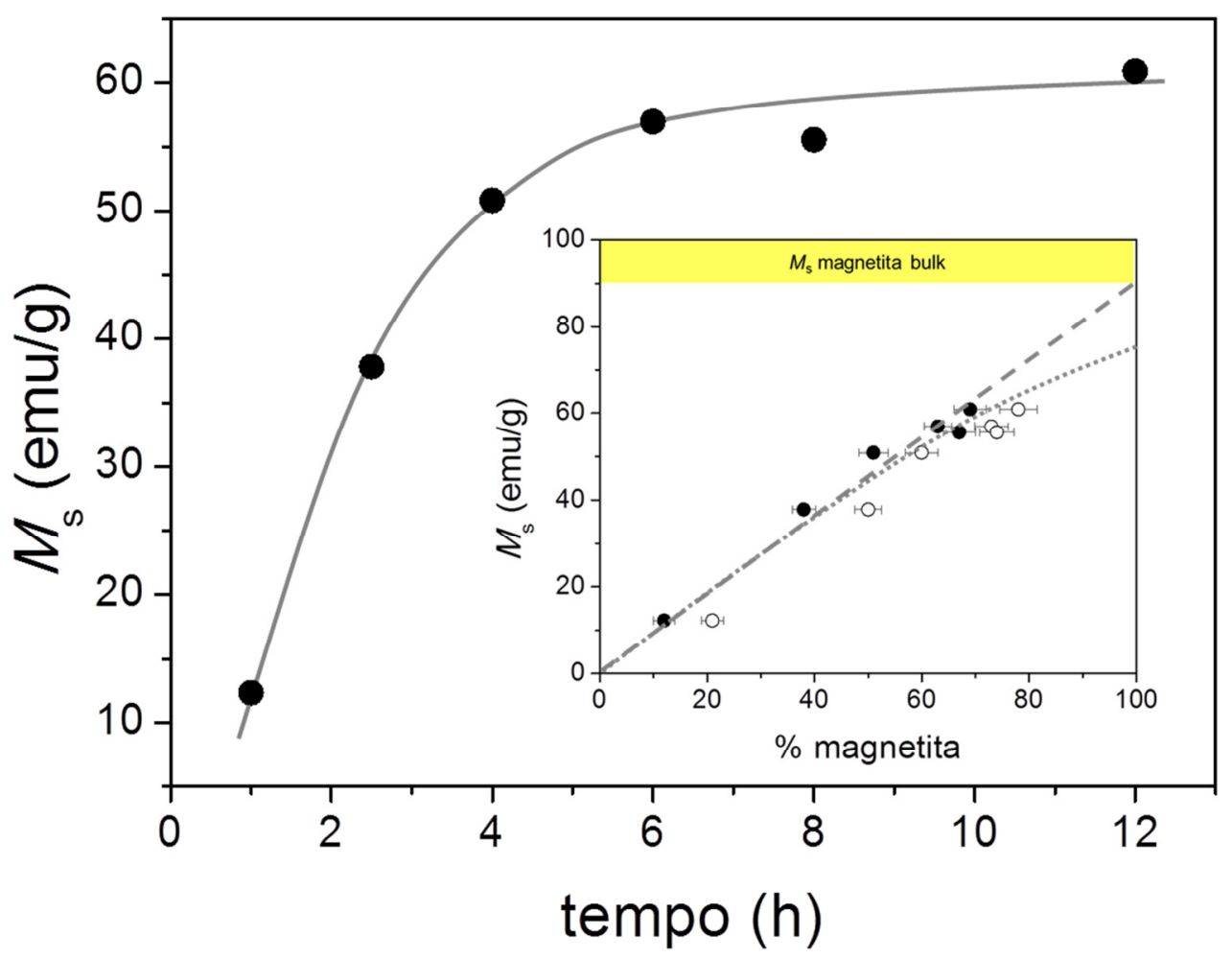

Figura 14 - Valores de magnetização de saturação plotados em função do tempo de refluxo para nanopartículas obtidas em $\mathrm{CO}\left(\mathrm{NH}_{2}\right)_{2}$, com $\mathrm{NH}_{4} \mathrm{Fe}\left(\mathrm{SO}_{4}\right)_{2} / \mathrm{FeSO}_{4}, \frac{\mathrm{Fe}_{\text {tot }}}{\text { ureia }}=1 / 5$. No gráfico inserido, a magnetização à saturação é plotada em função do \% de magnetita calculado por Rietveld (círculos pretos) e por dosagens químicas (círculos brancos).

No gráfico, inserido na figura 14 , as magnetizações de saturação foram plotadas em função do percentual em massa de magnetita, calculado por Rietveld (círculos pretos) e por dosagens químicas (círculos brancos). A linha tracejada mostra a tendência esperada - uma reta que vai de uma magnetização aproximadamente nula, para o caso 
da ausência de magnetita, até o valor de $M_{\mathrm{s}}$ da magnetita maciça ( $\left.90 \mathrm{emu} / \mathrm{g}\right)$, na ausência de goethita. Nota-se que os pontos experimentais tendem a seguir essa linha, porém há tendência de desvio (curva pontilhada), principalmente após maior tempo de refluxo. Esse desvio, que leva a valores menores do que o esperado para magnetização de saturação, pode ser devido a vários fatores: a parcial ou completa oxidação da $\mathrm{Fe}_{3} \mathrm{O}_{4}$ a $\gamma-\mathrm{Fe}_{2} \mathrm{O}_{3}$ - de fato, a magnetização de saturação da maguemita é cerca de $80 \%$ do valor de $M_{\mathrm{s}}$ da magnetita. Principalmente após maior tempo de refluxo, e pelo fato de ser um procedimento em temperatura alta e em atmosfera com oxigênio, há possibilidade de essa oxidação ocorrer, conforme representado pela reação da equação (5); outro fator está ligado ao confinamento dimensional, que pode levar a uma baixa correlação entre os spins de superfície em relação aos spins do núcleo das nanopartículas e, assim, a uma diminuição da magnetização de saturação [68,69]; ainda, redistribuições catiônicas, defeitos estruturais e variação de composição - fatores que são mais acentuados na escala nanométrica - podem levar a essa diminuição [66,70].

Foram retiradas alíquotas, em diferentes tempos de reação $(2$ h, 4 h, 6 h, 8 h, 10 h e 12h) da síntese que empregou uma maior razão molar de ferro total/ureia ( $\mathrm{Fe}_{\text {tot }} /$ ureia $=1 / 25)$. As imagens obtidas por MET para as alíquotas separadas após $2 \mathrm{~h}, 6 \mathrm{~h}$ e $12 \mathrm{~h}$ de refluxo são mostradas na figura 15. Nesse caso, estruturas de multidomínios acirculares submicrométricas são formadas após 2 h de síntese. Essas partículas, por sua vez, parecem ser formadas por aglomerados de partículas menores e alongadas. 

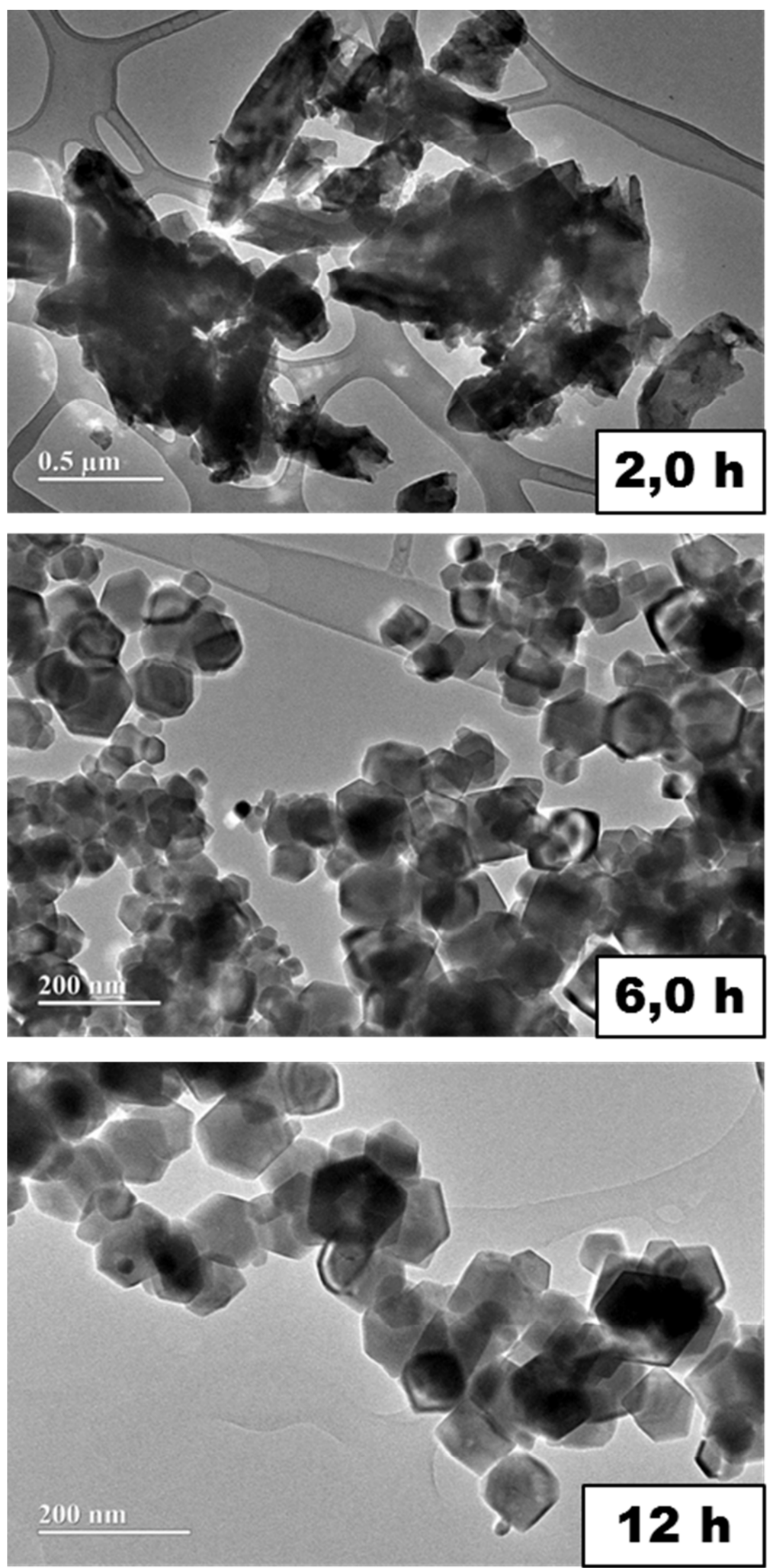

Figura 15 - Imagens de MET para nanopartículas obtidas em $\mathrm{CO}\left(\mathrm{NH}_{2}\right)_{2}$, com $\mathrm{NH}_{4} \mathrm{Fe}\left(\mathrm{SO}_{4}\right)_{2} / \mathrm{FeSO}_{4}$, $\frac{\mathrm{Fe}_{\text {tot }}}{\text { ureia }}=1 / 25$, em diferentes tempos de síntese. 
À medida que o tempo de refluxo aumenta, nanopartículas com a forma aproximadamente hexagonal são formadas, como pode ser observado nas imagens das amostras recolhidas com 6 h e 12 h de síntese. Qualitativamente, é possível notar que o tamanho médio dessas nanopartículas tende a aumentar com o tempo, bem como a distribuição em tamanho parece ficar mais homogênea.

Os difratogramas de raios $\mathrm{X}$ dessas amostras estão plotados no gráfico da figura 16. Nesse caso, inicialmente, a presença de goethita também foi notada como uma segunda fase em que a magnetita predominava.

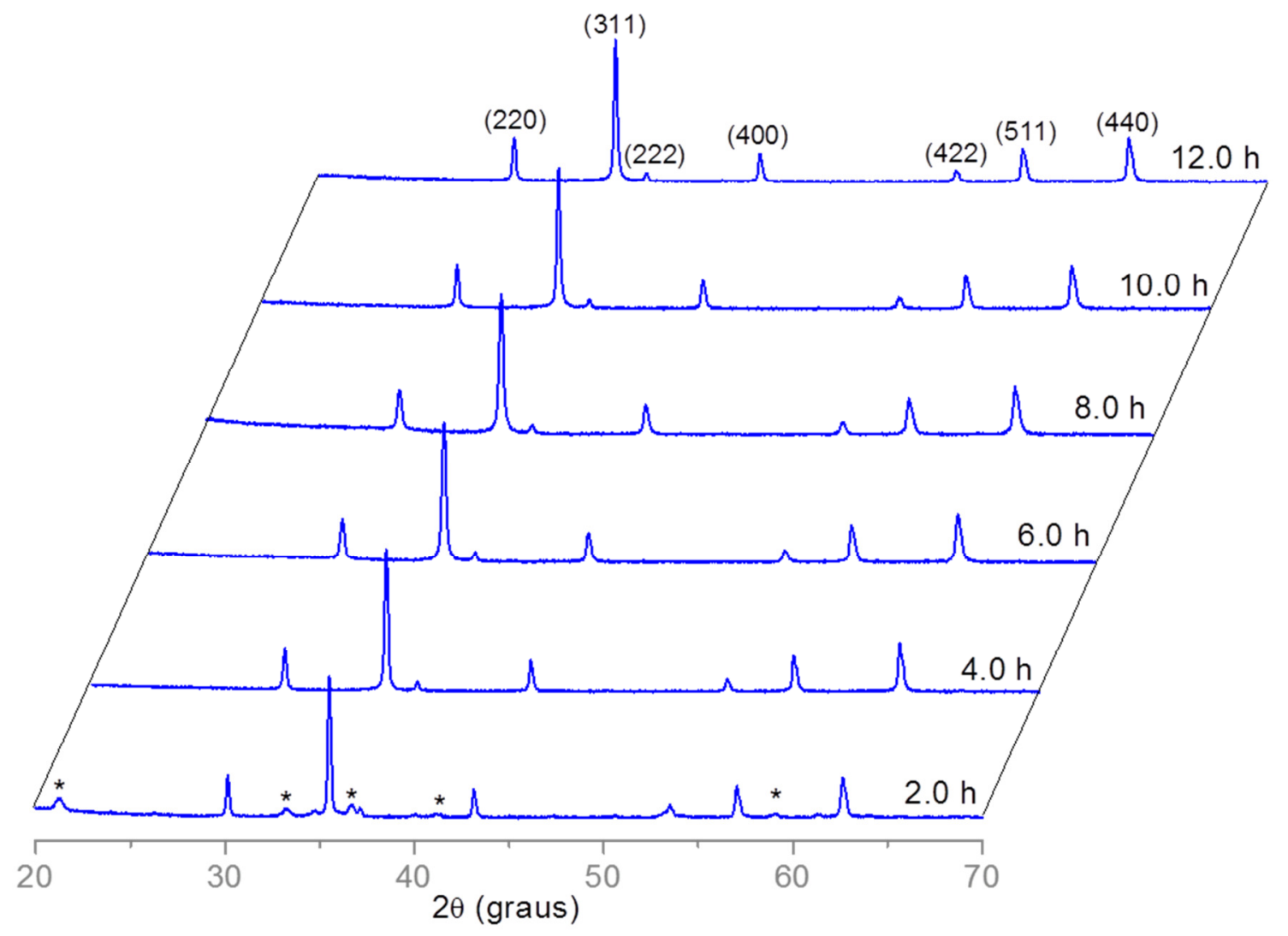

Figura 16 - Difratogramas de raios $\mathrm{X}$ para nanopartículas obtidas em $\mathrm{CO}\left(\mathrm{NH}_{2}\right)_{2}$, com $\mathrm{NH}_{4} \mathrm{Fe}\left(\mathrm{SO}_{4}\right)_{2} / \mathrm{FeSO}_{4}, \frac{\mathrm{Fe}_{\text {tot }}}{\text { ureia }}=1 / 25$, em diferentes tempos de síntese. Os índices são para a estrutura cristalina da magnetita e os asteriscos indicam os principais picos da estrutura cristalina da goethita. 
Porém, diferentemente da síntese que utilizou a razão ferro total/ureia $=1 / 5$, os picos relativos à fase da goethita $(\alpha-\mathrm{FeOOH})$ ficaram menos intensos e praticamente imperceptíveis à medida que o tempo de refluxo avançou. As mesmas análises - pelo refinamento de Rietveld dos dados de DRX e pela dosagem química - foram aplicadas a essas amostras para se calcular o teor em massa de magnetita. Os dados dessas análises estão listados na tabela 5.

\begin{tabular}{|c|c|c|c|c|c|c|}
\hline \multirow{2}{*}{$\begin{array}{c}\text { Tempo } \\
\text { (h) }\end{array}$} & \multirow[b]{2}{*}[\mathrm{Fe}^{3+}]{$/\left[\mathrm{Fe}^{2+}\right]$} & \multicolumn{2}{|c|}{$\% \mathrm{Fe}_{3} \mathrm{O}_{4}(\mathrm{~m} / \mathrm{m})$} & \multicolumn{3}{|c|}{ Características magnéticas } \\
\hline & & $\begin{array}{c}\text { Dosagem } \\
\text { química }\end{array}$ & $\begin{array}{c}\text { DRX } \\
\text { Rietveld }\end{array}$ & $\begin{array}{c}M_{\mathrm{S}} \\
(\mathrm{emu} / \mathrm{g})\end{array}$ & $\begin{array}{c}\mathbf{H}_{\mathrm{C}} \\
(\mathbf{O e})\end{array}$ & $\begin{array}{c}\mathbf{M}_{\mathbf{R}} \\
(\mathrm{emu} / \mathrm{g})\end{array}$ \\
\hline 2.0 & 3,4 & 65 & 55 & 57,0 & 73,4 & 4,7 \\
\hline 4.0 & 3,2 & 72 & 60 & 76,7 & 116,6 & 11,6 \\
\hline 6.0 & 2,7 & 78 & 65 & 79,0 & 138,0 & 13,7 \\
\hline 8.0 & 2,6 & 81 & 76 & 78,9 & 130,0 & 12,5 \\
\hline 10.0 & 2,7 & 80 & 74 & 79,7 & 120,0 & 12,1 \\
\hline 12.0 & 2,7 & 82 & 78 & 80,0 & 130,6 & 13,4 \\
\hline
\end{tabular}

Tabela 5 - Dados de composição e características magnéticas a $300 \mathrm{~K}$ para as nanopartículas obtidas em ureia, com $\mathrm{NH}_{4} \mathrm{Fe}\left(\mathrm{SO}_{4}\right)_{2} / \mathrm{FeSO}_{4}, \frac{\mathrm{Fe}_{\text {tot }}}{\text { ureia }}=1 / 5$, em diferentes tempos de síntese.

Nesse caso, após duas horas de refluxo, a quantidade de magnetita é próxima daquela observada para a síntese que usou menos ureia e o máximo encontrado, após 12 h, é cerca de $80 \%$.

Curvas de magnetização típicas para essas amostras, para as alíquotas extraídas com 2 h e 12 h, são mostradas na figura $13 \mathrm{c}$ e, na figura $13 \mathrm{~d}$ é mostrada a região em campos menos intensos, para amostra retirada com $12 \mathrm{~h}$ de refluxo. Para todas as amostras, a magnetização aumenta à medida que o campo magnético se intensifica, até 
atingir as magnetizações de saturação $\left(M_{\mathrm{s}}\right)$ listadas na tabela 3, assim como os valores de magnetização remanente $\left(M_{\mathrm{r}}\right)$ e campo coercitivo $\left(H_{\mathrm{c}}\right)$.

\subsection{O efeito da variação do pH na formação das NPMs}

Em suma, os resultados apresentados até aqui indicam que a elongação das NPs não depende, apenas da presença/concentração do $\mathrm{SO}_{4}{ }^{2-}$ - um "agente construtor" de estruturas bem conhecido [71], mas também de como o pH do meio de síntese aumenta. $\mathrm{Na}$ verdade, quando as amostras são sintetizadas com $\mathrm{NH}_{4} \mathrm{OH}$, segue o equilíbrio químico - bastante deslocado para a direita. Assim, as espécies $\mathrm{NH}_{4}{ }^{+}$e o $\mathrm{OH}^{-}$ficam bastante disponíveis para reagir com o $\mathrm{Fe}^{2+}$ e $\mathrm{Fe}^{3+}$ e formar a magnetita. Devido ao excesso do $\mathrm{OH}^{-}$(o agente precipitante), a supersaturação relativa do meio é alta e induz predomínio da nucleação em detrimento ao crescimento cristalino, rendendo partículas menores [72]. Além disso, conforme já relatado para essas condições de síntese [73], a alta temperatura e a atmosfera oxidante levam à oxidação da magnetita em maguemita, conforme representado pela equação (5).

$$
\begin{aligned}
& 2 \mathrm{Fe}^{3+}+\mathrm{Fe}^{2+}+8 \mathrm{OH}^{-} \rightarrow \mathrm{Fe}_{3} \mathrm{O}_{4}+4 \mathrm{H}_{2} \mathrm{O} \\
& 2 \mathrm{Fe}_{3} \mathrm{O}_{4}+1 / 2 \mathrm{O}_{2} \rightarrow 3 \mathrm{Fe}_{2} \mathrm{O}_{3}
\end{aligned}
$$$$
\text { (Eq. Quím. 4) }
$$

O que explica o reduzido tamanho observado para as NPs mostradas na figura 8a e a predominância da fase cristalina maguemita, que é a forma oxidada, no material sintetizado com $\mathrm{NH}_{4} \mathrm{OH}$.

Por outro lado, as equações (6) e (7) representam a decomposição térmica da $\mathrm{CO}\left(\mathrm{NH}_{2}\right)_{2}$ em meio aquoso para gerar $\mathrm{OH}^{-}$em solução, de maneira lenta e homogênea. 
Isso induz a uma supersaturação relativa menor, quando comparada à síntese com $\mathrm{NH}_{4} \mathrm{OH}$. Nesse caso, o crescimento cristalino desempenha papel mais importante que a nucleação, sobre as características morfológicas dos cristais formados [74].

$$
\begin{aligned}
& \mathrm{CO}\left(\mathrm{NH}_{2}\right)_{2}+\mathrm{H}_{2} \mathrm{O} \rightarrow \mathrm{CO}_{2}+2 \mathrm{NH}_{3} \\
& \mathrm{NH}_{3}+\mathrm{H}_{2} \mathrm{O} \rightarrow \mathrm{NH}_{4}^{+}+\mathrm{OH}^{-}
\end{aligned}
$$

$\mathrm{Na}$ verdade, a base utilizada nos dois processos de síntese é o $\mathrm{NH}_{4} \mathrm{OH}$, porém, a forma como ele é gerado em solução é o diferencial entre a síntese com $\mathrm{NH}_{4} \mathrm{OH}$ e $\mathrm{CO}\left(\mathrm{NH}_{2}\right)_{2}$. Isso é mais bem compreendido ao se observar a figura 10 , que mostra o comportamento do $\mathrm{pH}$ (i.e. $\left[\mathrm{OH}^{-}\right]$) durante a síntese com esses dois reagentes. Quando o $\mathrm{NH}_{4} \mathrm{OH}$ é utilizado, como no caso da amostra exibida na figura $8 \mathrm{a}$, o pH inicial do meio de síntese aumenta para cerca de 12 , assim que o $\mathrm{NH}_{4} \mathrm{OH}$ é introduzido. À medida que a reação ocorre e sistema entra em refluxo, a $\mathrm{NH}_{3}$ é volatilizada, diminuindo a concentração de $\mathrm{OH}^{-}$e, assim, levando o pH para cerca de 8, após 5 h de reação, conforme mostrado na curva de cor preta, na figura 17. Por outro lado, no caso da $\mathrm{CO}\left(\mathrm{NH}_{2}\right)_{2}$, como na síntese das NPs exibidas na figura $8 \mathrm{~b}$, o $\mathrm{pH}$ inicial é menor que $2 \mathrm{e}$, à medida que a $\mathrm{CO}\left(\mathrm{NH}_{2}\right)_{2}$ se decompõe, o $\mathrm{pH}$ aumenta suavemente conforme a curva azul mostrada na figura 17 e se estabiliza em torno de 7 . Se, nessas mesmas condições de síntese, a concentração de $\mathrm{CO}\left(\mathrm{NH}_{2}\right)_{2}$ é aumentada em cinco vezes, o perfil de liberação de $\mathrm{OH}^{-}$muda: inicialmente em torno de 3 , o pH aumenta de maneira menos sutil com a decomposição da $\mathrm{CO}\left(\mathrm{NH}_{2}\right)_{2}$, para cerca de 8-9, na primeira hora, e se mantém constante em torno desse valor nas próximas horas. 


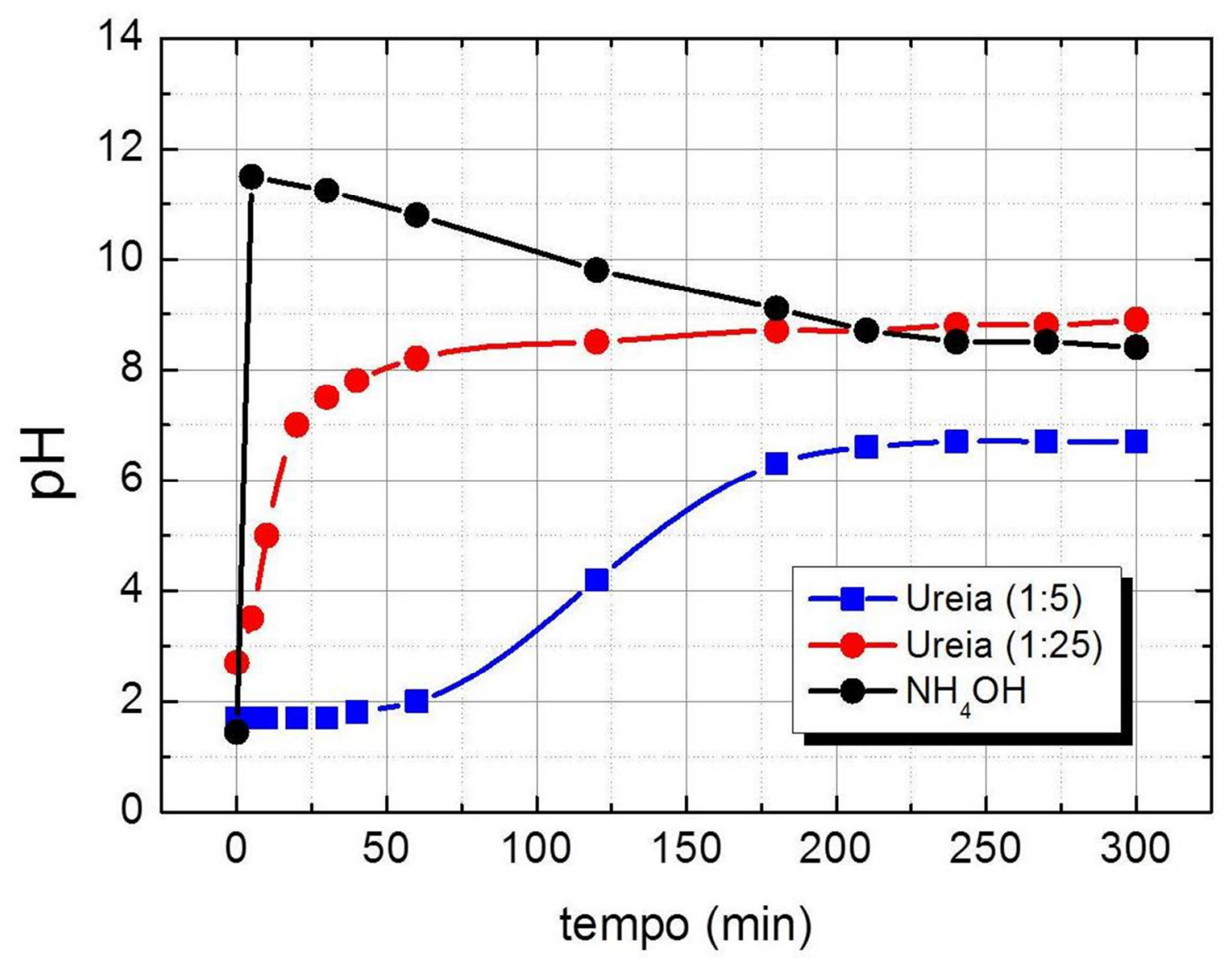

Figura 17 - Variação do pH em função do tempo para sistemas contendo: (círculos preto) $\frac{\mathrm{Fe}_{t o t}}{\mathrm{NH}_{4} \mathrm{OH}}=$ 1/10; (quadrado azul) $\frac{\mathrm{Fe}_{t o t}}{\text { ureia }}=1 / 5$; (círculos vermelho) $\frac{\mathrm{Fe}_{t o t}}{\text { ureia }}=1 / 25$, a $95^{\circ} \mathrm{C}$.

Utilizando-se $\mathrm{NH}_{4} \mathrm{OH}$, parte-se de um excesso que é parcialmente consumido pela reação, mas, mesmo com a perda por evaporação, o $\mathrm{OH}^{-}$está sempre em excesso no meio. Já com a $\mathrm{CO}\left(\mathrm{NH}_{2}\right)_{2}$ em menor concentração, a decomposição fornece $\mathrm{OH}^{-}$ que é consumido à medida que é liberado, de forma que o excesso desse reagente só é alcançado após mais de duas horas de reação. No caso em que a $\mathrm{CO}\left(\mathrm{NH}_{2}\right)_{2}$ está em maior concentração, apesar da $\left[\mathrm{OH}^{-}\right]$ser mínima inicialmente, após o começo da decomposição da $\mathrm{CO}\left(\mathrm{NH}_{2}\right)_{2}$, a concentração de $\mathrm{OH}^{-}$aumenta rapidamente, garantindo um excesso em quase toda extensão da reação, porém menor que a gerada pelo $\mathrm{NH}_{4} \mathrm{OH}$ 


\subsection{Mecanismo de formação das NPs}

De uma maneira geral, em meio aquoso, os diferentes óxidos(hidróxidos) de ferro podem ser produzidos pela hidrólise de íons $\mathrm{Fe}^{3+}$ e/ou pela oxidação (seguida de hidrólise) de íons $\mathrm{Fe}^{2+}$ em solução - as mesmas fontes de ferro das sínteses realizadas nesse trabalho. O tipo de óxido formado é governado por fatores como $\mathrm{pH}$, taxa de oxidação, temperatura, concentração de $\mathrm{Fe}^{2+}$ e $\mathrm{Fe}^{3+}$ e, também, pela presença e concentração de íons estranhos à solução. Entretanto, é muito difícil controlar as condições de reação para se obter produtos monofásicos; ao invés disso, uma característica das reações em meio aquoso é a formação de uma mistura de óxidos(hidróxidos) de ferro [20].

Em geral, uma vez que os valores do produto de solubilidade do $\mathrm{Fe}(\mathrm{OH})_{2}$ e do $\mathrm{Fe}(\mathrm{OH})_{3}$ são $\sim 10^{-15}$ e $\sim 10^{-39}$, respectivamente, a hidrólise do $\mathrm{Fe}^{3+}$ é preferencial em relação à do $\mathrm{Fe}^{2+}$ [75]. Além disso, a obtenção de óxidos de maior simetria requer a hidrólise e formação de aquocátions que geram espécies polinucleares a serem supridas durante o crescimento do cristal [50]. Por outro lado, a oxidação do $\mathrm{Fe}^{2+}$ depende da acidez do meio, sendo extremamente lenta abaixo de $\mathrm{pH} \sim 6$ e aumentando acentuadamente acima desse valor . A oxidação e a hidrólise do $\mathrm{Fe}^{2+}$ leva a óxidos, seja, diretamente e/ou via "green rusts" (ferrugen verde) - óxidos de ferro que consistem em camadas de octaedros de $\mathrm{Fe}^{\mathrm{II}} \mathrm{OH}$, nos quais alguns íons de ferro divalentes são substituídos por íons férricos e cujas cargas são balanceadas por ânions como o $\mathrm{Cl}^{-} \mathrm{e}$ $\mathrm{SO}_{4}{ }^{2-}-$ ou via $\mathrm{Fe}(\mathrm{OH})_{2}$. Aqui, é importante considerar que óxidos de maior simetria podem ser obtidos a partir da conversão dessas espécies precursoras, por reação em estado sólido, ou em meio aquoso. Se há uma diferença estrutural entre os precursores e o óxido final, uma transformação reconstrutiva via dissolução/ reprecipitação parece 
mais provável, em meio aquoso. Entretanto, um rearranjo cristalino durante uma oxidação topoquímica para uma nova fase também pode acontecer [76].

Em relação aos óxidos(hidróxidos) de ferro aqui detectados (magnetita/maguemita e goethita), a concentração de $\mathrm{OH}^{-}$é um dos mais importantes parâmetros que governam os tipos de produtos de síntese. Alguns autores observaram que, em soluções moderadamente alcalinas contendo $\mathrm{Fe}^{2+}, \mathrm{o} \mathrm{Fe}(\mathrm{OH})_{2}$ é o precursor preferencial para formação da magnetita [77] e que, em pH $=11$ e $65^{\circ} \mathrm{C}$, inicialmente, goethita e magnetita são formadas. Porém, a formação da goethita é cessada, uma vez que o $\mathrm{Fe}^{2+}$ interage com a goethita para formar magnetita [78]. A uma razão molar $\mathrm{Fe}^{3+} / \mathrm{Fe}^{2+} \sim 2$, a formação da magnetita é mais favorável acima de $\mathrm{pH} \sim 9$. Em temperaturas mais elevadas, a oxidação do $\mathrm{FeSO}_{4} \mathrm{em} \mathrm{pH} \mathrm{6} \mathrm{gera} \mathrm{goethita} \mathrm{e,} \mathrm{acima} \mathrm{de} \mathrm{7,}$ leva a magnetita [79]. De fato, as condições de predominância de um dos compostos (goethita ou magnetita) a partir da hidrólise e oxidação do $\mathrm{Fe}^{2+}$ são: rápida oxidação, pHs mais ácidos e a presença de $\mathrm{SO}_{4}{ }^{2-}$, para a goethita; e, para a magnetita, oxidação lenta, altas temperaturas, alta $\left[\mathrm{Fe}^{2+}\right]$ e meios mais básicos.

Entretanto, é importante levar em conta que, nos procedimentos de síntese desse trabalho, $\mathrm{Fe}^{3+}$ e $\mathrm{Fe}^{2+}$ estão presentes desde o início da reação. Além disso, a hidrólise/oxidação do ferro ocorre (em atmosfera oxidativa - ar) em meio homogêneo, onde, pela decomposição térmica da $\mathrm{CO}\left(\mathrm{NH}_{2}\right)_{2}$, o $\mathrm{pH}$ da solução aumenta de maneira mais sutil que nos processos convencionais de precipitação em que uma base é adicionada ao sistema. Dessa maneira, com base nos resultados obtidos, nas condições específicas das sínteses e em observações encontradas nos trabalhos prévios citados, foi feita uma proposta de mecanismo para formação, que está resumido na figura 18.

Acredita-se, com as evidências experimentais apresentadas, que a goethita seja um composto intermediário para a formação da magnetita. Essa hipótese é 
principalmente reforçada pelos resultados obtidos, utilizando-se as diferentes bases e concentrações. Ao passo que $\left[\mathrm{OH}^{-}\right]$aumenta com a decomposição da $\mathrm{CO}\left(\mathrm{NH}_{2}\right)_{2}$ (tempo de refluxo), a hidrólise dos aquocátions de $\mathrm{Fe}^{3+}$ - que vão se desprotonando - pode ocorrer para formar a goethita: $\left[\mathrm{Fe}\left(\mathrm{H}_{2} \mathrm{O}\right)_{6}\right]^{3+} \rightarrow \mathrm{FeOOH}+3 \mathrm{H}^{+}+4 \mathrm{H}_{2} \mathrm{O}$. Levando-se em conta que a formação da goethita é favorecida em pHs mais ácidos, o fato de não ser detectada na síntese com $\mathrm{NH}_{4} \mathrm{OH}$ - e ter uma presença mais perseverante na síntese com menor concentração de $\mathrm{CO}\left(\mathrm{NH}_{2}\right)_{2}$ - pode ser facilmente explicado pelas rampas de variação de $\mathrm{pH}$ mostrados na figura $10 . \mathrm{Em} \mathrm{NH}_{4} \mathrm{OH}$, o alto $\mathrm{pH}$ de síntese desfavorece a formação de goethita e, em $\mathrm{CO}\left(\mathrm{NH}_{2}\right)_{2}$ menos concentrada, o intervalo de $\mathrm{pH}$ atingido é menor que em $\mathrm{CO}\left(\mathrm{NH}_{2}\right)_{2}$ mais concentrada. Assim, a goethita é mais facilmente detectada no sistema com $\mathrm{CO}\left(\mathrm{NH}_{2}\right)_{2}$ e, majoritariamente, naquele com menor concentração.

Paralelamente, com o aumento do $\mathrm{pH}$, a oxidação do $\mathrm{Fe}^{2+}$ se torna mais importante e a oxidação dos compostos "green rusts", formados a partir da oxidação dos aquocátions de ferro divalente $\left(\mathrm{Fe}(\mathrm{OH})_{\mathrm{x}}{ }^{2-\mathrm{x}}\right)$ também pode ocorrer (ver figura 18). Além disso, conforme mencionado, a formação da goethita é favorecida pela presença de $\mathrm{SO}_{4}{ }^{2-}$, que foi utilizado nos experimentos. Assim, a oxidação leva a decomposição de "green rusts" para formar goethita, como, por exemplo, simplificado na reação:

$$
2 \mathrm{Fe}_{3}(\mathrm{OH})_{5} \mathrm{SO}_{4}+\mathrm{O}_{2} \rightarrow 6 \mathrm{FeOOH}+4 \mathrm{H}_{2} \mathrm{SO}_{4} \text {. }
$$

$\mathrm{O} \mathrm{SO}_{4}{ }^{2-}$ tem um efeito promotor na formação da goethita, tal que, enquanto para valores pequenos de $\mathrm{SO}_{4}{ }^{2-} / \mathrm{Fe}^{3+}$, a formação da magnetita é predominante na hidrólise forçada do $\mathrm{Fe}^{3+}$, quando a concentração de $\mathrm{SO}_{4}{ }^{2-}$ alcança um valor crítico, essa hidrólise gera quase $100 \%$ de goethita [80]. Além disso, em valores de $\mathrm{pH}$ levemente ácido, "green rusts" solúveis, como $\left[\mathrm{Fe}_{3} \mathrm{O}_{\mathrm{x}}(\mathrm{OH})_{2(3-\mathrm{x})}\right]^{2+} \cdot \mathrm{xH}_{2} \mathrm{O}$, podem sofrer desidratação para formar, diretamente, magnetita, conforme mostrado na rota 2 da figura 19. Entretanto, 
devido à presença das duas espécies $\mathrm{Fe}^{3+}$ e $\mathrm{Fe}^{2+}$, desde o início da síntese, acredita-se que o mecanismo mais provável para formação da magnetita, nesse trabalho, seja aquele descrito na rota 1 da figura 18 , em que o ferro divalente interage com os núcleos formados de goethita via desidratação, conforme representado pela reação:

$$
2 \mathrm{FeOOH}+\mathrm{Fe}(\mathrm{OH})_{2} \rightarrow \mathrm{Fe}_{3} \mathrm{O}_{4}+2 \mathrm{H}_{2} \mathrm{O} \text {. }
$$

(Eq. Quím. 9)

Além de ter um efeito promotor na formação de óxido com composição preferencial, o íon $\mathrm{SO}_{4}{ }^{2-}$ teve participação importante como catalisador na construção da morfologia das nanopartículas. Conforme mostrado anteriormente, a adição de $\mathrm{SO}_{4}{ }^{2-}$ mesmo em pequena proporção, conduziu à formação de nanopartículas alongadas com formato de bastões. Em primeiro lugar, é preciso considerar, conforme mencionado nos parágrafos anteriores, que o $\mathrm{SO}_{4}{ }^{2-}$ induz à formação de goethita, cuja morfologia básica já é acicular [81]. Por outro lado, pelo seu caráter complexante, a adsorção do $\mathrm{SO}_{4}{ }^{2-}$ a faces (direções) específicas desses óxidos pode retardar/atenuar o crescimento do cristal na direção normal a esse eixo, acrescentando uma anisotropia no processo de crescimento dos cristais, o que gera NPs alongadas [82]. 


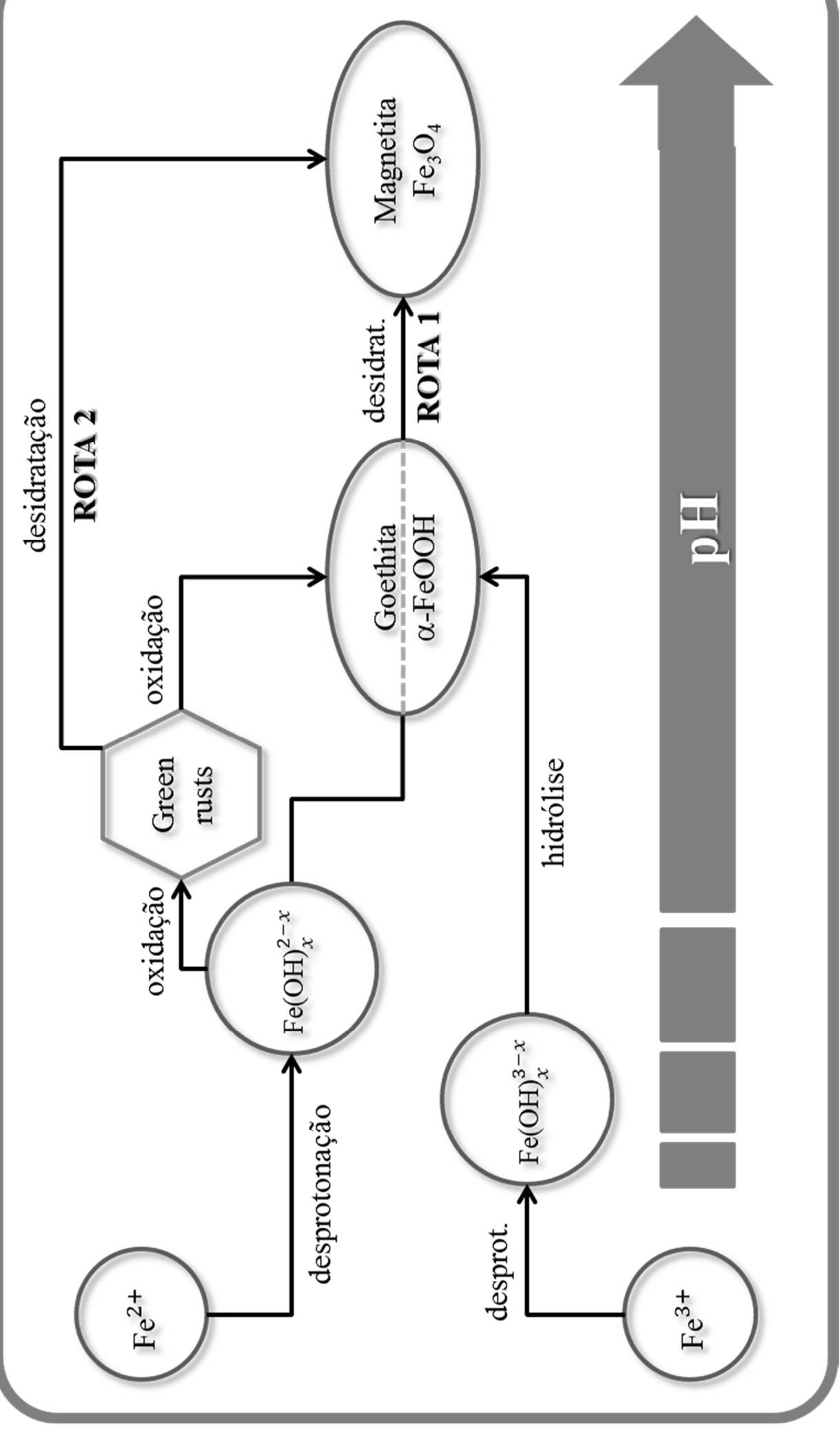

Figura 18 - Mecanismo e rotas de síntese propostos para a formação da magnetita, em meio aquoso e em função do $\mathrm{pH}$, a partir dos íons de $\mathrm{Fe}^{2+}$ e $\mathrm{Fe}^{3+}$ em solução. 
De fato, devido as suas propriedades ácido-base, a espécie $\mathrm{SO}_{4}{ }^{2-}$ é predominante acima de $\mathrm{pH}=4$, enquanto que as outras formas protonadas $\left(\mathrm{HSO}_{4-} \mathrm{e}_{2} \mathrm{SO}_{4}\right)$ são observadas apenas em pHs menores - os valores de pKa para o $\mathrm{H}_{2} \mathrm{SO}_{4}$ são aproximadamente -8 e 2 [83]. Essa espécie $\mathrm{SO}_{4}{ }^{2-}$, por sua vez, adsorve fortemente as faces paralelas ao eixo $c$ do cristal de goethita por meio de uma ligação bidentada com os átomos de ferro superficiais, conforme ilustrado na figura 18, o que impede (ou atenua) a adsorção de mais espécies contendo átomos de ferro nessas faces. Como resultado, o crescimento do cristal é favorecido na direção paralela a essas faces e partículas anisométricas (alongadas) são formadas. No caso desses óxidos, a complexação é favorecida, já que as distâncias $\mathrm{O}-\mathrm{O}$ do $\mathrm{SO}_{4}{ }^{2-}$ se assemelham as distâncias Fe-Fe nessas faces [84].
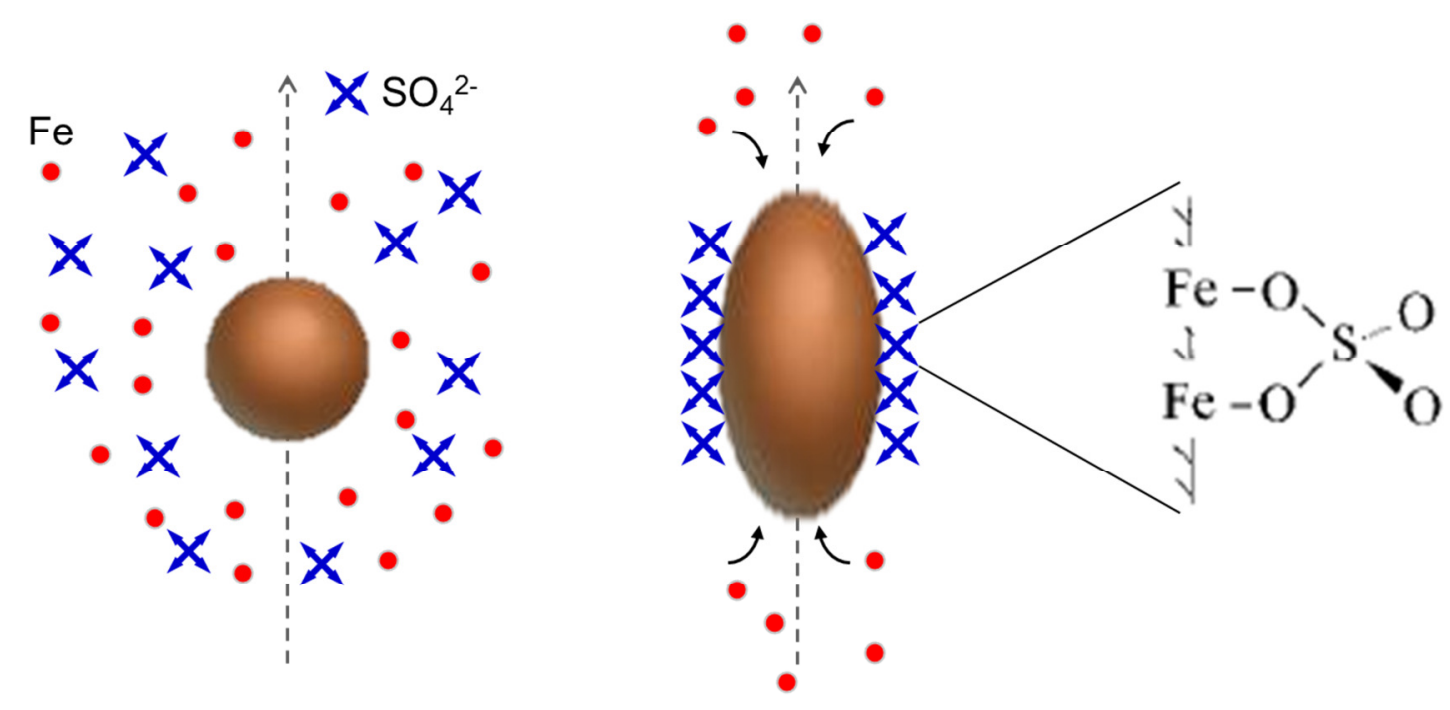

Figura 19 - Representação da adsorção preferencial do $\mathrm{SO}_{4}{ }^{2-}$ a faces paralelas a um determinado eixo de cristais de óxido de ferro, impedindo a adsorção de mais espécies metálicas nessas faces e, assim, o crescimento isotrópico da partícula. 
Levando-se em conta essas observações e informaçãoes, é possível inferir que o formato das nanopartículas sintetizadas com em presença desse contra-íon pode ser resultado tanto da adsorção específica do $\mathrm{SO}_{4}{ }^{2-}$, quanto da transformação topotática do provável intermediário goethita (que já é assimétrico) em magnetita.

A CO(NH $)_{2}$ (i.e. precipitação em meio homogêneo) parece ter papel importante na anisometria das partículas alongadas, uma vez que, mesmo utilizando $\mathrm{SO}_{4}{ }^{2-}$ no meio de síntese, nanopartículas esféricas foram obtidas quando a base era $\mathrm{NH}_{4} \mathrm{OH}$. Nesse caso, a abrupta introdução do $\mathrm{NH}_{4} \mathrm{OH}$ eleva a supersaturação do meio, de forma que a nucleação se torna o evento mais importante para a formação das nanopartículas, promovendo um crescimento isotrópico das mesmas. Isso reduz a seletividade de precipitação entre o $\mathrm{Fe}^{3+}$ e $\mathrm{Fe}^{2+}$ (e suas espécies intermediárias) e, conforme discutido anteriormente, favorece a formação da magnetita, sem passar pela goethita. Por outro lado, na precipitação com $\mathrm{CO}\left(\mathrm{NH}_{2}\right)_{2}$, o pH aumenta mais lentamente, além de operar em uma faixa mais ácida, preservando a supersaturação do meio em um nível mais baixo e constante. Nesse caso, quando a taxa de crescimento cristalino excede a taxa de nucleação, somando-se à presença de $\mathrm{SO}_{4}{ }^{2-}$ na solução, o surgimento da goethita é evidente/esperado e, conforme discussão anterior, o crescimento do cristal é favorecido em direção preferencial [85].

\subsection{Magnetohipertermia}

O gráfico da figura 20 mostra a variação da temperatura em função do tempo, obtida a partir de medidas magnetotérmicas a diferentes campos aplicados e frequência de $300 \mathrm{~Hz}$, para as nanopartículas descritas na figura 13c. Nesse gráfico, foi feito um ajuste linear para poder extrair a variação da temperatura, utilizando-se a relação da potência dissipada específica (SLP) mostrada na introdução. 


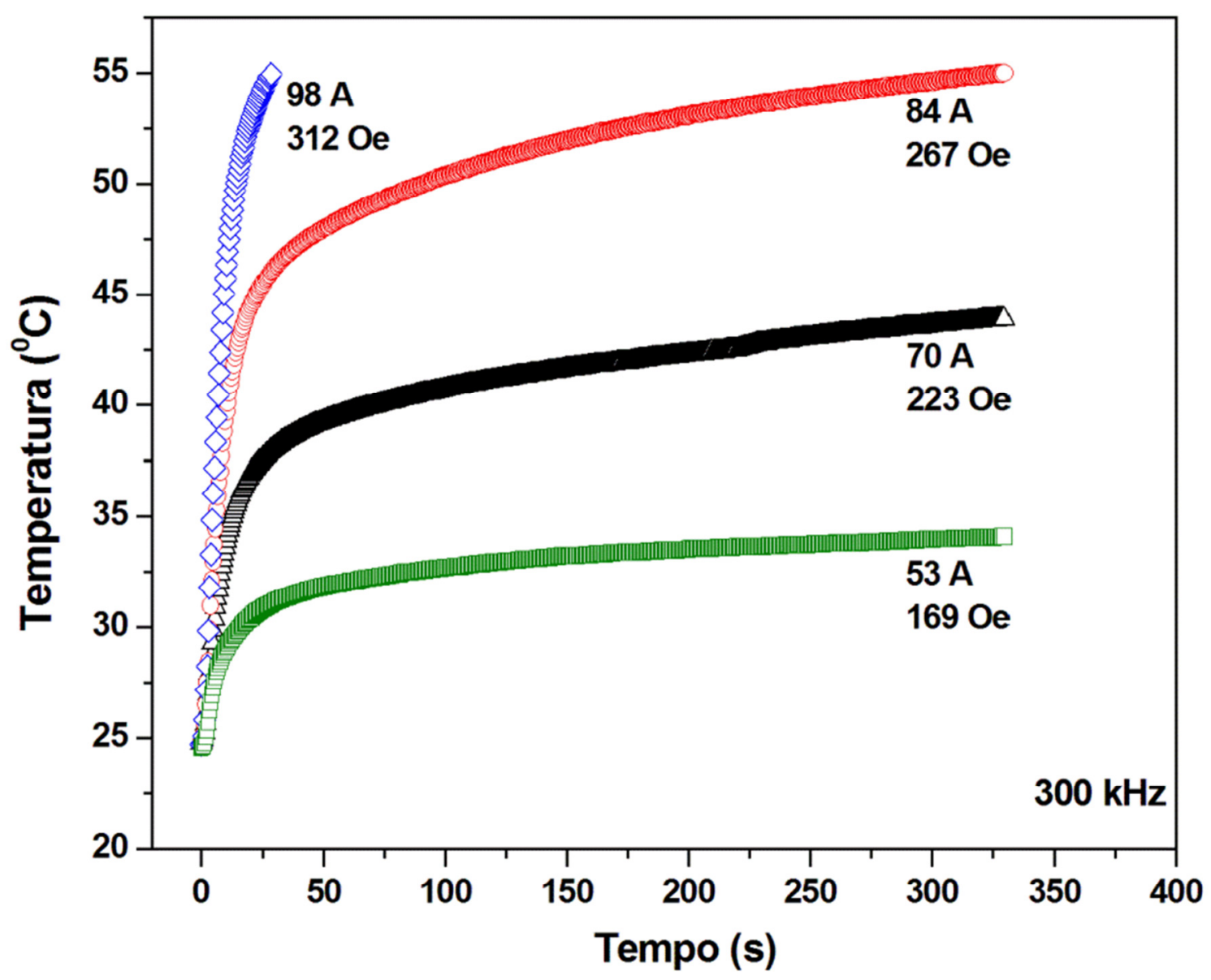

Figura 20 - Variação da temperatura em função do tempo de medição para a amostra obtidas em $\mathrm{CO}\left(\mathrm{NH}_{2}\right)_{2}$, com $\mathrm{NH}_{4} \mathrm{Fe}\left(\mathrm{SO}_{4}\right)_{2} / \mathrm{FeSO}_{4}, \frac{\mathrm{Fe}_{\text {tot }}}{\text { ureia }}=1 / 5,6 \mathrm{~h}$ de refluxo, variando-se o campo magnético aplicado.

Nessa figura, observa-se que quanto maior o campo magnético, maior a variação de temperatura obtida. Partindo-se da temperatura ambiente, o início da faixa de temperatura preferencial de hipertermia $\left(42-44{ }^{\circ} \mathrm{C}\right)$ foi atingido após, aproximadamente, 3 min, quando um campo de 223 Oe foi aplicado. A variação de temperatura continua aumentando com o tempo, apesar de ser de maneira mais suave, chegando aos $44{ }^{\circ} \mathrm{C}$, em cerca de 6 min. Fazendo uma projeção simples pelo perfil da curva, após o tempo requerido para causar a lise das células tumorais (cerca de $30 \mathrm{~min}$ ), a temperatura terá aumentado, aproximadamente, $20^{\circ} \mathrm{C}$, o que poderia causar danos irreversíveis para as 
células normais circunvizinhas nesse caso. Isso trata de outro aspecto interessante dessas curvas, que é o aumento de sua inclinação com o aumento do campo magnético aplicado, ou seja, um aumento da taxa de aquecimento. Em um perfil de curva ideal, a temperatura de hipertermia seria atingida rapidamente e mantida estável durante o tempo requerido. Dessa maneira, se teria um gráfico com duas inclinações: a primeira, referente à variação de temperatura inicial, com a maior inclinação possível; e a segunda, um patamar na temperatura desejada. Nesse caso, a temperatura aumenta rapidamente no início (primeira inclinação) e depois de certo ponto, continua aumentando, porém com uma taxa menor que no início (segunda inclinação). O aumento da primeira inclinação mostra que, com o aumento do campo magnético aplicado, a variação da temperatura inicial é mais rápida, o que de certo modo é desejável. O aumento mais suave da segunda inclinação pode estar associado a fatores experimentais e não necessariamente às características das nanopartículas, como por exemplo, o aquecimento da bobina dentro da qual as medidas são realizadas.

Este fenômeno de aquecimento, com aumento de frequência, pode ser demonstrado pela teoria do regime linear, em que a potência de aquecimento depende, também, da frequência aplicada: $S L P=\mu_{0} \pi f \chi_{0} H_{0}^{2} \frac{2 \pi f \tau}{1+(2 \pi f \tau)^{2}}$. Aqui, $f$ é a frequência, $\chi_{0}$ é a susceptibilidade inicial, $H_{0}$ é a amplitude de campo e $t$ é o tempo de relaxação.

Dessa forma, na figura 21, apresenta-se os dados de potência dissipada, mas em função do campo ao quadrado, de acordo com a equação anterior, confirmando esse regime linear. 


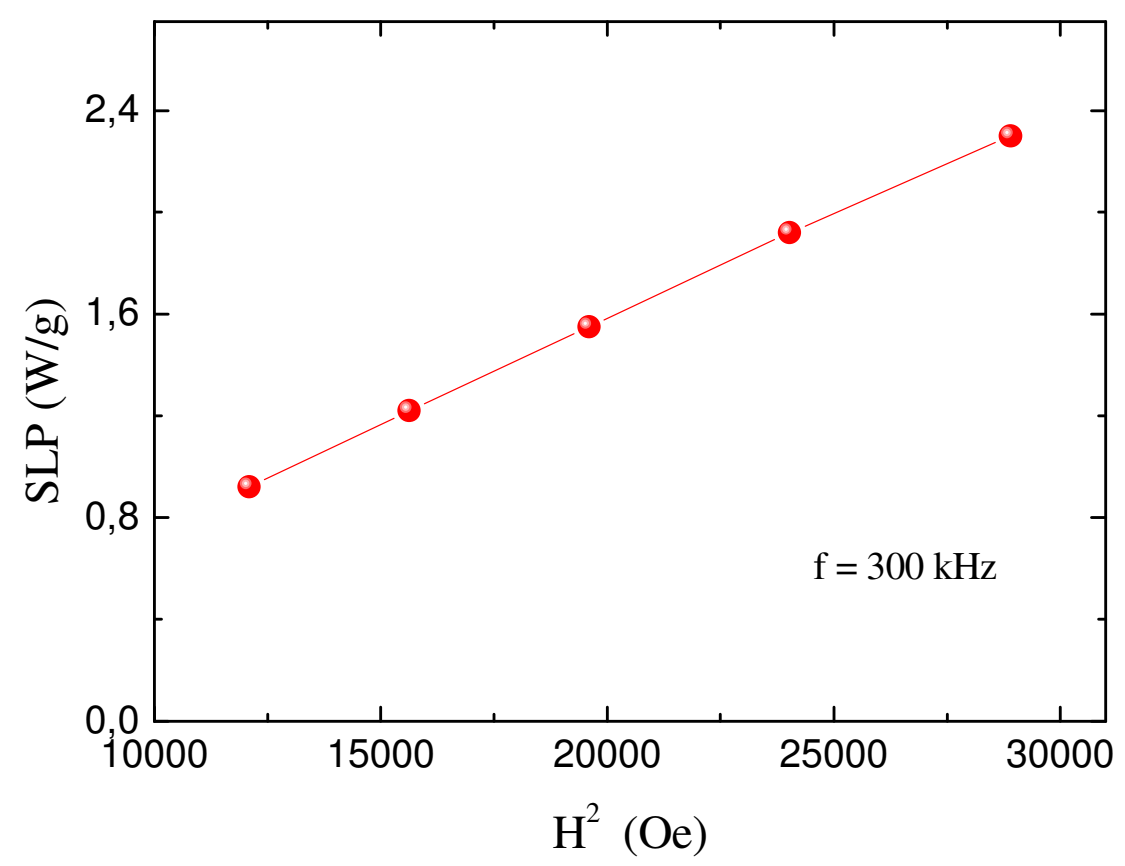

Figura 21 - Variação da potência dissipada específica (SLP) em função do campo quadrado para a amostra obtidas em $\mathrm{CO}\left(\mathrm{NH}_{2}\right)_{2}$, com $\mathrm{NH}_{4} \mathrm{Fe}\left(\mathrm{SO}_{4}\right)_{2} / \mathrm{FeSO}_{4}, \frac{\mathrm{Fe}_{\text {tot }}}{\text { ureia }}=1 / 5,6 \mathrm{~h}$ de refluxo.

No gráfico da figura 22, comparando-se os resultados obtidos para essas nanopartículas alongadas com curvas de aquecimento para a amostra contendo NPs esféricas (figura 13a), nota-se que as nanopartículas esféricas aquecem melhor a baixos campos do que as nanopartículas anisométricas, até um campo crítico (223 Oe). A partir desse campo, as curvas se cruzam e a situação se inverte, ou seja, as nanopartículas da amostra alongada passam a se aquecer mais com o campo aplicado. Esse fenômeno pode ser compreendido a partir da constante de anisotropia das nanopartículas. 

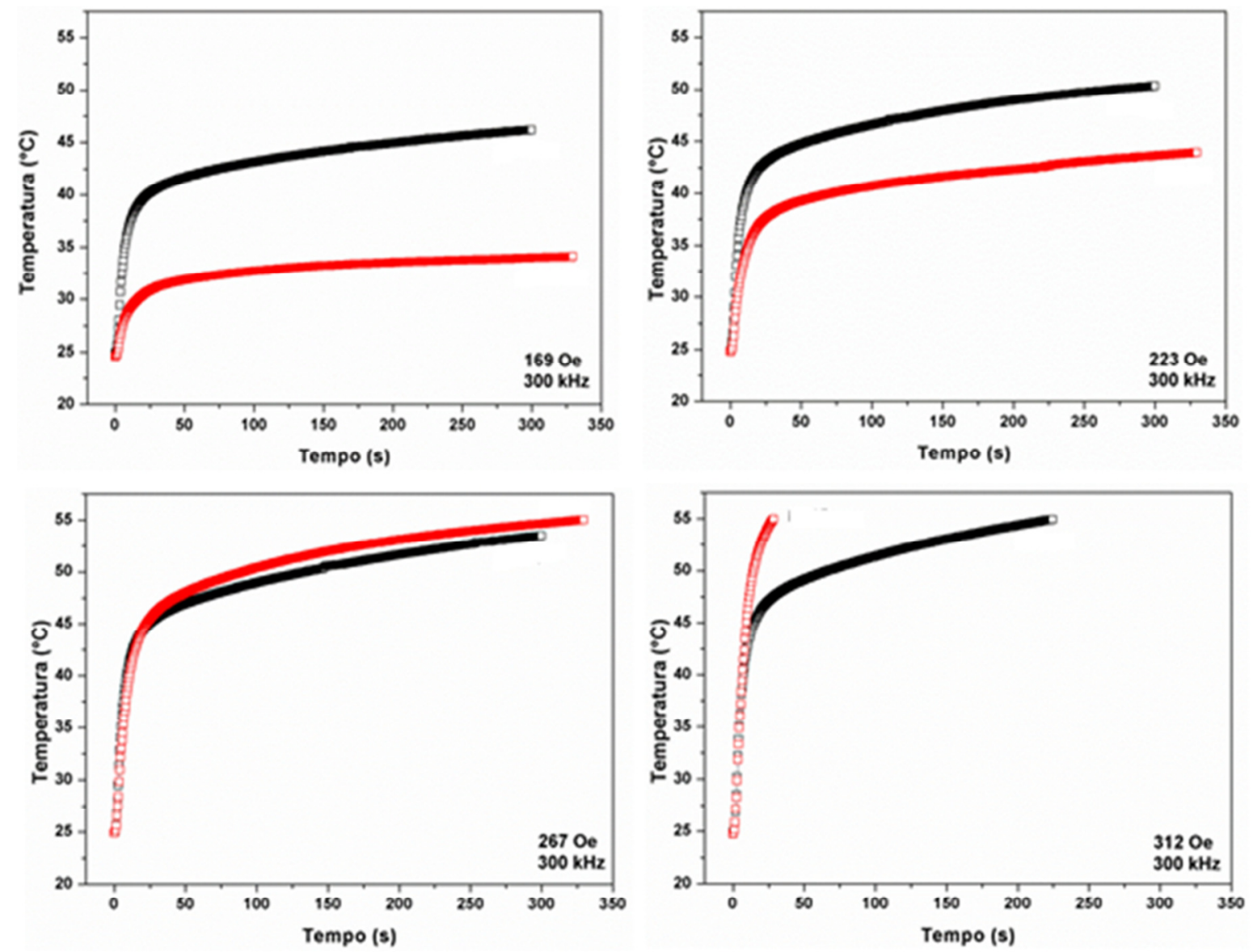

Figura 22 - . Comparação da variação da temperatura em função do tempo de medição entre as amostras: (vermelhos) alongadas e (preto) esféricas, em diferentes campos.

Pelas curvas de magnetização, realizadas em frequência quase estática (figura 13), observou-se que as nanopartículas da amostra alongadas apresentaram laço de histerese nessas condições. Em contraposição, as nanopartículas esférica da amostra da figura 8a, apresentaram comportamento superparamagnético [73] e, dessa forma, é esperado que a constante de anisotropia dessa amostra seja menor. Uma menor constante de anisotropia responde melhor a baixos campos, um dos motivos pelo qual a amostra esférica aquece melhor nessas circunstâncias. O aquecimento, contudo, depende da área da histerese. Após romper a barreira energética que estava impedindo a rotação dos spins na amostra alongada em baixos campos, ela se aquece muito mais, devido a sua maior constante de anisotropia. O baixo aquecimento visualizado nessa 
amostra a baixos campos, provavelmente, deve-se à rotação dos spins das partículas menores, visualizadas no histograma de distribuição de tamanhos (figura 11), conforme descrito previamente na literatura para outras partículas [86,44]

De qualquer maneira, os resultados preliminares obtidos nessa etapa do estudo foram positivos, indicando que as nanopartículas estudadas têm potencial para aplicações magnetohipertermia. 
CONCLUSÕES 


\section{CONCLUSÕES}

Com base na informação de que o íon $\mathrm{SO}_{4}{ }^{2-}$ é um agente catalisador de forma, que induz a obtenção de nanopartículas alongadas, dois tipos de base foram testadas para a elaboração de nanoestruturas magnéticas a partir da coprecipitação de íons de $\mathrm{Fe}^{2+} \mathrm{e} \mathrm{Fe}^{3+}$, na presença de $\mathrm{SO}_{4}{ }^{2-}$ : uma base convencional $\left(\mathrm{NH}_{4} \mathrm{OH}\right)$ e $\left(\mathrm{CO}\left(\mathrm{NH}_{2}\right)_{2}\right)$, uma base que gera $\mathrm{OH}^{-}$homogeneamente, por decomposição. Os resultados mostraram que, apesar da presença do $\mathrm{SO}_{4}{ }^{2-}$, nanopartículas magnéticas alongadas foram obtidas somente com $\mathrm{CO}\left(\mathrm{NH}_{2}\right)_{2}$.

Utilizando-se a $\mathrm{CO}\left(\mathrm{NH}_{2}\right)_{2}$ como agente precipitante, a influência da ausência ou presença/concentração de $\mathrm{SO}_{4}{ }^{2-}$ nas características das nanopartículas foi testada. Nesse caso, apesar de utilizar a $\mathrm{CO}\left(\mathrm{NH}_{2}\right)_{2}$, nanopartículas magnéticas alongadas somente foram obtidas em presença de $\mathrm{SO}_{4}{ }^{2-}$. De fato, nas concentrações estudadas, nanopartículas maiores foram obtidas em maior proporção $\mathrm{SO}_{4}{ }^{2-}$ ferro.

A variação do $\mathrm{pH}$ em função do tempo de síntese foi avaliada para o $\mathrm{NH}_{4} \mathrm{OH}$ e, para o caso da $\mathrm{CO}\left(\mathrm{NH}_{2}\right)_{2}$, duas concentrações foram estudadas. Observou-se que, quando se usa $\mathrm{NH}_{4} \mathrm{OH}$, o pH, bastante alto imediatamente a adição desse reagente, vai diminuindo com a reação e evaporação da amônia, ate se fixar próximo de 8 , durante o refluxo. No caso da $\mathrm{CO}\left(\mathrm{NH}_{2}\right)_{2}$, à medida que esse reagente se decompõe, o pH aumenta homogeneamente - mais(menos) lentamente em menor(maior) concentração de $\mathrm{CO}\left(\mathrm{NH}_{2}\right)_{2} \cdot \mathrm{O} \mathrm{NH}_{4} \mathrm{OH}$, sempre em alta concentração, promove alta supersaturação relativa do meio, enquanto que a geração homogênea do $\mathrm{OH}^{-}$pela $\mathrm{CO}\left(\mathrm{NH}_{2}\right)_{2}$ proporciona uma supersaturação baixa.

Para as duas concentrações de $\mathrm{CO}\left(\mathrm{NH}_{2}\right)_{2}$ estudadas, dois grupos de NPs foram obtidos em diferentes tempos de síntese. Em ambos os casos, as fases goethita e 
magnetita foram observadas, sendo que, com a evolução do tempo a fase goethita deu lugar à magnetita, nos dois casos. Para menor concentração de $\mathrm{CO}\left(\mathrm{NH}_{2}\right)_{2}$, nanopartículas alongadas de comprimento $\sim 70 \mathrm{~nm}$ e largura $\sim 15 \mathrm{~nm}$ foram observadas. Para maior concentração, nanopartículas hexagonais de $200 \mathrm{~nm}$ foram obtidas. A composição desses materiais foram determinadas quimicamente e por XRD (Rietveld) e magnetização mostrou um comportamento ferromagnético, com saturação de magnetização maior que $60 \mathrm{emu} / \mathrm{g}$ e traços de remanência e campo coercitivo à temperatura ambiente.

Com base nos resultados, uma rota de reação foi proposta, em que a magnetita formada é oriunda tanto do $\mathrm{Fe}^{2+}$ e $\mathrm{Fe}^{3+}$ em solução, passando pelo intermediário goethita. $\mathrm{A} \mathrm{CO}\left(\mathrm{NH}_{2}\right)_{2}$, que faz o pH aumentar lenta e homogeneamente, associada à presença de íons $\mathrm{SO}_{4}{ }^{2-}$ - um conhecido catalisador de forma - são os responsáveis pelo crescimento anisotrópico dos cristais e pela forma alongada das nanopartículas.

Finalmente, os testes de magnetohipertermia mostraram que, para as nanopartículas alongadas, a variação de temperatura é proporcional ao campo alternado aplicado e sensível às diferentes frequências. De fato, partindo-se da temperatura ambiente, o início da faixa de temperatura preferencial de hipertermia $\left(42-44{ }^{\circ} \mathrm{C}\right)$ foi atingido após, aproximadamente, 3 min, quando um campo moderado.

Os resultados preliminares obtidos nessa etapa do estudo foram positivos, indicando que as nanopartículas estudadas têm potencial para aplicações magnetohipertermia. Entretanto, essas nanopartículas alongadas necessitam ser funcionalizadas e dispersas em solução para se aprofundar os estudos de toxicidade e de magnetohipertermia, tanto in vitro, quanto in vivo. 


\section{REFERÊNCIAS}

\section{BIBLIOGRÁFICAS}




\section{REFERÊNCIAS BIBLIOGRÁFICAS}

[1] Hood JD. Tumor regression by targeted gene delivery to the neovasculature (vol 296, pg 2404, 2002). Science. 2002 Oct;298(5592):364-. PubMed PMID: WOS:000178510400025. English

[2] Pankhurst QA, Connolly J, Jones SK, Dobson J. Applications of magnetic nanoparticles in biomedicine. Journal of Physics D-Applied Physics. 2003 Jul;36(13):R167-R81. PubMed PMID: WOS:000185360900004. English.

[3] Gudiksen MS, Lauhon LJ, Wang J, Smith DC, Lieber CM. Growth of nanowire superlattice structures for nanoscale photonics and electronics. Nature. 2002 Feb;415(6872):617-20. PubMed PMID: WOS:000173709100039. English.

[4] Neuberger T, Schopf B, Hofmann H, Hofmann M, von Rechenberg B. Superparamagnetic nanoparticles for biomedical applications: Possibilities and limitations of a new drug delivery system. Journal of Magnetism and Magnetic Materials. 2005 May;293(1):483-96. PubMed PMID: WOS:000229661400074. English.

[5] Hergt R, Dutz S. Magnetic particle hyperthermia-biophysical limitations of a visionary tumour therapy. Journal of Magnetism and Magnetic Materials. 2007 Apr;311(1):187-92. PubMed PMID: WOS:000245524800040. English.

[6] Laurent S, Dutz S, Hafeli UO, Mahmoudi M. Magnetic fluid hyperthermia: Focus on superparamagnetic iron oxide nanoparticles. Advances in Colloid and Interface Science. 2011 Aug;166(12):8-23. PubMed PMID: WOS:000293550200002. English.

[7] Thiesen B, Jordan A. Clinical applications of magnetic nanoparticles for hyperthermia. International Journal of Hyperthermia. 2008;24(6):467-74. PubMed PMID: WOS:000260050900003. English.

[8]. Zhang JP, Dewilde AH, Chinn P, Foreman A, Barry S, Kanne D, et al. Herceptin directed nanoparticles activated by an alternating magnetic field selectively kill HER-2 positive human breast cells in vitro via hyperthermia. International Journal of Hyperthermia. 2011;27(7):682-97. PubMed PMID: WOS:000295799800006. English.

[9] Tietze R, Lyer S, Durr S, Alexiou C. Nanoparticles for cancer therapy using magnetic forces. Nanomedicine. 2012 Mar;7(3):447-57. PubMed PMID: WOS:000301778900019. English.

[10] Di Corato R, Espinosa A, Lartigue L, Tharaud M, Chat S, Pellegrino T, et al. Magnetic hyperthermia efficiency in the cellular environment for different nanoparticle designs. Biomaterials. 2014 Aug;35(24):6400-11. PubMed PMID: WOS:000338804500025. English.

[11] Nazir S, Hussain T, Ayub A, Rashid U, MacRobert AJ. Nanomaterials in combating cancer: Therapeutic applications and developments. Nanomedicine-Nanotechnology Biology and Medicine. 2014 Jan;10(1):19-34. PubMed PMID: WOS:000329103500004. English.

[12] López MB, Teijeiro A, Rivas J, Magnetic nanoparticle-based hyperthermia for cancer treatment. Reports of practical oncology and radiotherapy. 2013 Jun:18(6):397-400.

[13] Figuerola A, Di Corato R, Manna L, Pellegrino T. From iron oxide nanoparticles towards advanced iron-based inorganic materials designed for biomedical applications. Pharmacological Research. 2010 Aug;62(2):126-43. PubMed PMID: WOS:000279491400006. English.

[14] Dobson J. Magnetic nanoparticles for drug delivery. Drug Development Research. 2006 Jan;67(1):55-60. PubMed PMID: WOS:000237681400007. English.

[15] Sun C, Lee JSH, Zhang MQ. Magnetic nanoparticles in MR imaging and drug delivery. Advanced Drug Delivery Reviews. 2008 Aug;60(11):1252-65. PubMed PMID: WOS:000258313900004. English. 
[16] Barry SE. Challenges in the development of magnetic particles for therapeutic applications. International Journal of Hyperthermia. 2008;24(6):451-66. PubMed PMID: WOS:000260050900002. English.

[17] Deatsch AE, Evans BA. Heating efficiency in magnetic nanoparticle hyperthermia. Journal of Magnetism and Magnetic Materials. 2014 Mar;354:163-72. PubMed PMID: WOS:000329109300027. English.

[18] Issels RD. Hyperthermia adds to chemotherapy. European Journal of Cancer. 2008 Nov;44(17):2546-54. PubMed PMID: WOS:000261562700010. English.

[19]. Kumar C, Mohammad F. Magnetic nanomaterials for hyperthermia-based therapy and controlled drug delivery. Advanced Drug Delivery Reviews. 2011 Aug;63(9):789-808. PubMed PMID: WOS:000293482300008. English.

[20] Cornell, R. M.; Schwertmann, U.; The Iron Oxides: Structure, Properties, Reactions, Occurrence and Uses, 1st ed.; VCH Publishers, Inc.: Nova Iorque, EUA, 1996.

[21] Ramimoghadam D, Bagheri S, Hamid SBA. Progress in electrochemical synthesis of magnetic iron oxide nanoparticles. Journal of Magnetism and Magnetic Materials. 2014 Nov;368:207-29. PubMed PMID: WOS:000340049600034. English.

[22] King JG, Williams W, Wilkinson CDW, McVitie S, Chapman JN. Magnetic properties of magnetite arrays produced by the method of electron beam lithography. Geophysical Research Letters. 1996 Oct;23(20):2847-50. PubMed PMID: WOS:A1996VL37000034. English.

Rishton SA, Lu Y, Altman RA, Marley AC, Bian XP, Jahnes C, et al. Magnetic tunnel junctions fabricated at tenth-micron dimensions by electron beam lithography. Microelectronic Engineering. 1997 Feb;35(1-4):249-52. PubMed PMID: WOS:A1997WM32900056. English.

Lee CS, Lee H, Westervelt RM. Microelectromagnets for the control of magnetic nanoparticles. Applied Physics Letters. 2001 Nov;79(20):3308-10. PubMed PMID: WOS:000172046800032. English.

Mathur S, Barth S, Werner U, Hernandez-Ramirez F, Romano-Rodriguez A. Chemical vapor growth of one-dimensional magnetite nanostructures. Advanced Materials. 2008 Apr;20(8):1550-+. PubMed PMID: WOS:000255694200028. English.

[23] Massart R. Preparation of aqueous magnetic liquids in alkaline and acidic media. Ieee Transactions on Magnetics. 1981;17(2):1247-8. PubMed PMID: WOS:A1981LK31900013. English.

Wu JH, Ko SP, Liu HL, Kim S, Ju JS, Keun-Kim Y. Sub 5 nm magnetite nanoparticles: Synthesis, microstructure, and magnetic properties. Materials Letters. 2007 Jun;61(14-15):3124-9. PubMed PMID: WOS:000247320500073. English.

[24] Sun SH, Zeng H, Robinson DB, Raoux S, Rice PM, Wang SX, et al. Monodisperse MFe2O4 (M = Fe, Co, Mn) nanoparticles. Journal of the American Chemical Society. 2004 Jan;126(1):273-9. PubMed PMID: WOS:000187945400063. English.

[25] Khollam YB, Dhage SR, Potdar HS, Deshpande SB, Bakare PP, Kulkarni SD, et al. Microwave hydrothermal preparation of submicron-sized spherical magnetite (Fe3O4)powders. Materials Letters. 2002 Oct;56(4):571-7. PubMed PMID: WOS:000178888500036. English.

Chen FH, Gao Q, Hong GY, Ni JZ. Synthesis and characterization of magnetite dodecahedron nanostructure by hydrothermal method. Journal of Magnetism and Magnetic Materials. 2008 Jun;320(11):1775-80. PubMed PMID: WOS:000255512200008. English. 
[26] Dacoata GM, Degrave E, Debakker PMA, Vandenberghe RE. Synthesis and characterization of some iron-oxides by sol-gel method. Journal of Solid State Chemistry. 1994 Dec;113(2):405-12. PubMed PMID: WOS:A1994PX18600026. English.

Itoh H, Sugimoto T. Systematic control of size, shape, structure, and magnetic properties of uniform magnetite and maghemite particles. Journal of Colloid and Interface Science. 2003 Sep;265(2):283-95. PubMed PMID: WOS:000184967300010. English.

[27] Breulmann M, Colfen H, Hentze HP, Antonietti M, Walsh D, Mann S. Elastic magnets: Templatecontrolled mineralization of iron oxide colloids in a sponge-like gel matrix. Advanced Materials. 1998;10(3):237-+.

[28] Amemiya Y, Arakaki A, Staniland SS, Tanaka T, Matsunaga T. Controlled formation of magnetite crystal by partial oxidation of ferrous hydroxide in the presence of recombinant magnetotactic bacterial protein Mms6. Biomaterials. 2007;28(35):5381-9.

Vereda F, Rodriguez-Gonzalez B, de Vicente J, Hidalgo-Alvarez R. Evidence of direct crystal growth and presence of hollow microspheres in magnetite particles prepared by oxidation of $\mathrm{Fe}(\mathrm{OH})(2)$. Journal of Colloid and Interface Science. 2008;318(2):520-4.

[29] Salazar-Alvarez G, Muhammed M, Zagorodni AA. Novel flow injection synthesis of iron oxide nanoparticles with narrow size distribution. Chemical Engineering Science. 2006;61(14):4625-33.

[30] Cabrera L, Gutierrez S, Menendez N, Morales MP, Heffasti P. Magnetite nanoparticles: Electrochemical synthesis and characterization. Electrochimica Acta. 2008;53(8):3436-41.

Marques RFC, Garcia C, Lecante P, Ribeiro SJL, Noe L, Silva NJO, et al. Electro-precipitation of $\mathrm{Fe}(3) \mathrm{O}(4)$ nanoparticles in ethanol. Journal of Magnetism and Magnetic Materials. 2008;320(19):2311-5.

[31] Strobel R, Pratsinis SE. Direct synthesis of maghemite, magnetite and wustite nanoparticles by flame spray pyrolysis. Advanced Powder Technology. 2009 Mar;20(2):190-4. PubMed PMID: WOS:000267574600012. English.

[32] Enomoto N, Akagi J, Nakagawa Z. Sonochemical powder processing of iron hydroxides. Ultrasonics Sonochemistry. 1996 Jul;3(2):S97-S103. PubMed PMID: WOS:A1996VD97700004. English.

Dang F, Enomoto N, Hojo J, Enpuku K. Sonochemical synthesis of monodispersed magnetite nanoparticles by using an ethanol-water mixed solvent. Ultrasonics Sonochemistry. 2009 Jun;16(5):64954. PubMed PMID: WOS:000266542000012. English.

[33] Eckert CA, Knutson BL, Debenedetti PG. Supercritical fluids as solvents for chemical and materials processing. Nature. 1996 Sep;383(6598):313-8. PubMed PMID: WOS:A1996VJ43900037. English.

Lam UT, Mammucari R, Suzuki K, Foster NR. Processing of iron oxide nanoparticles by supercritical fluids. Industrial \& Engineering Chemistry Research. 2008 Feb;47(3):599-614. PubMed PMID: WOS:000252777500015. English.

[34] Dar MA, Kulkarni SK, Ansari ZA, Ansari SG, Shin HS. Preparation and characterization of alphaFeOOH and alpha-Fe2O3 by sol-gel method. Journal of Materials Science. 2005 Jun;40(11):3031-4. PubMed PMID: WOS:000229878400048. English.

[35] Haneda k, Morrish AH. Magnetite Maghemite transformation in ultrafine particles. Journal de Physique. 1977;38:321-3. PubMedMID: WOS:A1977DH82900063.

[36] Bloss DA. Crystallography and Crystal Chemistry - an Introduction. Holt Rinehart and Winston Inc. New York. 1971. 545pp.

[37] Kittel, C., Introduction to Solid State Physics, $8^{a}$ Ed., John Wiley \& Sons, Inc.: Nova Iorque, EUA, 2005. 
[38] Shriver, D. F.; Atkins, P. W.; Química Inorgânica; Gomes, M. A. B., trad.; Bookman: Porto Alegre, $2003,3^{\mathrm{a}}$ ed.

[39] Teja AS, Koh PY. Synthesis, properties, and applications of magnetic iron oxide nanoparticles. Progress in Crystal Growth and Characterization of Materials. 2009;55(1-2):22-45. PubMed PMID: WOS:000265726900002. English.

[40] Knobel M. Partículas Finas: Superparamagnetismo e Magnetoresistência Gigante. Revista Brasileira de Ensino de Física. 2000 Set; 3(22):387-395.

[41] Kalambur VS, Han B, Hammer BE, Shield TW, Bischof JC. In vitro characterization of movement, heating and visualization of magnetic nanoparticles for biomedical applications. Nanotechnology. 2005 Aug;16(8):1221-33. PubMed PMID: WOS:000231410600041. English.

[42] Bacri JC, Perzynski R, Salin D, Cabuil V, Massart R. Magnetic colloidal properties of ionic ferrofluids. Journal of Magnetism and Magnetic Materials. 1986 Nov;62(1):36-46. PubMed PMID: WOS:A1986F231400005. English.

[43] Dormann JL, Fiorani D (Eds.). Magnetic Properties of Fine Particles. North-Holland Amsterdam: Elsevier Science Publisher; 1992. ISBN: 978-0-444-89552-3

[44] Verde EL, Landi GT, Carriao MS, Drummond AL, Gomes JA, Vieira ED, et al. Field dependent transition to the non-linear regime in magnetic hyperthermia experiments: Comparison between maghemite, copper, zinc, nickel and cobalt ferrite nanoparticles of similar sizes. Aip Advances. 2012 Sep;2(3):23. PubMed PMID: WOS:000309388800020. English.

[45] Jiles DC. Modeling the effects of eddy-current losses on frequency-dependent hysteresis in electrically conducting media. Ieee Transactions on Magnetics. 1994 Nov;30(6):4326-8. PubMed PMID: WOS:A1994PU42900173. English.

[46] Jozefczak A, Skumiel A. Heating effect in biocompatible magnetic fluids with the BSA surfactant layer. Magnetohydrodynamics. 2007 Oct-Dec;43(4):445-51. PubMed PMID: WOS:000255055200008. English.

[47] Hergt R, Andra W, d'Ambly CG, Hilger I, Kaiser WA, Richter U, et al. Physical limits of hyperthermia using magnetite fine particles. Ieee Transactions on Magnetics. 1998 Sep;34(5):3745-54. PubMed PMID: WOS:000075964800011. English.

[48] Rosensweig RE. Heating magnetic fluid with alternating magnetic field. Journal of Magnetism and Magnetic Materials. 2002 Nov;252(1-3):370-4. PubMed PMID: WOS:000179686200116. English.

[49] Verde EL, Landi GT, Gomes JA, Sousa MH, Bakuzis AF. Magnetic hyperthermia investigation of cobalt ferrite nanoparticles: Comparison between experiment, linear response theory, and dynamic hysteresis simulations. Journal of Applied Physics. 2012 Jun;111(12):8. PubMed PMID: WOS:000305832100076. English.

[50] Flynn CM. Hydrolysis of inorganic iron(III) salts. Chemical Reviews. 1984;84(1):31-41. PubMed PMID: WOS:A1984SK75400003. English.

[51] Sugimoto T, Itoh H, Mochida T. Shape control of monodisperse hematite particles by organic additives in the gel-sol system. Journal of Colloid and Interface Science. 1998 Sep;205(1):42-52. PubMed PMID: WOS:000075786100005. English.

[52] Ozaki M, Kratohvil S, Matijevic E. Formation of monodispersed spindle-type hematite particles. Journal of Colloid and Interface Science. 1984;102(1):146-51. PubMed PMID: WOS:A1984TR36100014. English. 
[53] Sugimoto T, Muramatsu A, Sakata K, Shindo D. Characterization of hematite particles of different shapeS. Journal of Colloid and Interface Science. 1993 Jul;158(2):420-8. PubMed PMID: WOS:A1993LH12300018. English.

[54] Stachen M, Morales MP, Ocana M, Serna CJ. Effect of precursor impurities on the magnetic properties of uniform gamma-Fe2O3 ellipsoidal particles. Physical Chemistry Chemical Physics. 1999 Sep;1(18):4465-71. PubMed PMID: WOS:000082601000045. English.

[55] Shen HX, Yao JL, Gu RA. Fabrication and characteristics of spindle Fe2O3@Au core/shell particles. Transactions of Nonferrous Metals Society of China. 2009 Jun;19(3):652-6. PubMed PMID: WOS:000266892200025. English.

[56] Serna CJ, Ocana M, Iglesias JE. Optical-properties of alpha-Fe2O3 microcrystals in the infrared. Journal of Physics C-Solid State Physics. 1987 Jan;20(3):473-84. PubMed PMID: WOS:A1987F856200017. English.

[57] Radeva T. Overcharging of ellipsoidal particles by oppositely charged polyelectrolytes. Colloids and Surfaces a-Physicochemical and Engineering Aspects. 2002 Sep;209(2-3):219-25. PubMed PMID: WOS:000178147100014. English.

[58] Ozaki M, Matijevic E. Preparation and magnetic-properties of monodispersed spindle-type gammaFe2O3 particles. Journal of Colloid and Interface Science. 1985;107(1):199-203. PubMed PMID: WOS:A1985AQT7900021. English.

[59] Sugimoto T, Khan MM, Muramatsu A. Preparation of monodisperse peanut-type alpha-Fe2O3 particles from condensed ferric hydroxide gel. Colloids and Surfaces a-Physicochemical and Engineering Aspects. 1993 Mar;70(2):167-9. PubMed PMID: WOS:A1993KV50200006. English.

[60] Ocana M, Morales MP, Serna CJ. Homogeneous precipitation of uniform alpha-Fe2O3 particles from iron salts solutions in the presence of urea. Journal of Colloid and Interface Science. 1999 Apr;212(2):317-23. PubMed PMID: WOS:000079500500015. English.

[61] Harris, D. C. Análise Química Quantitativa. 5ª ed. Riehl, C. A. S.,; Guarino, A. W. S., trad.; LTC Livros Técnicos e Científicos Editora S.A.: Rio de Janeiro, 2001.

[62] Fischer WR, Schwertmann U. The formation of hematite from amorphous iron (III) hydroxide. Clays and Clay Minerals, March 1975, v. 23, p. 33-37, published online March 1, 1975.

[63] $\mathrm{Hu} \mathrm{CQ}$, Gao ZH, Yang XR. Facile synthesis of single crystalline alpha-Fe2O3 ellipsoidal nanoparticles and its catalytic performance for removal of carbon monoxide. Materials Chemistry and Physics. 2007 Aug;104(2-3):429-33. PubMed PMID: WOS:000248982100038. English.

[64] Wang GH, Li WC, Jia KM, Spliethoff B, Schuth F, Lu AH. Shape and size controlled alpha$\mathrm{Fe} 2 \mathrm{O} 3$ nanoparticles as supports for gold-catalysts: Synthesis and influence of support shape and size on catalytic performance. Applied Catalysis a-General. 2009 Jul;364(1-2):42-7. PubMed PMID: WOS:000268512500006. English.

[65] Drummond, A. L. Desenvolvimento de sistemas magnéticos nanoestruturados para aplicações biomédicas. Tese de Doutorado. Universidade de Brasília, 2012.

[66] Gomes JA, Sousa MH, Tourinho FA, Mestnik J, Itri R, Depeyrot J. Rietveld structure refinement of the cation distribution in ferrite fine particles studied by X-ray powder diffraction. Journal of Magnetism and Magnetic Materials. 2005 Mar;289:184-7. PubMed PMID: WOS:000228117100054. English.

[67] Kim W, Suh CY, Cho SW, Roh KM, Kwon H, Song K, et al. A new method for the identification and quantification of magnetite-maghemite mixture using conventional X-ray diffraction technique. Talanta. 2012 May;94:348-52. PubMed PMID: WOS:000305167300053. English. 
[68] Sousa EC, Sousa MH, Goya GF, Rechenberg HR, Lara M, Tourinho FA, et al. Enhanced surface anisotropy evidenced by Mossbauer spectroscopy in nickel ferrite nanoparticles. Journal of Magnetism and Magnetic Materials. 2004 May;272:E1215-E7. PubMed PMID: WOS:000202897200481. English.

[69] Saenger JF, Neto KS, Morais PC, Sousa MH, Tourinho FA. Investigation of the anisotropy in frozen nickel ferrite ionic magnetic fluid using magnetic resonance. Journal of Magnetic Resonance. 1998 Sep;134(1):180-3. PubMed PMID: WOS:000076275600025. English.

[70] Aquino R, Depeyrot J, Sousa MH, Tourinho FA, Dubois E, Perzynski R. Magnetization temperature dependence and freezing of surface spins in magnetic fluids based on ferrite nanoparticles. Physical Review B. 2005 Nov;72(18):10. PubMed PMID: WOS:000233603600062. English.

[71] Sugimoto T, Khan MM, Muramatsu A, Itoh H. Formation mechanism of monodisperse peanut-type alpha-fe2o3 particles from condensed ferric hydroxide gel. Colloids and Surfaces a-Physicochemical and Engineering Aspects. 1993 Nov;79(2-3):233-47. PubMed PMID: WOS:A1993MK91500011. English.

[72] Sugimoto T. Fine Particles: Synthesis, Characterization, and Mechanisms of Growth. Surfactant Science Series. Ed. A.T. Hubbard. New York. Marcel Dekker. 2000.

[73] Drummond AL, Feitoza NC, Duarte GC, Sales MJA, Silva LP, Chaker JA, et al. Reducing SizeDispersion in One-Pot Aqueous Synthesis of Maghemite Nanoparticles. Journal of Nanoscience and Nanotechnology. 2012 Oct;12(10):8061-6. PubMed PMID: WOS:000312620200060. English.

[74] Gordon L, Salutsky ML, Willard HH. Precipitation from homogeneous solution. Analytica Chimica Acta. $1959 ; 21: 97$.

[75] Byrne RH, Luo YR, Young RW. Iron hydrolysis and solubility revisited: observations and comments on iron hydrolysis characterizations. Marine Chemistry. 2000 May;70(1-3):23-35. PubMed PMID: WOS:000087534100003. English.

[76] Stumm W, Lee GF. Oxygenation of ferrous iron. Industrial and Engineering Chemistry. 1961;53(2):143-6. PubMed PMID: WOS:A1961XG22600037. English.

[77] Tamura H, Goto K, Nagayama M. Effect of anions on oxygenation of ferrous ion in neutral solutions. Journal of Inorganic \& Nuclear Chemistry. 1976;38(1):113-7. PubMed PMID: WOS:A1976BA05000024. English.

[78] Sidhu PS, Gilkes RJ, Posner AM. Mechanism of low-temperature oxidation of synthetic magnetites. Journal of Inorganic \& Nuclear Chemistry. 1977;39(11):1953-8. PubMed PMID: WOS:A1977EC11400008. English.

[79] Tamaura Y, Ito K, Katsura T. Transformation of gamma-FeO(OH) TO Fe3O4 by adsorption of iron(II) ion on gamma-FeO(OH). Journal of the Chemical Society-Dalton Transactions. 1983 (2):189-94. PubMed PMID: WOS:A1983QC39700001. English.

[80] Sugimoto T. Monodispersed Particles. Elsevier, Amsterdam. 2001 Jan.

[81] Schwertmann U, Cambier P, Murad E. Properties of goethites of varying crystallinity. Clays and Clay Minerals. 1985;33(5):369-78. PubMed PMID: WOS:A1985ASF2000001. English.

[82] Jia CJ, Sun LD, Luo F, Han XD, Heyderman LJ, Yan ZG, et al. Large-Scale Synthesis of SingleCrystalline Iron Oxide Magnetic Nanorings. Journal of the American Chemical Society. 2008 Dec;130(50):16968-77. PubMed PMID: WOS:000263320400035. English.

[83] Sugimoto T, Wang YS. Mechanism of the shape and structure control of monodispersed alphaFe2O3 particles by sulfate ions. Journal of Colloid and Interface Science. 1998 Nov;207(1):137-49. PubMed PMID: WOS:000076924700018. English. 
[84] Peak D, Ford RG, Sparks DL. An in situ ATR-FTIR investigation of sulfate bonding mechanisms on goethite. Journal of Colloid and Interface Science. 1999 Oct;218(1):289-99. PubMed PMID: WOS:000082747100031. English.

[85] Itoh H, Sugimoto T. Systematic control of size, shape, structure, and magnetic properties of uniform magnetite and maghemite particles. Journal of Colloid and Interface Science. 2003 Sep;265(2):283-95. PubMed PMID: WOS:000184967300010. English.

[86] Bordelon DE, Cornejo C, Gruttner C, Westphal F, DeWeese TL, Ivkov R. Magnetic nanoparticle heating efficiency reveals magneto-structural differences when characterized with wide ranging and high amplitude alternating magnetic fields. Journal of Applied Physics. 2011 Jun;109(12):8. PubMed PMID: WOS:000292331200149. English. 